\title{
HOW THE
}

MIDDLE

EAST USED

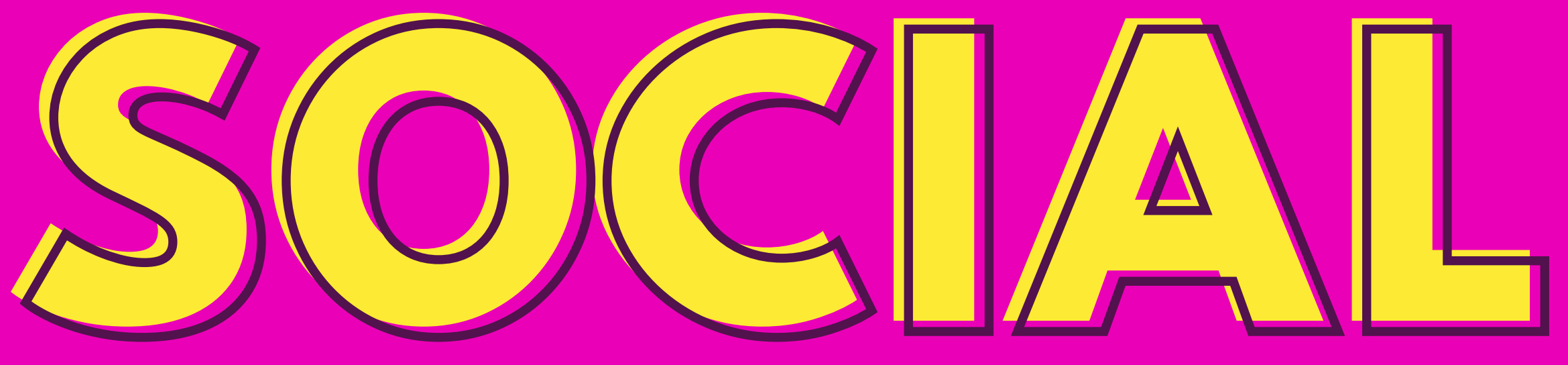

Q3 ACADEMY

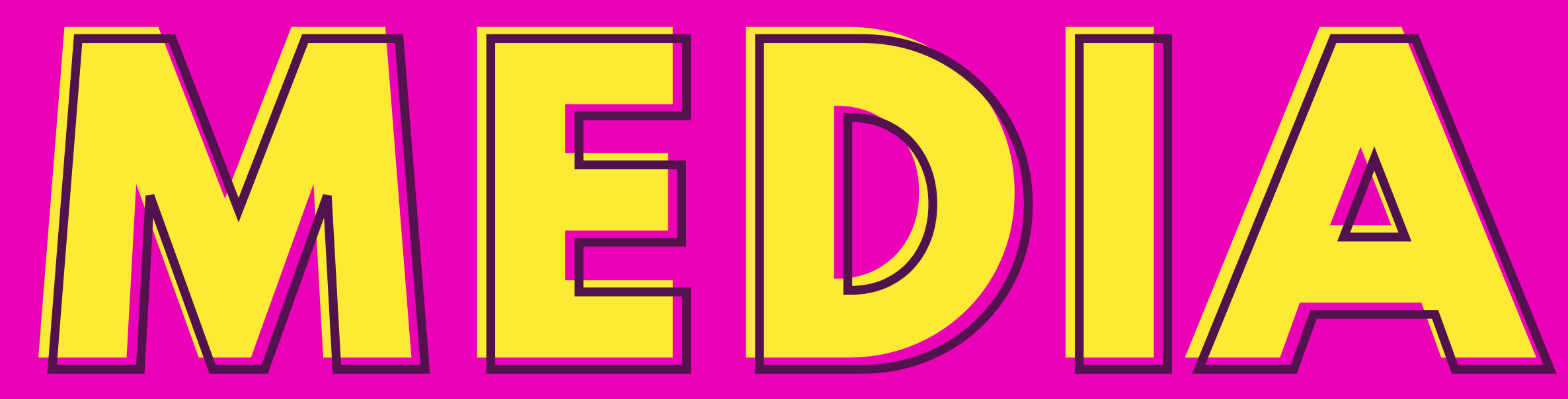

IN 2020 


\section{THE PURPOSE: NEW MEDIA ACADEMY}

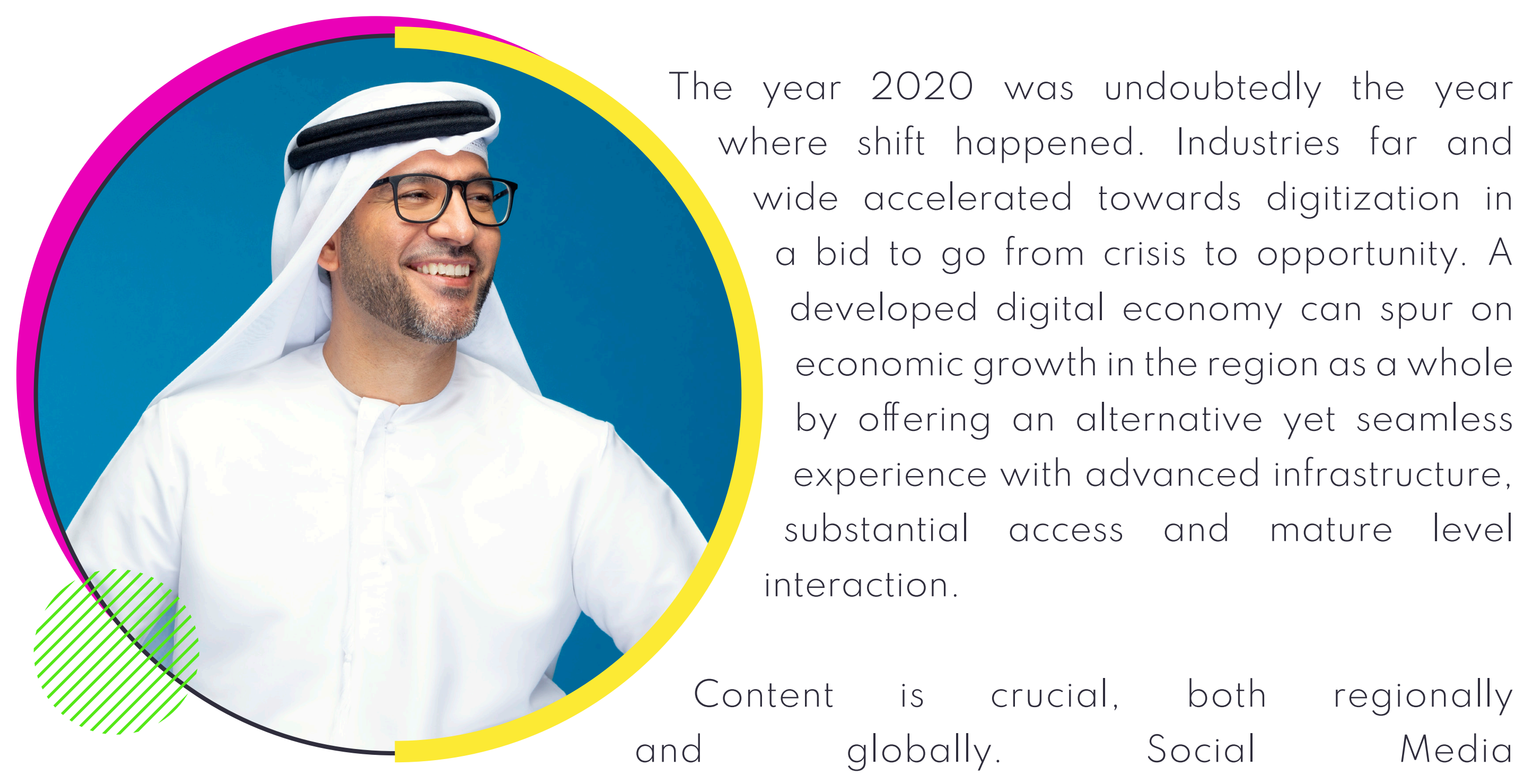

is a fundamental force for forging connectivity and lifting the lid on what is happening on the ground through powerful story-telling. The Arab world has historically been misconstrued and misplaced in our own narrative as well as the world's - now is the time to refract our content through a renewed and purposeful prism
The New Media Academy is an organization that works within the space of development, with a focus on harnessing opportunities in the digital space. We are committed to developing a new generation of change-makers who naturally excel in the digital space with programs and skills bolstered by a world-class digital education system, delivered by top digital practitioners

We have a civic duty to effect change to the entire region, beyond our home turf The Arab world deserves to be seen and heard in a creative and authentic light based on the realities and aspirations of its key thinkers and culture shapers. Across our three pillars of support: Education, Talent and Content, our change-makers are shaping the narrative and driving action leadership in the ever-evolving digital world.

This report is the bedrock of the Social Media industry. With these real-time findings, you will be able to develop strategies to tell the next best story.

\section{Rashid Al Awadhi}

Chief Executive Officer at New Media Academy 


\section{INTRODUCTION}

283

This year's study is produced in partnership with the New Media Academy. The New Media Academy was inaugurated in June 2020, by His Highness Sheikh Mohammed bin Rashid Al Maktoum, UAE Vice President and Prime Minister, and ruler of Dubai, to work within the space of development, with a focus on harnessing opportunities in the digital space. We are committed to developing a new generation of change-makers who naturally excel in the digital space with programs and skills bolstered by a worldclass digital education system, delivered by top digital practitioners.

Using a broad range of industry, academic and media sources, we dive into the trends - and biggest stories - which shaped MENA's relationship with social media during the past year. Not surprisingly, this study is heavily influenced by the impact of COVID-19. The novel coronavirus impacted on everyone's lives around the world, including the Middle East. One by-product of the pandemic could be seen in our changing media habits. Social media usage - across all platforms - increased during the early stages of the outbreak.

More widely, given the importance of social media in our media diets, platforms industry and governments alike sought to use these networks to promote public health messages, as well as counter misinformation related to the COVID crisis.
Alongside these developments, we have also seen continued investment in content on social media platforms - especially during Ramadan - and growing partnerships between traditional media players and social media channels and influencers. These developments reflect the popularity of high quality digital content consumed on social media, and a desire to reach audiences on these platforms, or bring existing social audiences onto other networks.

We expect that this synergy will only rise, not least because many media habits developed during the pandemic may well continue post-COVID. As a result, social networks will become an increasingly important source for talent spotting, as well as a key avenue for content and information consumption.

This trend, as we outline at the end of this report, matters for brands, creators and influencers, as well as governments and other public entities. Social media is already an important part of digital media habits and digital marketing strategies. In 2021, that importance looks set to continue and grow even further.

\section{Damian Radcliffe and Hadil Abuhmaid}

\section{March 2021}




\section{ABOUT THE AUTHORS}

С2)

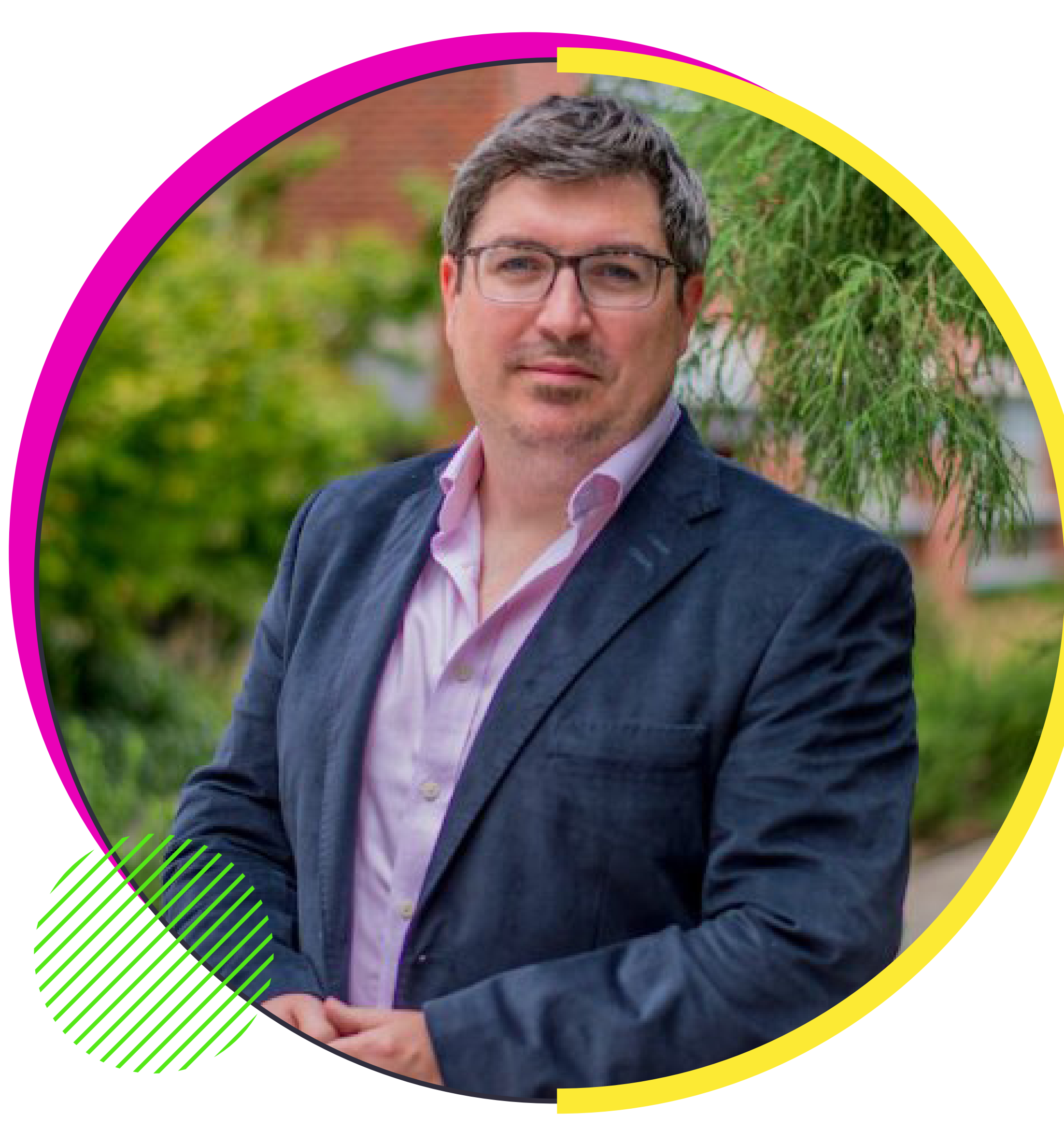

Damian Radcliffe is the Carolyn S. Chambers Professor in Journalism, a Professor of Practice, an affiliate of the Department for Middle East and North Africa Studies (MENA), and a Research Associate of the Center for Science Communication Research (SCR) at the University of Oregon. Alongside holding the Chambers Chair at the School of Journalism and Communication (SOJC), he is also a Fellow of the Tow Center for Digital Journalism at Columbia University, an Honorary Research Fellow at Cardiff University's School of Journalism, Media and Culture Studies, and a fellow of the Royal Society for the Encouragement of Arts, Manufactures and Commerce (RSA)

An experienced Digital Analyst, Consultant, Journalist and Researcher, Damian writes about digital trends, social media, technology, the business of media, and the evolution of journalism. He tweets @damianradcliffe.

Damian has worked in editorial, research, policy, and teaching positions for the past two decades in the UK, Middle East, and USA. This includes roles in all media sectors (commercial, public, government, regulatory, academic, and nonprofit/civil society) and all platforms (print, digital, TV and radio). In these roles, and through his company Kenja Media Consulting, he undertakes a wide range of teaching, consultancy, research and journalistic work, which includes writing a monthly column on technology in the Middle East for ZDNet (which he has done since December 2013)

He has produced an annual report charting social media developments across the Middle East and North Africa (MENA) since 2012. Between 2012-2014 he worked for Qatar's Ministry of Information and Communications Technology (ictQATAR) as an analyst and researcher. He joined the University of Oregon in 2015 


\section{ABOUT THE AUTHORS}

Hadil Abuhmaid is a Media Studies PhD student and a Graduate Employee at the University of Oregon. Her primary area of research interest explores national identity and culture in Palestinian cinema.

Hadil earned a BS in Journalism and Political Science from Bir-Zeit University in Palestine and an MA in Nonprofit Management from the University of Oregon, with a focus on Arts Administration. She is the co-founder of Filmlab: Palestine, a nonprofit company based in Ramallah, that aims at developing the cinema industry in Palestine.

Her work in the field of cinema has created a base for her research interest in Palestinian self-representation. Through her research, Hadil aims at examining the formation and self-re-presentation of the national identity in Palestinian feature films produced within the historical map of Palestine by researching their production and aesthetics. Her research interests include cinema studies, diasporic studies, representations, and national identity

In addition to academic work. Hadil is a member of the Graduate School Advisory Board at the University of Oregon, a member of the Dean of Students' Advisory Board, and a board member of Creating Connections; a graduate student group that supports the traditionally marginalized population in the U.S. higher education.

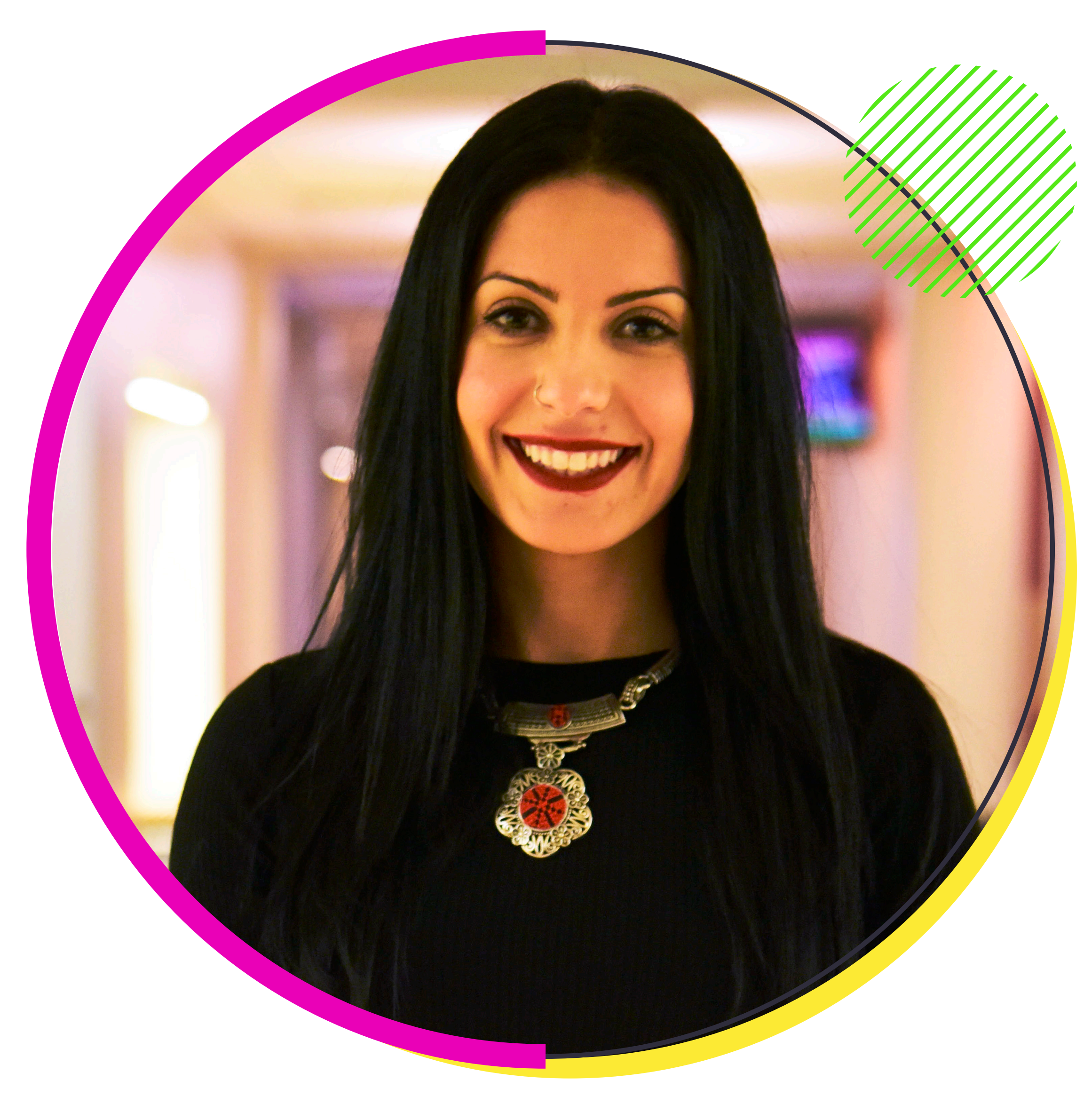




\section{ABOUT THE AUTHORS}

\section{DESIGNERS AND OUTREACH}

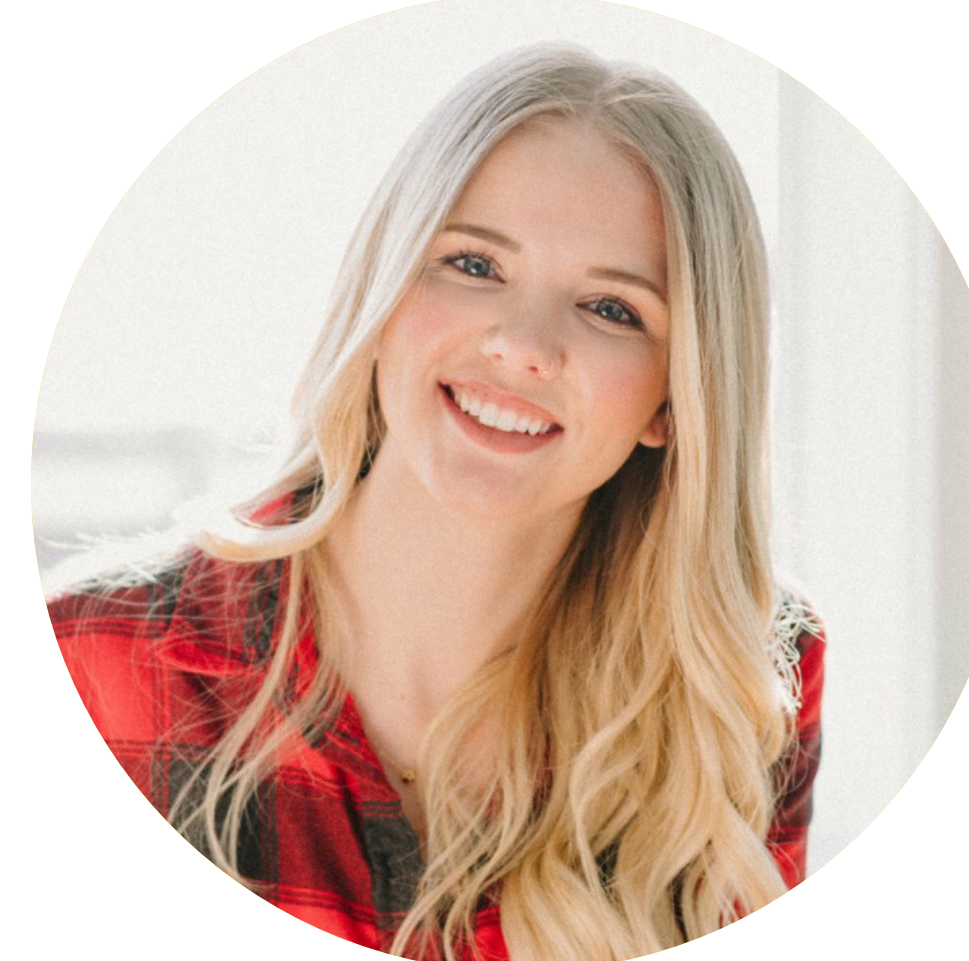

Terra Johnston is a content creator and digital marketing strategist based in Seattle, Washington. She specializes in brand development and management, and her areas of service include graphic design, social media, web design, media relations, and copywriting. She received her Bachelor's degree in public relations,

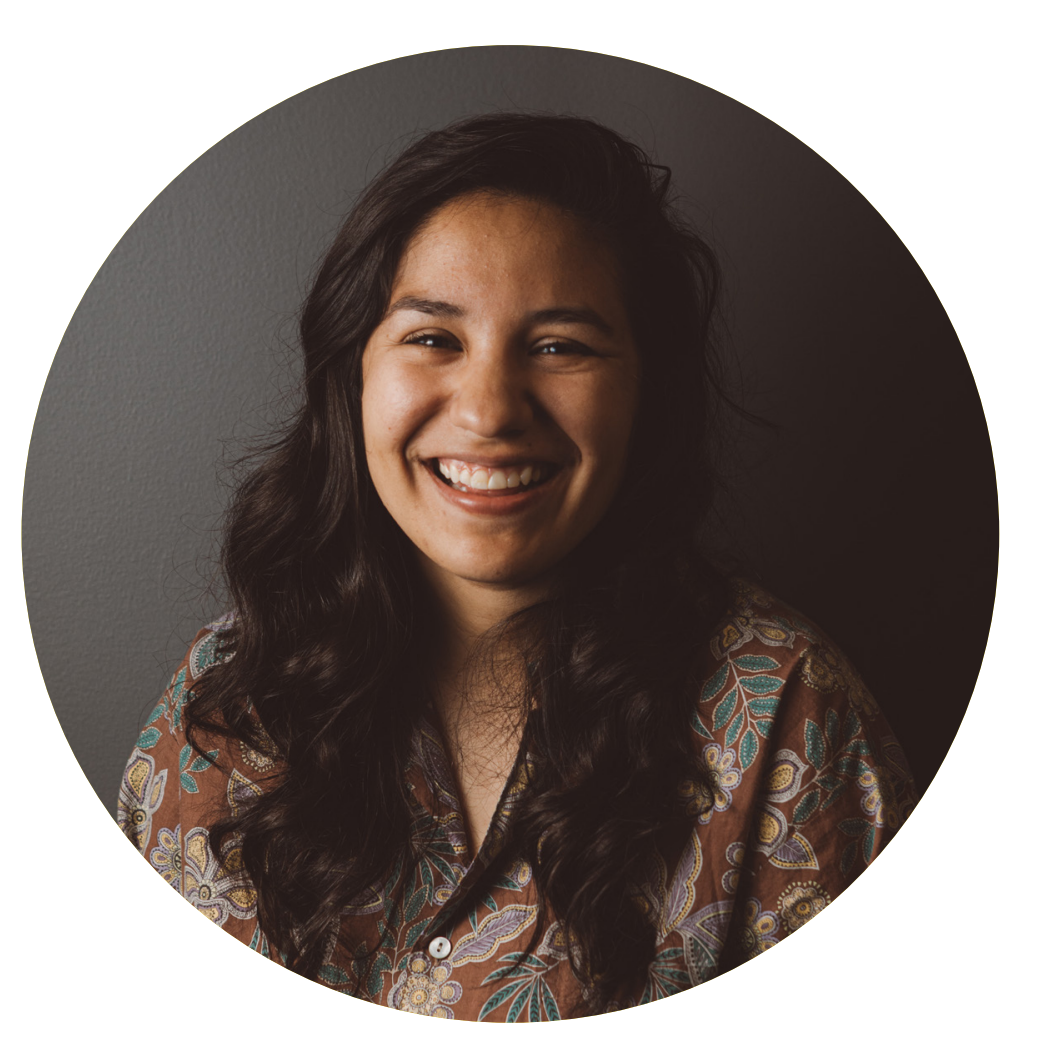

Jackie Gutierrez is a sports journalist and the writer and founder of Women Kick Balls, which is an independent news source that exists to capture women's soccer in an authentic voice. She is also a freelance content creator who specializes in brand development through social media, graphics, website design, and photography.

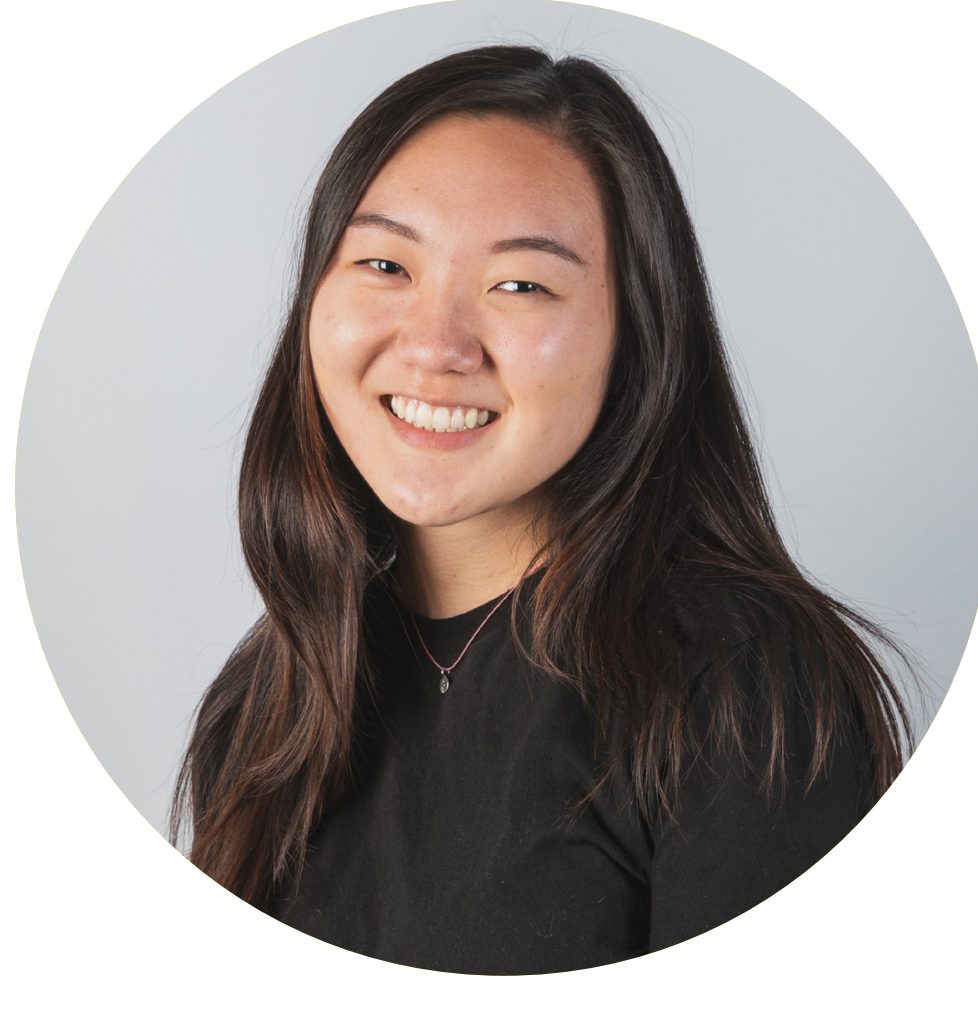

Kelly Kondo is a Production Coordinator at Servco Pacific Inc. and former Marketing Designer for Yoga Ed., based in Honolulu. Hawaii. She graduated from the Advertising and Brand Responsibility Master's program at the University of Oregon, where she also received her Bachelor's degree in Advertising.

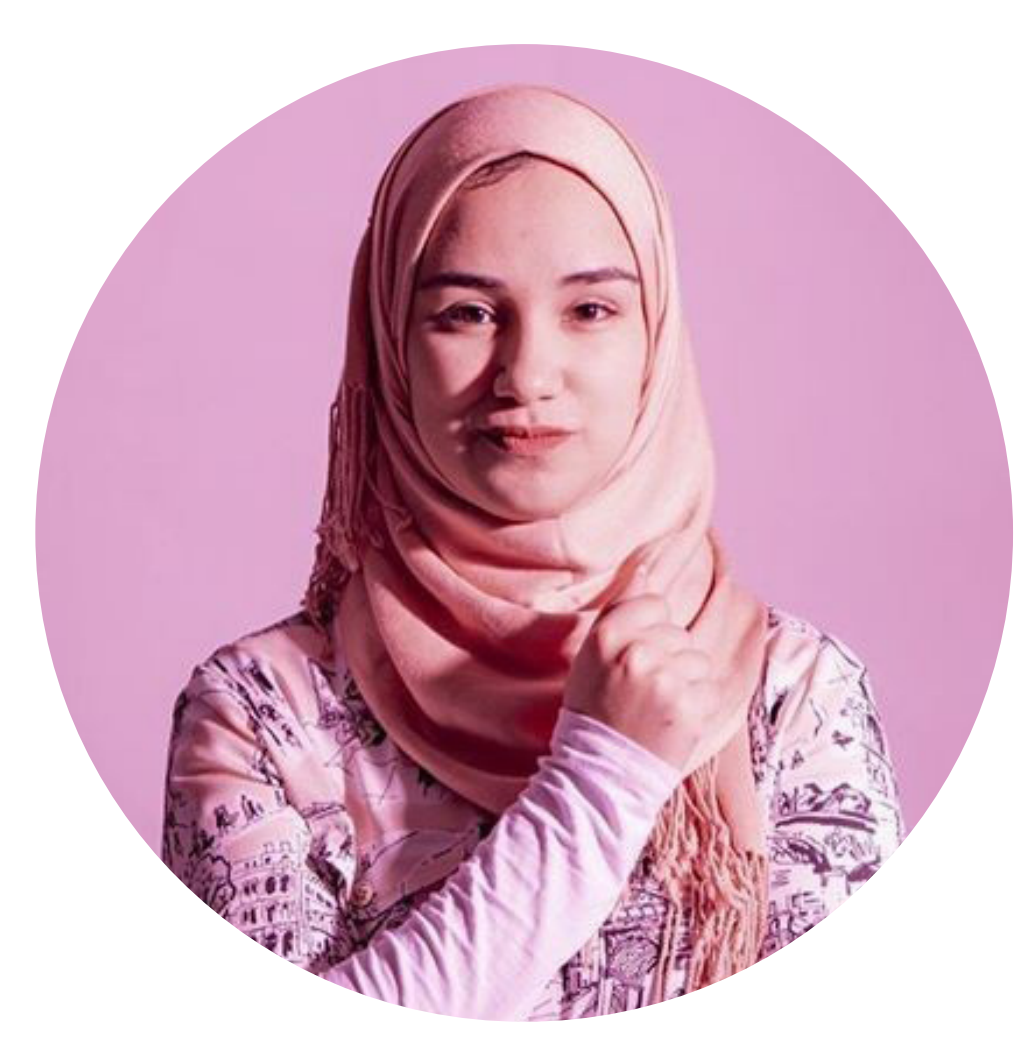

Hanin Najjar is an ArabAmerican multimedia journalist based in Portland, Oregon, USA. She is the Editor-in-Chief at Parachute Media, a start-up media company run by and for Gen Z women of color. 


$$
00
$$

Executive

Summary

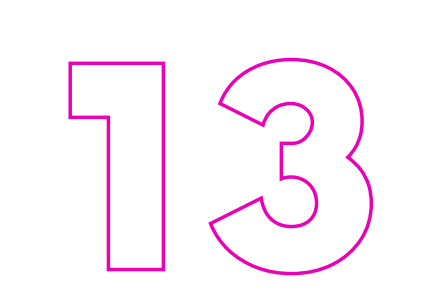

Implications

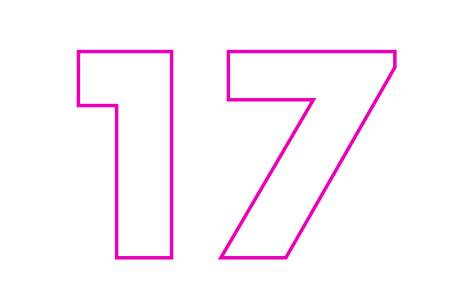

Market Context

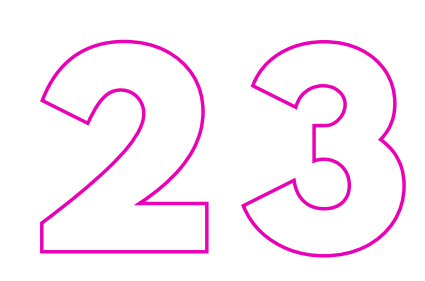

Facebook

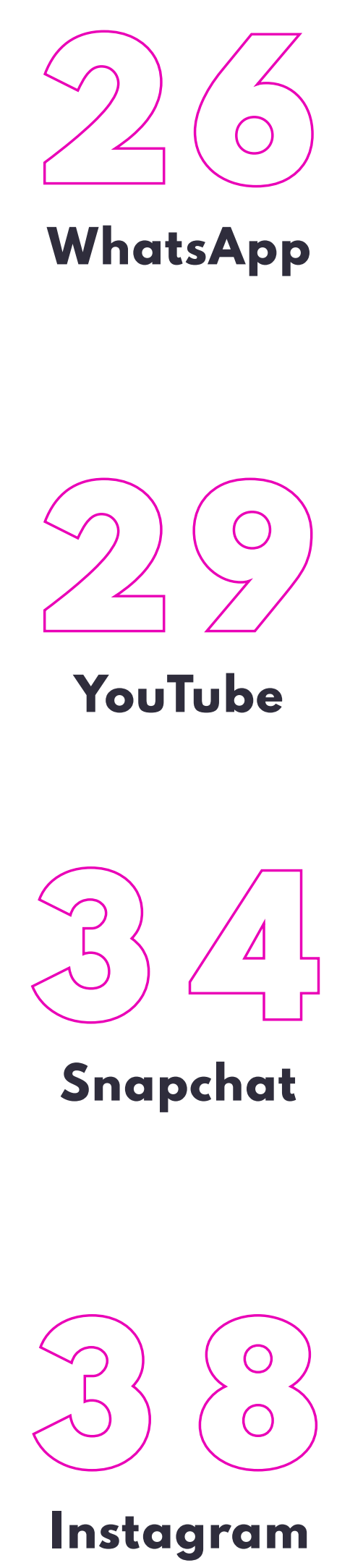

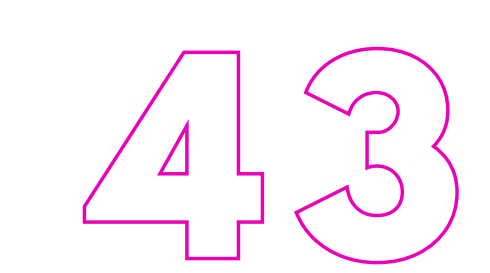

TikTok \& Twitter

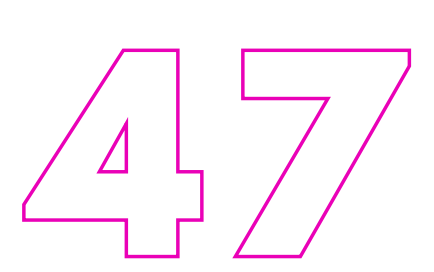

Trending Hashtags

$$
56
$$

Fake News \&

Misinformation

$$
\sum_{\text {Covid-19 }}^{\square}
$$

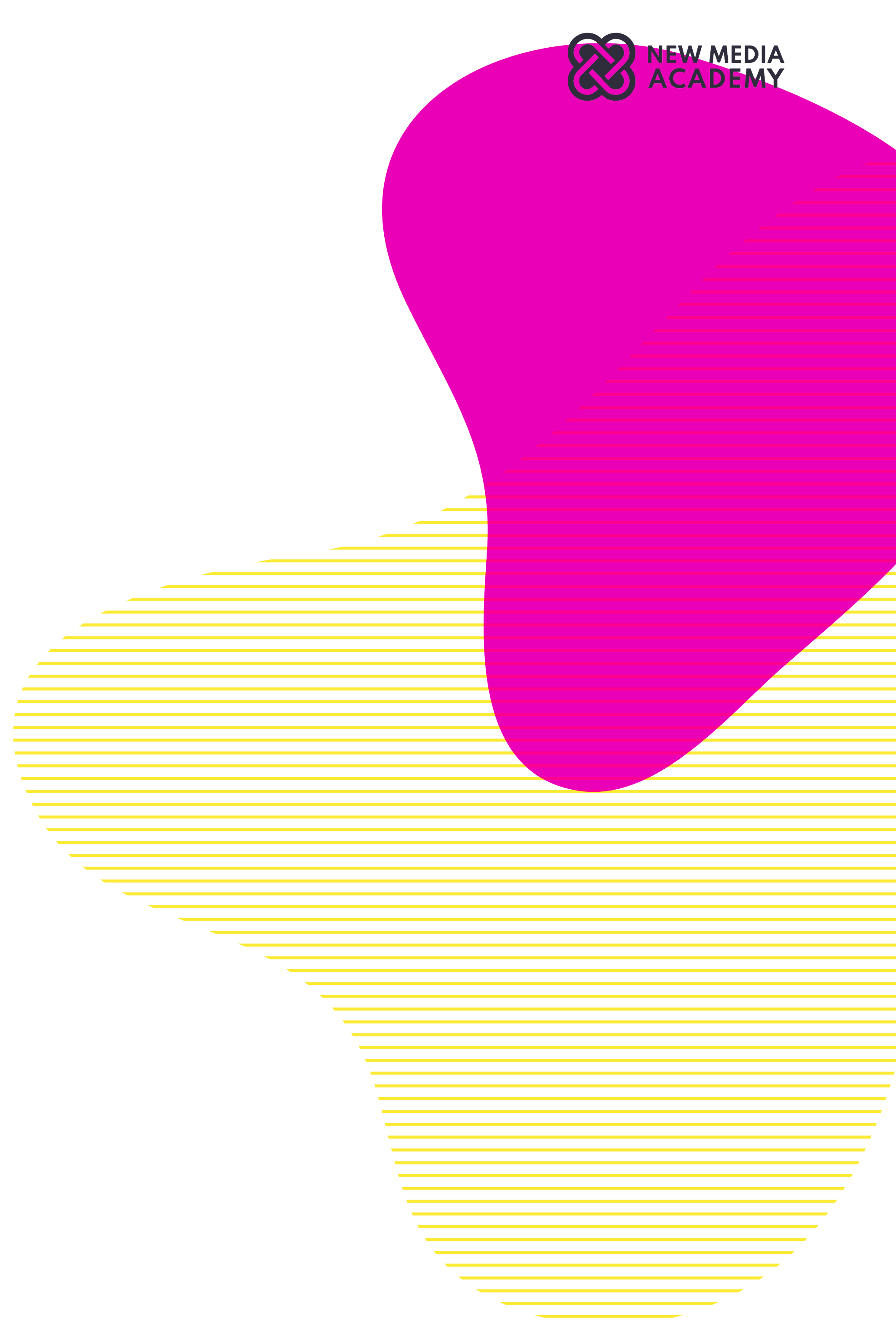




\section{EXECUTIVE SUMMARY:}

\section{KEY STATS FROM 2020}

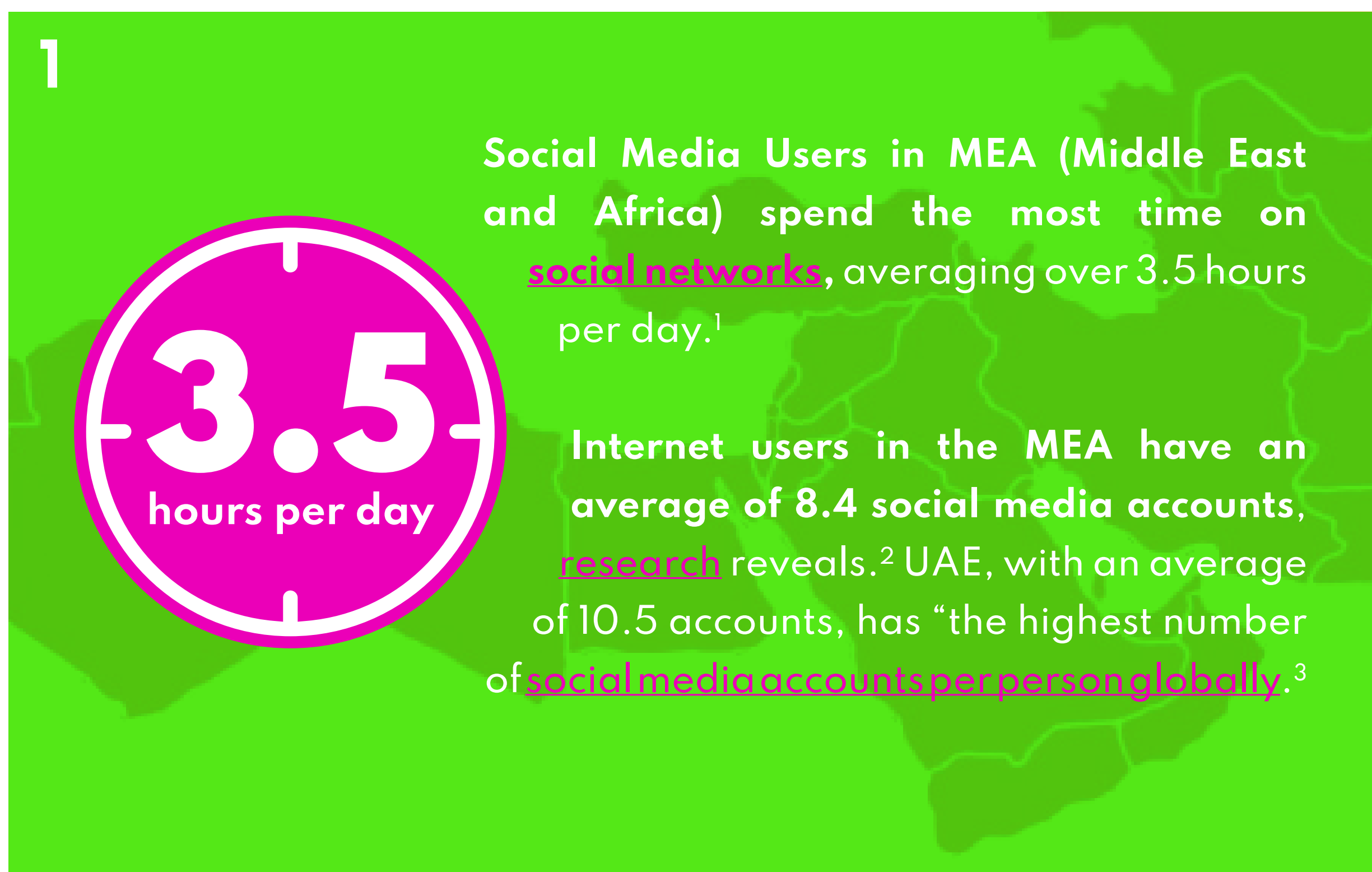

4

Four MENA Countries, Saudi Arabia (17.9 million users), Turkey $(9.7 \mathrm{~m})$, Iraq $(9.6 \mathrm{~m})$ and Egypt $(8.9 \mathrm{~m})$ are in the 13 largest national markets for Audiences are continuing to grow, highlighting the importance of the app. ${ }^{\circ}$

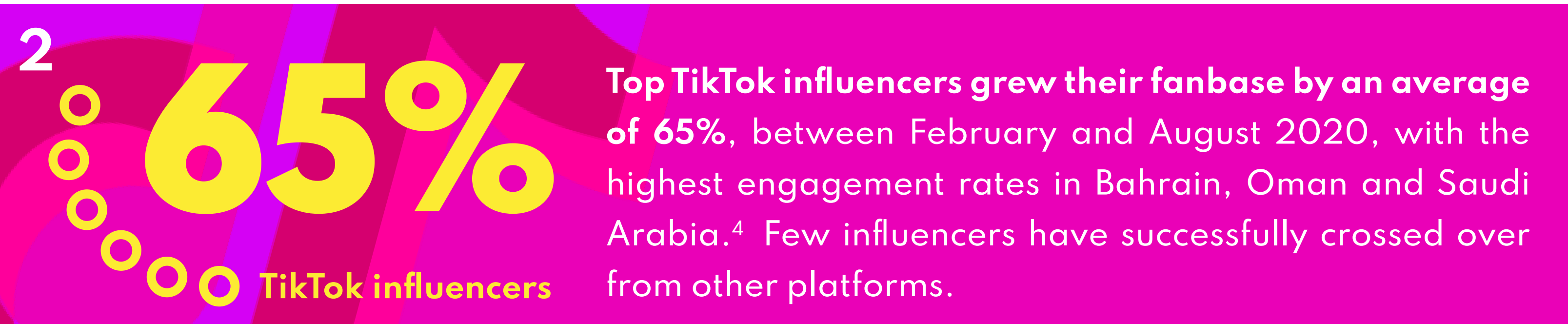

3 Egypt is the 9th largest national market for Facebook in the world, with 44 million users, by

Turkey is the only other MENA country in the Top 20, with 37 million users.
5

$79 \%$ of Arab Youth say they get their news from social media. That's up from $25 \%$ in 2015.

(2)

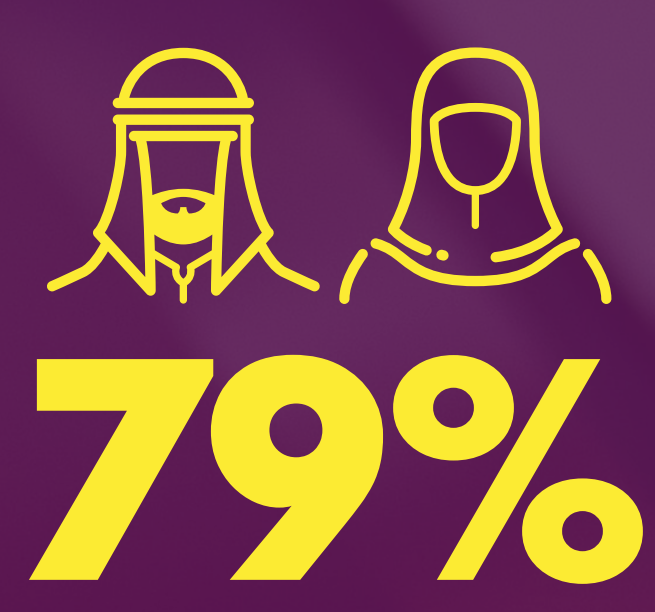




\section{EXECUTIVE SUMMARY: \\ DIGITAL CONTENT, INFLUENCERS AND COLLABORATIONS}

6 Lebanese pop artist, Elissa, is the Arab world's most influential person on Twitter and the only Arab figure in the

8 published by

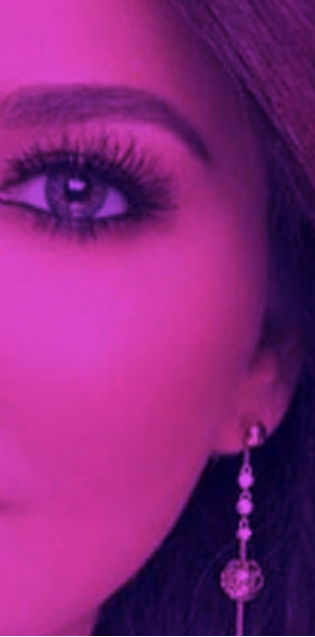

7

Facebook rolled out 9 content partnerships, ${ }^{9}$ while Snapchat launched 40 new shows, specifically for the Holy Month.

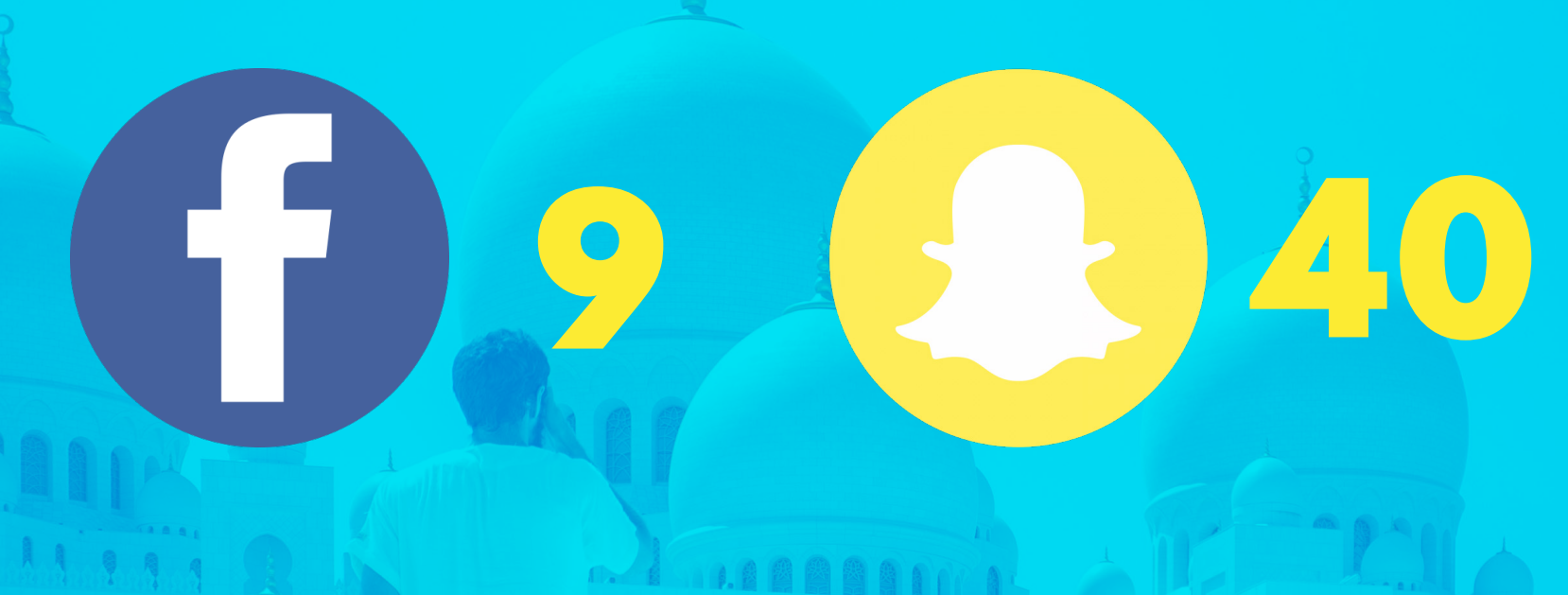

8

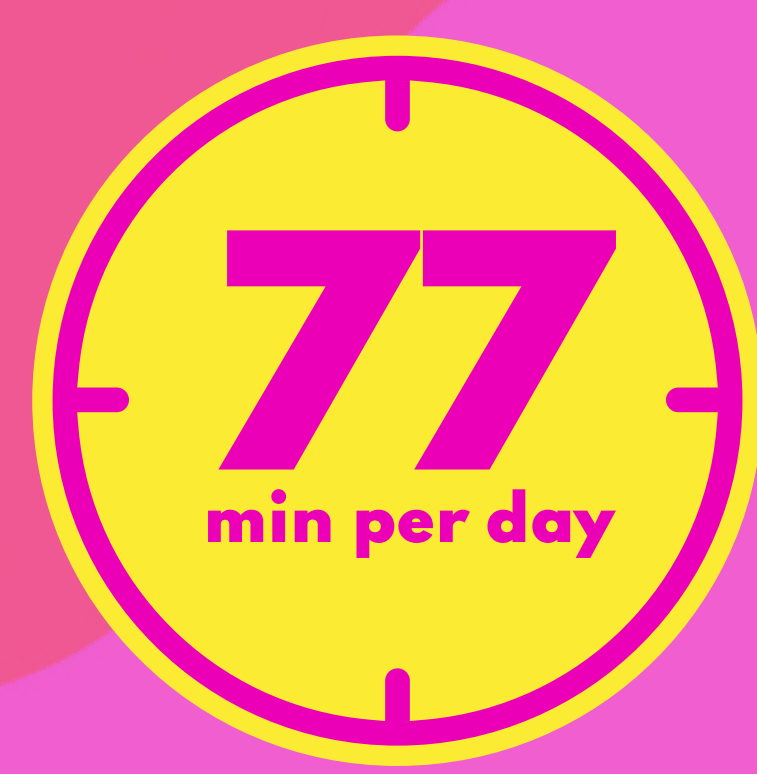

Snapchatters in UAE, Saudi Arabia, and Kuwait, spent 77 minutes a day on the app during the Holy Month. ${ }^{10}$ Watch time on Snapchat Discover had increased by over $50 \%$ year-over-year.
9

Influencer budgets appear to have been impacted by the COVID-19 pandemic, due to reduced marketing budgets, concerns about brands being linked with people sharing misinformation and relevance to COVID-era lifestyles."

\section{0}

Some content creators, like Nas Daily, continued to grow their businesses. ${ }^{12}$ (Disclosure, this includes a training partnership with New Media Academy.) ${ }^{13}$

Popular Saudi YouTubers, the Moshaya Family, partnered with Spacetoon, a pan-Arab free-to-air TV channel, to turn the family into a lifestyle franchise featuring toys, games and animation series. ${ }^{14}$ 


\section{EXECUTIVE SUMMARY: BRANDS, BUSINESSES AND DIGITAL MARKETING}

11

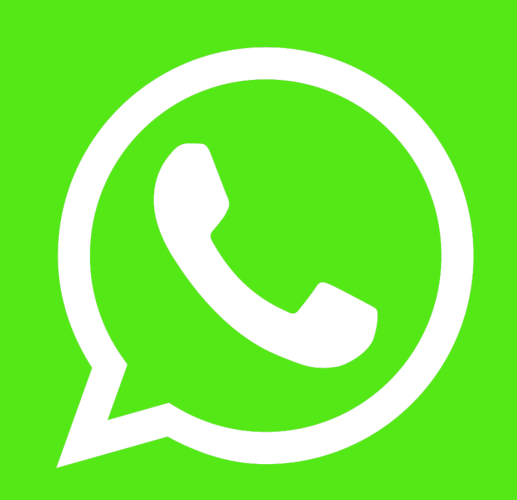

Businesses are increasingly using WhatsApp forbusiness communication. ${ }^{15}$ Travel agency Almosafer, ${ }^{16}$ telecom providers Zain Bahrain' and Ooredoo, ${ }^{18}$ as well as the leisure resort Yas Island in Abu Dhabi, ${ }^{19}$ are using the platform for customer relations.

14

Lockdowns encouraged some small businessesto digitize. A surveyin Egypt, Saudi Arabia and UAE, ${ }^{22}$ reported a $25 \%$ increase in digital sales, as more small businesses used social to promote goods and services. ${ }^{23}$

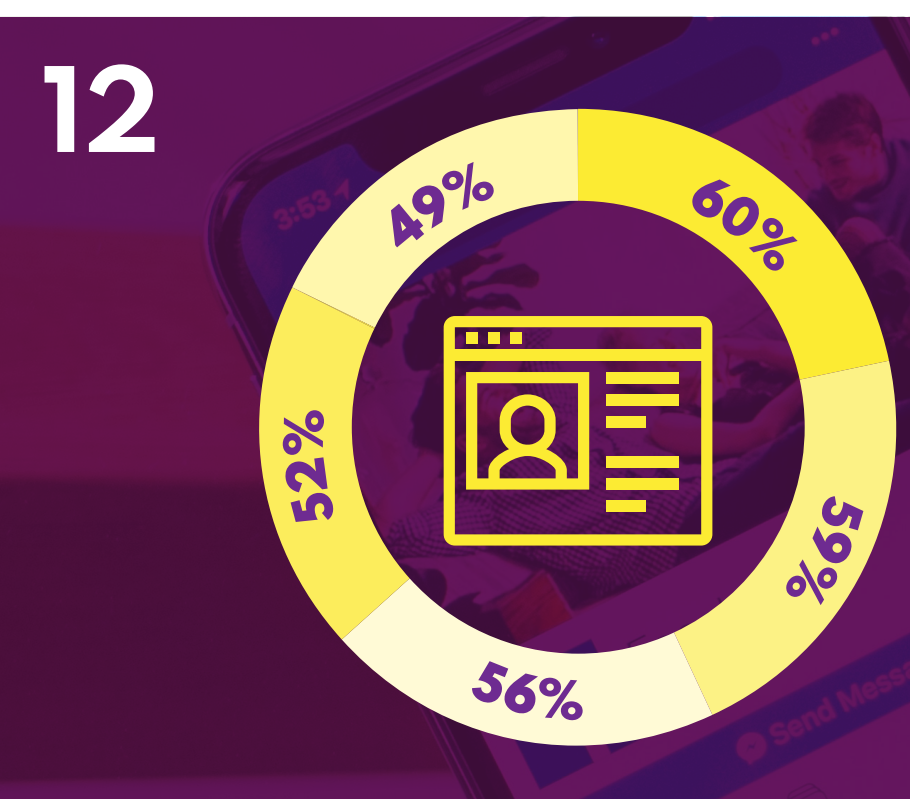

Social Media users in Morocco and Egypt (60\%), Saudi Arabia (59\%), Turkey (56\%), Israel (52\%) and UAE $(\mathbf{4 9 \%})$ are more likely to use social to research brands than the global average..$^{20}$

13 Platforms introduced a range of measures to promote public health information related to the pandemic, including special filters on Snapchat and links to the WHO on YouTube when users searched for COVID-19. ${ }^{2}$

15

10 Social networks and tech companies are some of the highest ranked brands in the region. Google, WhatsApp and YouTube were in the Top 10 for Egypt, Saudi Arabia and UAE in YouGov's 2020 Best Brand Rankings. ${ }^{24}$ 


\section{EXECUTIVE SUMMARY: GOVERNMENTS AND SOCIAL CAMPAIGNS}

16

WhatsApp was used by multiple governments to address issues and concerns related to COVID-19. Abu Dhabi's health department launched an automated "Chatbot" allowing users to get answers to common questions about the virus. ${ }^{25}$

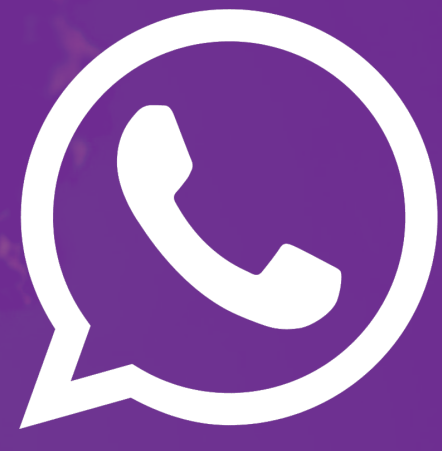

17

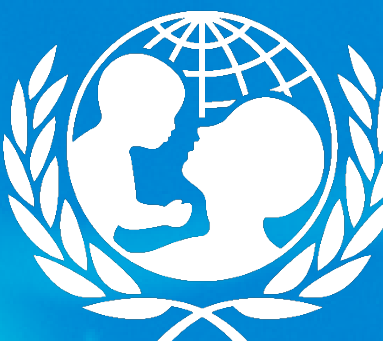

UNICEF and government agencies partnered with influencers and platforms to deliver public health UNICEF campaigns related to the pandemic. ${ }^{27}$

18

Platforms monitored and shut down social media accounts determined to be spreading pro-government messaging. ${ }^{28}$ Thousands of accounts from MENA across the region were suspended in 2020.

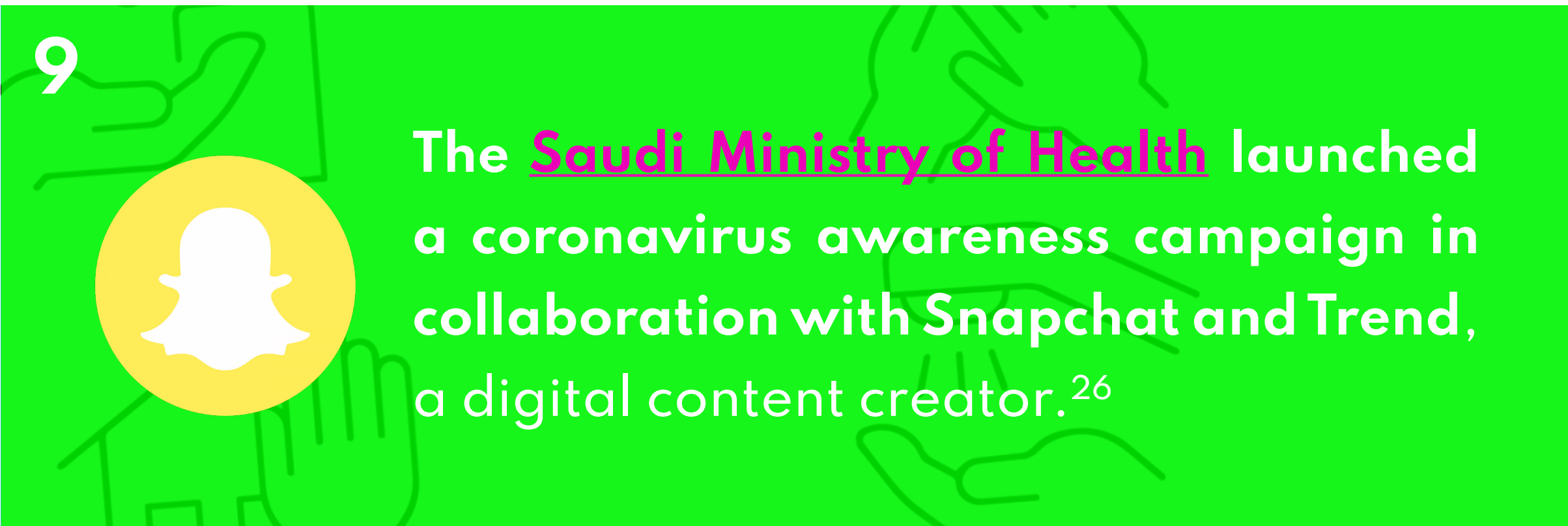

20

Grassroots, bottom-up campaigns also had an impact. Black Lives Matter resonated across parts of the region, as social media users discussed what this meant for the Arab World. ${ }^{29}$

In Lebanon, users responided on social media to the horrific explosion which killed several hundred people. ${ }^{30}$ Hundreds of Lebanese using \#OurHomesAreOpen in Arabic and to help those displaced by the tragic event. ${ }^{31}$ 


\section{IMPLICATIONS: 12 KEYTAKEAWAYS AND PREDICTIONS}

\section{FOR: CONTENT CREATORS, BRANDS AND DIGITAL MARKETERS}

1. Social networks have seen users spend more time on their channels as a result of COVID-19. It remains to be seen if audiences will revert to pre-pandemic media habits once the crisis ends, but some new digital behaviors are likely to remain engrained (e.g. social commerce). Brands and businesses will need to respond to this shift.

\section{Social media users in MENA are among those most likely to use social networks to} research brands; a habit which may also influence purchasing decisions. As the ability to buy directly on social networks develops (aka social commerce) the pathway from research to purchase needs to become as frictionless as possible. ${ }^{32}$

3. Social media's significance as a channel for content continues to grow during Ramadan. Tapping into this demand, and these media habits, remains a priority for content creators, platforms and brands alike.
4. Influencer marketing took a hit in $\mathbf{2 0 2 0}$ due to COVID. It is unclear if this will bounce back to pre-pandemic levels, or if these types of relationships will evolve. TikTok's rapid growth, and the emergence of a new generation of influencers, for example, is a trend to watch

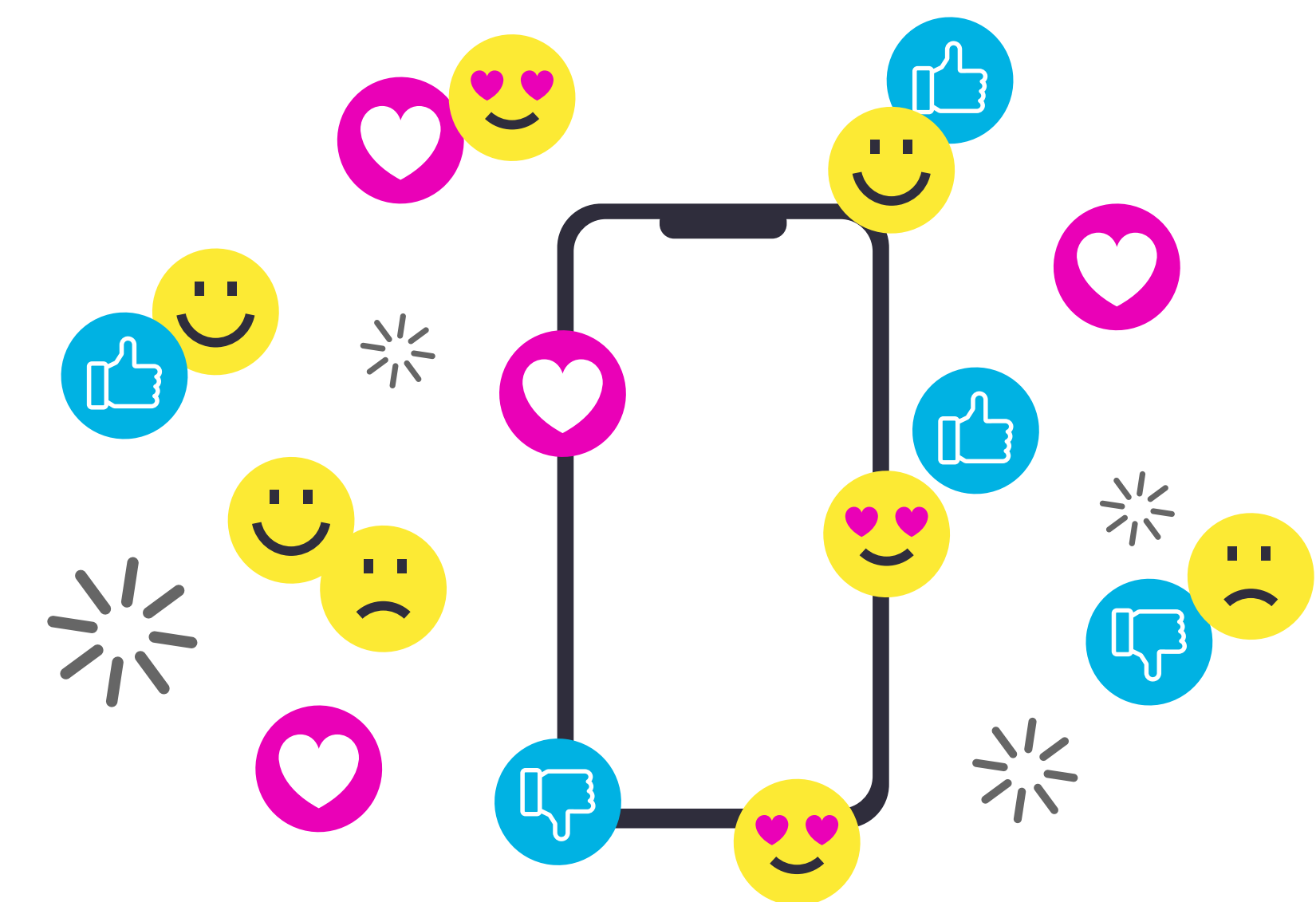




\section{IMPLICATIONS: 12 KEYTAKEAWAYS AND PREDICTIONS}

\section{FOR: PLATFORMS}

5. There remains a symbiotic relationship between the platforms, digital content creators and traditional media companies. We continue to see "media stars" emerge on social networks, as well as platforms and traditional media companies seeking to create content specifically for given social networks.

6. More than in previous years, it can be challenging for researchers, agencies and others to find up to date public data on audience behaviors, which can make it challenging to make informed investment decisions. We hope to see more data in the public domain, post-pandemic, to support businesses.

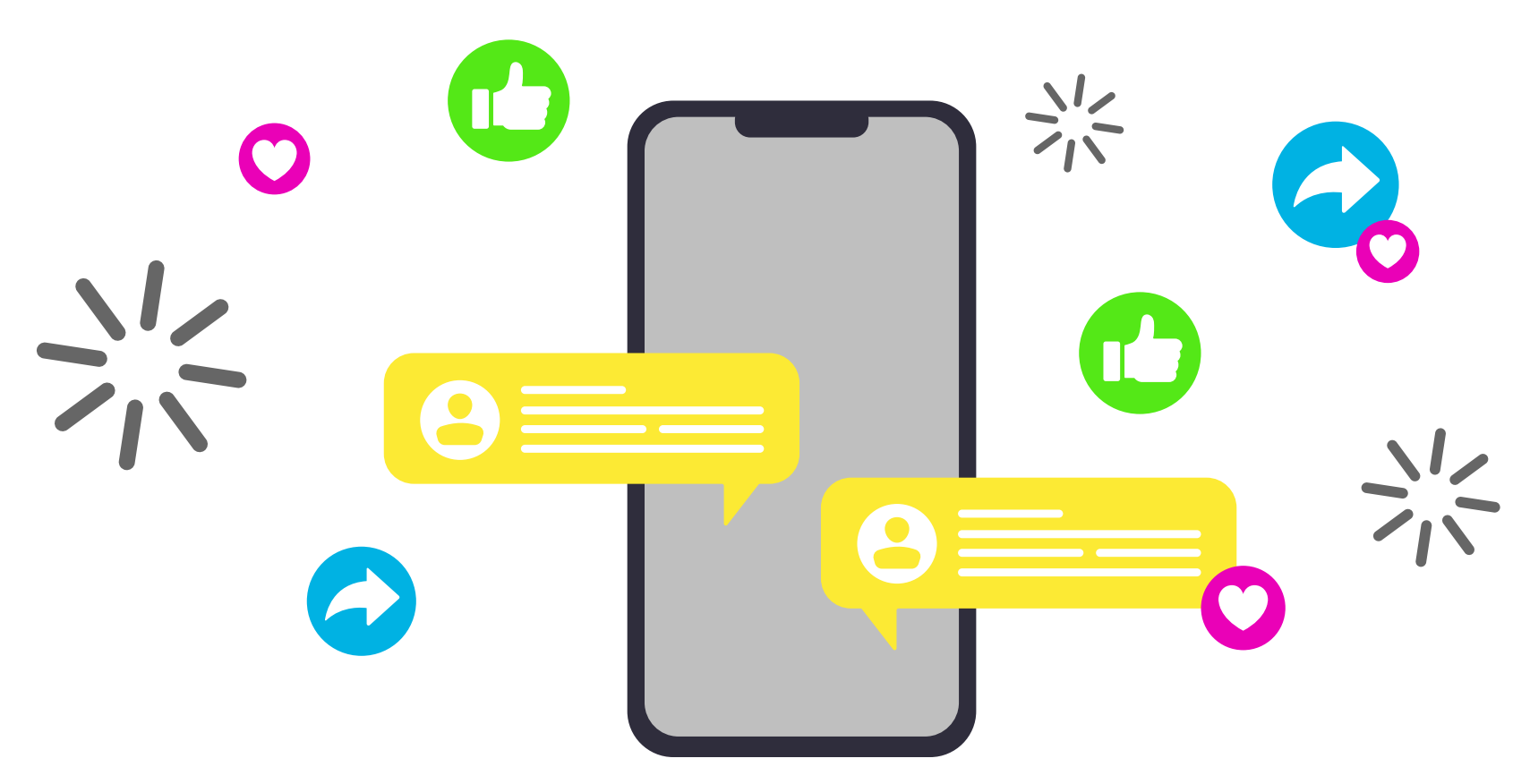

7. This matters, because platform consumption varies considerably from countryto-country, making it very difficult (and indeed inadvisable) to deploy a "one size fits all" regional strategy

For example, as Hussein Freijeh, Regional Director of Snap Inc. MENA, has revealed "In Saudi Arabia, more people watch Snapchat Discover content every day than any of the Top 10 TV channels, both before and during Covid-19."33 This situation is not necessarily replicated in other markets.

8. The use of Messaging Apps - like WhatsApp - for B2C (business to consumer) relationships is growing. Convenience, high levels of platform take up and familiarity with these channels are all drivers for consumers increasingly using these networks for customer service related activities.

In response, businesses must continue to adapt to these preferences, as social media habits increasingly replace more traditional communication methods such as customer service telephone lines. 


\section{IMPLICATIONS: 12 KEYTAKEAWAYS AND PREDICTIONS}

\section{FOR: GOVERNMENT AND NGOS}

9. Governments have embraced social networks as a key vehicle for both informing and supporting, citizens and residents during the coronavirus crisis.

We expect this trend to remain popular as the pandemic continues well into 2021, and that governments will also use these platforms - and the lessons learned from COVID - for other types of information and public awareness campaigns - in the future.

10. Influencers have been involved in numerous COVID campaigns - as voices advocating for behavioral change, or as amplifiers of key messages - again public information trends that we expect to see continuing beyond the end of the COVID crisis.

11. Ensuring that government agencies understand the potential of social media, and that they have the skills to use these networks, will continue to be a key training need.
12. The decision to suspend former U.S. President Donald Trump from Twitter, YouTube and Facebook, and Twitters' decision to ban an account linked to Iran's supreme Leader may irreversibly change the relationship that platforms have with government leaders, potentially making these types of suspensions more common place, and possibly changing the way in which political leaders use social platforms.

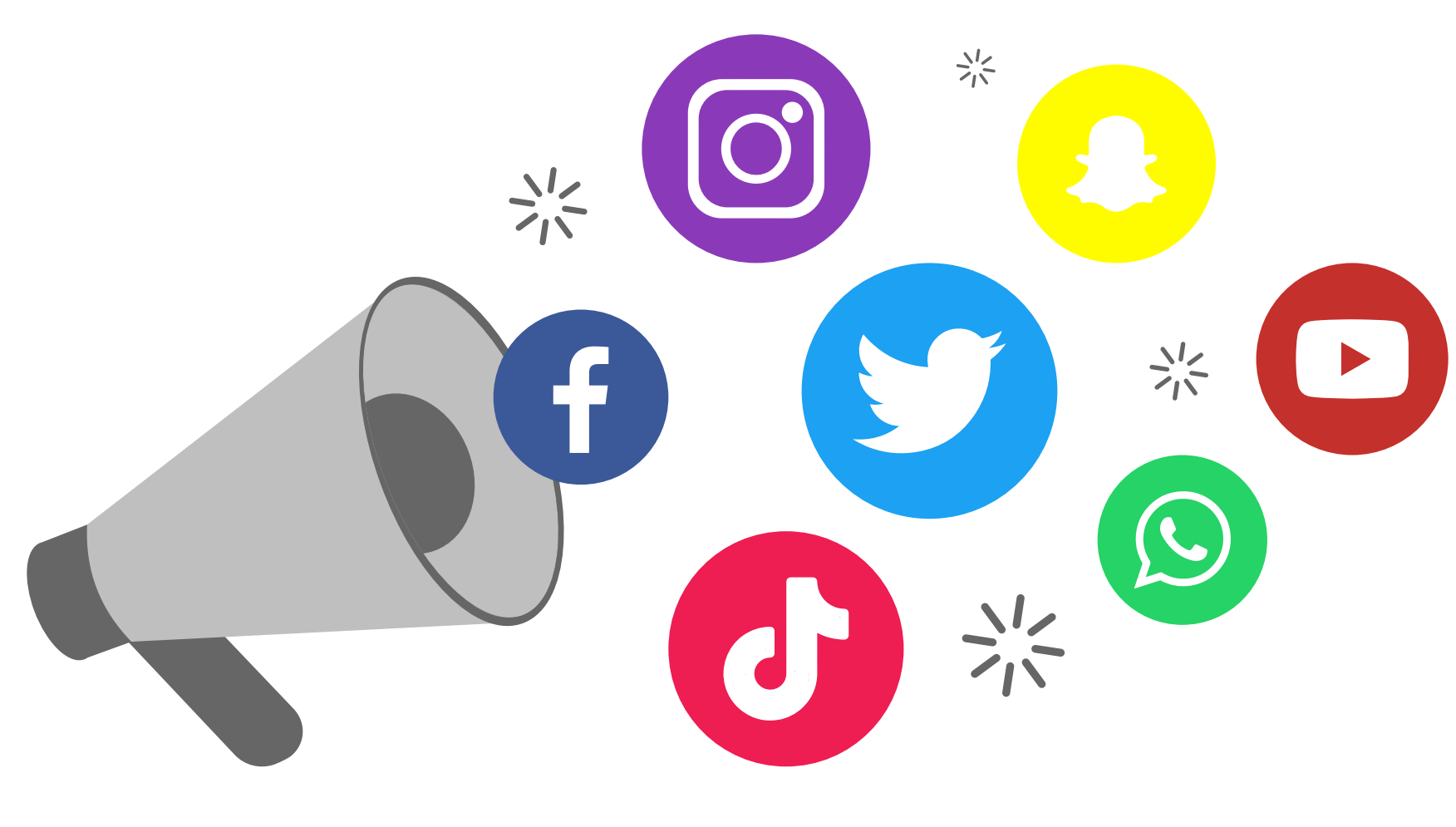


MARKET CONTEXT 


\section{MARKET CONTEXT}

Social Networks are powerful platforms in the Middle East, as they are around the world, shaping - and influencing - a wide range of online and offline behaviours This includes news consumption, shopping preferences, as well as entertainment habits and relationships with friends and family.

As the United Nations observed back in 2019

Social media are likely to play an increasing role in advertising digital arabic content. For an increasing number of people in the region, this is a "first filter" through which they access content.

Videos a re popular among arab youth and could be used as a conduit to push any kind of useful infotainment or edutainment content.

News [content] represent [s] an important segment of digital media as people in the region now predominantly use online sources to access information rather than more traditional media (print and radio, and to lesser extent television).
Statistics show how internet take-up has grown substantially in the past decade. As the Beirut-based Arab Development Portal, notes: "The percentage of individuals (\% of total population) using the internet in the Arab region has more than doubled in 2018 at $54.7 \%$ in 2018 up from $24 \%$ in $2010 . " 34$

Internet users in the Middle East have an average of $\mathbf{8 . 4}$ social media accounts, research from GlobalWeblndex (GWI) reveals. ${ }^{35}$ The figure is higher in UAE at an average of 10.5 accounts each, "the highest number of social media accounts per person globally," Forbes observed. 36

\section{MULTI-NETWORKING BY REGION}

Average number of social media accounts ${ }^{*}$ held by internet users in each region
Latin America

$$
\text { Q. } 7
$$

Middle East \& Africa
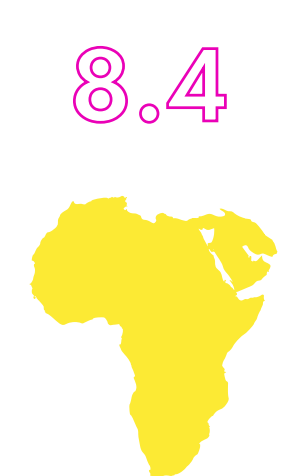

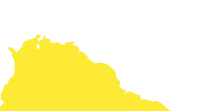

Asia Pacific

(9).3
Chart: Daily time spent w/social media pre-pandemic and in May-2020, via GWI
North America

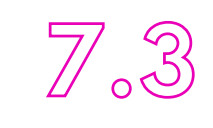

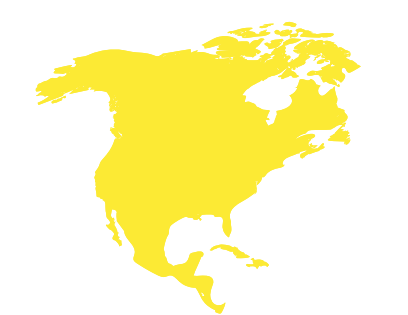


Mobile has - for some time - been an important part of the equation. Since $\mathbf{2 0 1 4}$ mobile social media penetration in the region has more than doubled to 44\%, GSMA - a trade body for the mobile industry - reports. ${ }^{37}$

Mobile connection speeds in some parts of the Middle East are among the fastest in the world, helping to fuel MENA's social media habit. Ookla's November 2020 Global Index placed three GCC countries in the Top 10, UAE (1st), Qatar (3rd) and Saudi Arabia (8th) with Kuwait at llth, "its highest mobile ranking to date ... most likely due to all major operators offering $5 G$ in the country." 38

Data published earlier in the year also shows that Morocco and Turkey also have mobile internet speeds above the world average. ${ }^{39}$

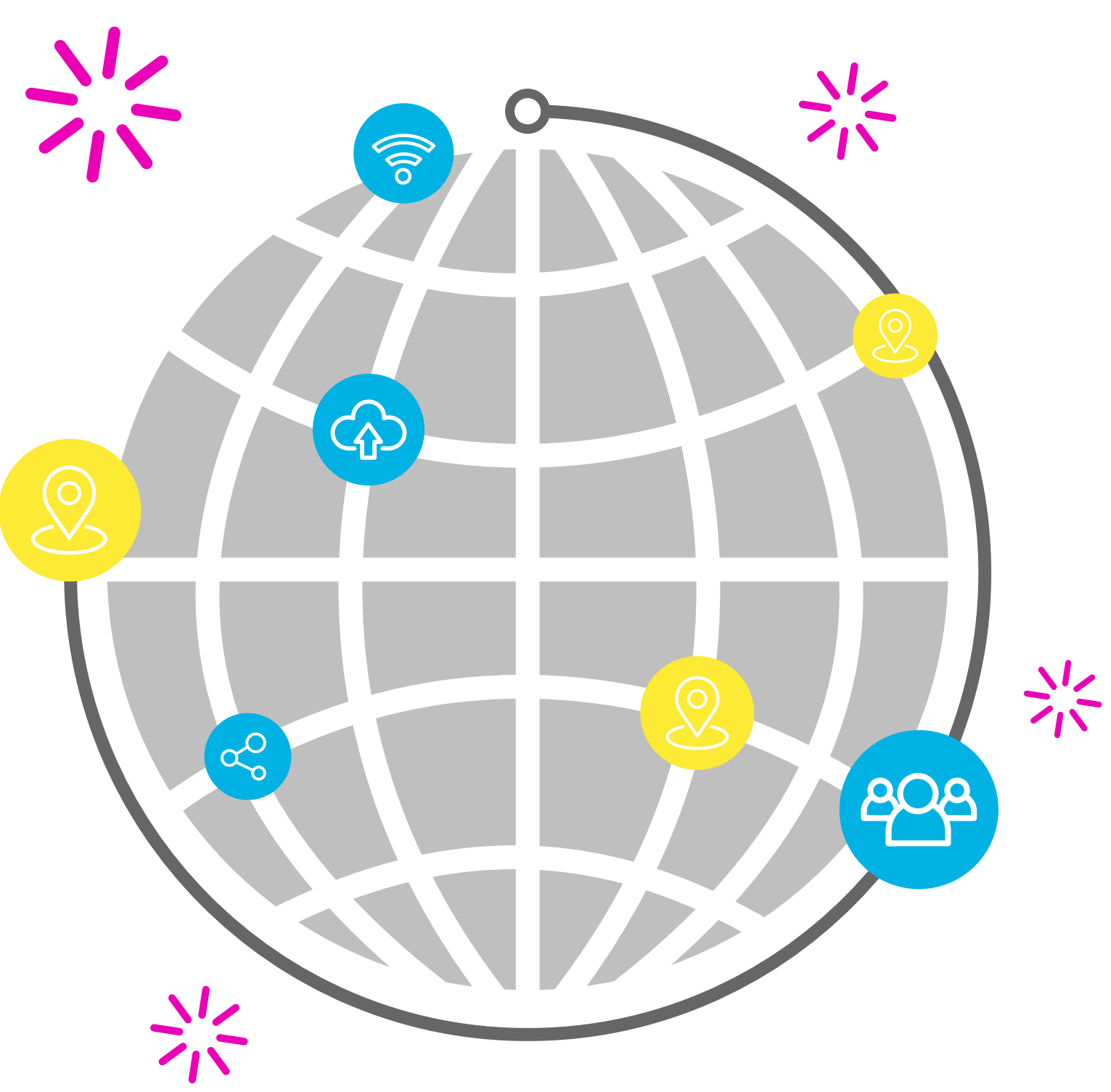

\section{SPEEDTEST ${ }^{\circledR}$ GLOBAL INDEX $^{2}$}

Ranking mobile and fixed broadband speeds from around the world on a monthly basis (November 2020)

\section{Mobile Global Average Download Speeds}

\section{Download Mbps Upload Mbps

$45.69 \quad 12.60$

\begin{tabular}{lc} 
1. United Arab Emirates & $\mathbf{1 7 0 . 3 0 ~ M b p s}$ \\
\hline 2. South Korea & $166.70 \mathrm{Mbps}$ \\
\hline 3. Qatar & $\mathbf{1 5 9 . 6 6 \mathrm { Mbps }}$ \\
\hline 4. China & $148.12 \mathrm{Mbps}$ \\
\hline 5. Australia & $113.16 \mathrm{Mbps}$ \\
\hline 6. Norway & $100.98 \mathrm{Mbps}$ \\
\hline 7. Netherlands & $99.67 \mathrm{Mbps}$ \\
\hline 8. Saudi Arabia & $99.34 \mathrm{Mbps}$ \\
\hline 9. Canada & $93.74 \mathrm{Mbps}$ \\
\hline 10. Switzerland & $87.73 \mathrm{Mbps}$ \\
\hline
\end{tabular}

Table: November 2020 Data showing mean download speed. via Speedtest ${ }^{\circledR}$ by Ookla ${ }^{\circledR}$ 
Social Media Users in MEA (Middle East and Africa) spend the most time on social networks, averaging over $\mathbf{3 . 5}$ hours a day. In May, more than half of users in those regions also told GlobalWeblndex that they were spending more time on social media as a result of the COVID-19 pandemic.

\section{DAILY TIME SPENT ON SOCIAL MEDIA}

Average hh:mm spent using social networks on a typical day (January - March).

$\frac{0}{9}$

\section{Latin America}

$03: 38$

Asia Pacific

02:08

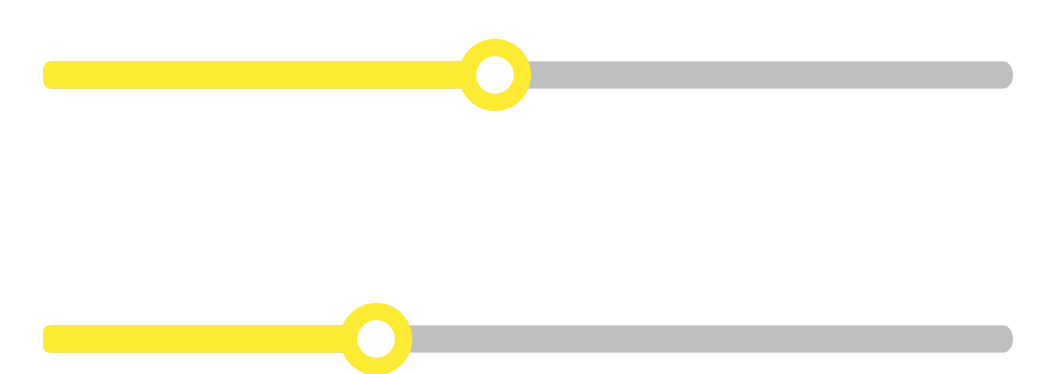

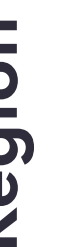

\section{Middle East \& Africa}

$03: 32$

Europe

$01: 40$

$02: 06$

\section{SPENDING LONGER ON} SOCIAL MEDIA

$\%$ in each region who have spent longer on social media because of

$$
\text { the outbreak (May). }
$$

North America
Daily usage of social media has increased in several MENA countries, notably Turkey (up 16 min, a day since 2017), UAE (up 21 min.) and Saudi Arabia (up 33 min.). In Egypt and Morocco use has dropped slightly in 2020, for reasons unknown, having previously held fairly steady between 2017-2019

\begin{tabular}{|c|c|c|c|c|}
\hline & 2017 & 2018 & 2019 & 2020 \\
\hline Egypt & $3: 06$ & $3: 05$ & $3: 02$ & $2: 38$ \\
\hline Israel & & & $1: 59$ & $2: 10$ \\
\hline Morocco & $2: 22$ & $2: 34$ & $2: 30$ & $2: 19$ \\
\hline Saudi Arabia & $2: 38$ & $2: 52$ & $3: 08$ & $3: 11$ \\
\hline Turkey & $2: 49$ & $2: 52$ & $2: 56$ & $3: 05$ \\
\hline UAE & $2: 56$ & $3: 00$ & $3: 03$ & $3: 17$ \\
\hline
\end{tabular}

Table: Average time (h: $\mathrm{mm}$ ) spent using social networks on a typical day, via GlobalWeblndex 40

Social Media users in MENA are among those most likely to use social networks to research brands; a habit which may also influence purchasing decisions.

Among social media users, consumers in Morocco and Egypt (60\%). Saudi Arabia (59\%), Turkey (56\%), Israel (52\%) and UAE (49\%) are all more likely to engage in this behaviour than the global average. ${ }^{41}$ 


\section{USE OF SOCIAL MEDIA FOR BRAND RESEARCH}

Percentage of internet users aged $\mathbf{1 6}$ to $\mathbf{6 4}$ who use social media when they're looking for information about brands (October 2020)

\begin{tabular}{lc} 
Kenya & $84 \%$ \\
\hline Nigeria & $84 \%$ \\
\hline Morrocco & $60 \%$ \\
\hline Egypt & $60 \%$ \\
\hline Saudi Arabia & $59 \%$ \\
\hline Turkey & $56 \%$ \\
\hline Israel & $55 \%$ \\
\hline UAE & $49 \%$ \\
\hline Average Worldwide & $44 \%$ \\
\hline Japan & $24 \%$ \\
\hline South Korea & $24 \%$ \\
\hline
\end{tabular}

Chart: Use of Social Media for Brand Research via We Are Social and Hootsuite
"In 2015, just 25\% of young Arabs cited social media as their main news source," the latest Arab Social Media report reminded us, "this year, $79 \%$ say they get their news from social media." 42

As these findings show, social media increasingly influences numerous aspects of digital diets in the Middle East. COVID-19, faster mobile networks and growing smartphone take-up has only increased these behaviors, creating social media habits which are only likely to grow.

\section{WHERE DOYOU GETYOUR NEWS?}

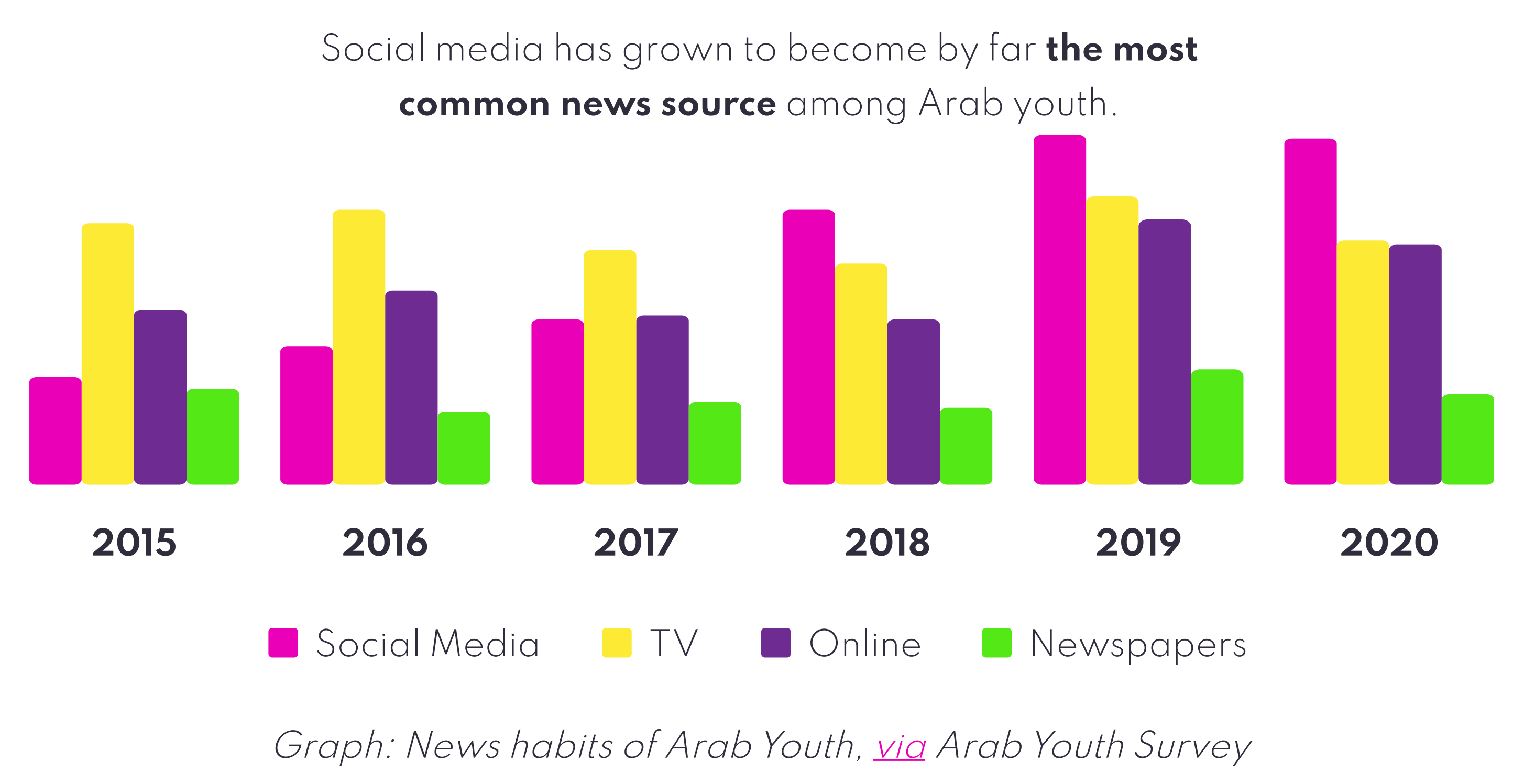

In the coming chapters, we examine some of the biggest stories and market developments seen across individual platforms in the past year, as well as diving into cross-cutting news stories and issues. 


\section{FACEBOOK}

\section{COUNTRIES \& TERRITORIES WITH THE GREATEST ABSOLUTE INCREASE}

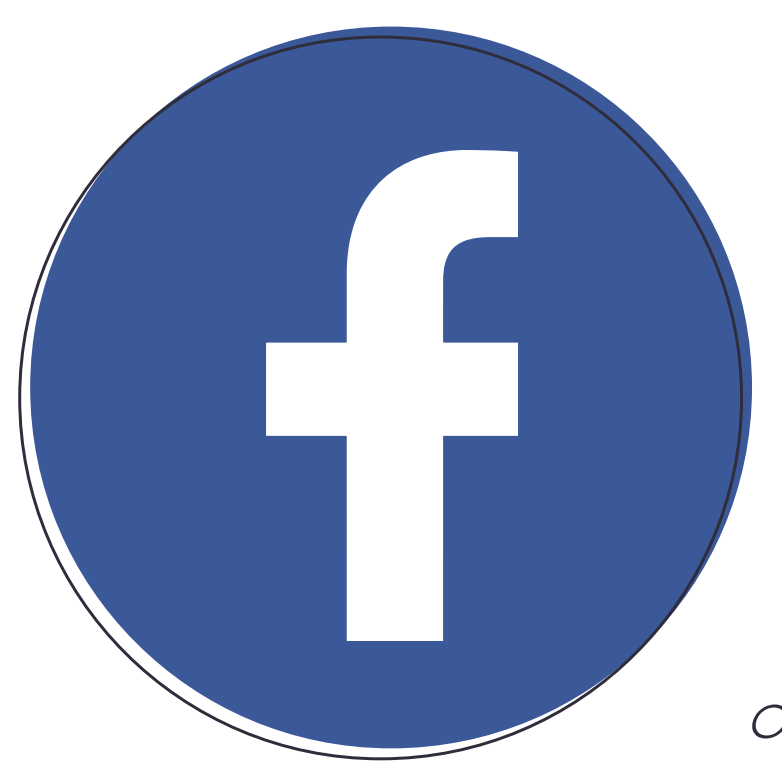

Facebook continues to be a powerful social media presence in the region, through both its core platform and other services: Instagram, WhatsApp and Facebook Messenger. The main service also continues to see growth, particularly in North Africa emphasizing the on-going importance of the region to the company.

Egypt is the 9th largest market for Facebook in the world, with 44 million users, as of October 2020.43 Turkey is the only other MENA country in the Top 20, ranked 13th - ahead of Columbia and behind the UK - with 37 million users

Libya (100\%), UAE (93\%) and Qatar (90\%) are among the countries with the highest levels of reach for Facebook, relative to the population. According to data from We Are Social and Hootsuite, Libya and the Philippines are the only countries in the world where Facebook penetration levels cover the entire population.

Facebook is also continuing to grow in several North African markets. Egypt is ranked fourth in the Top 10 countries and territories for the fastest growing number of Facebook users, followed by Morocco ranked at seventh, and Algeria ranked at ninth.

\begin{tabular}{|c|c|c|c|}
\hline$\#$ & ABSOLUTE INCREASE & USERS INCREASE & $\%$ INCREASE \\
\hline 01 & India & $+20,000,000$ & $+7 \%$ \\
\hline 02 & Philippines & $+5,000,000$ & $+7 \%$ \\
\hline 03 & Mexico & $+3,000,000$ & $+3 \%$ \\
\hline 04 & Egypt & $+2,000,000$ & $+5 \%$ \\
\hline 05 & Cambodia & $+1,000,000$ & $+10 \%$ \\
\hline 06 & Ukraine & $+1,000,000,000$ & $+7 \%$ \\
\hline 07 & Morocco & $+1,000,000$ & $+5 \%$ \\
\hline 08 & South Africa & $+1,000,000$ & $+5 \%$ \\
\hline 09 & Algeria & $+1,000,000$ & $+4 \%$ \\
\hline 10 & Peru & & $+5 \%$ \\
\hline
\end{tabular}

Table: Facebook Audience: Largest Increases Q3-Q4 2020, via We Are Social and Hootsuite 
Facebook is partnering with a number of global telecom providers, including Saudi Arabia's stc, Telecom Egypt, to build one of the world's largest subsea cable networks. ${ }^{44}$

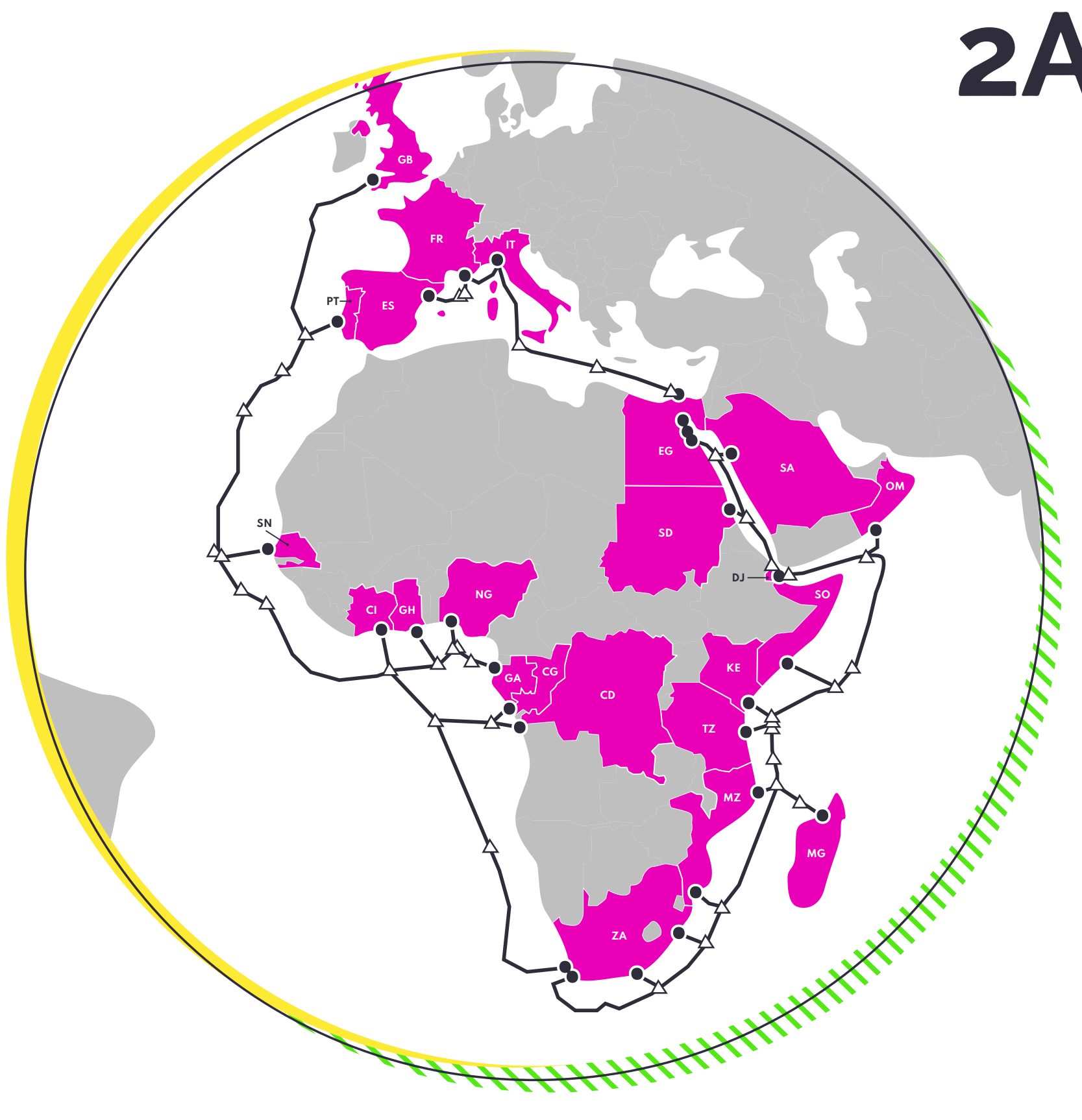

2AFRICA

Map: Highlighting the countries covered by the 2Africa Network, via Facebook.

The 2Africa network will boost internet capacity - and increasing demand for $4 G$ $5 G$ and broadband - across 23 interconnected countries in Africa, the Middle East. and Europe.

An important market for Facebook's potential growth, "Africa is currently the least connected continent," the company notes, "with just over a quarter of its 1.3 billion people connected to the internet." 45 Globally, more 3.5 billion people remain unconnected to the internet. 46
Facebook announced a new initiative, \#LoveLocal, to support local small and medium businesses in the Middle East and North Africa. Through the campaign, Facebook will provide business owners with access to their Middle East and North Africa SMB Training Hub, offering free courses exploring digital marketing, eCommerce and other online activities

"According to the 'Global State of Small Business' report [published by Facebook] in July 2020, 70\% of businesses in the MENA region reported reduced sales, with around $40 \%$ reducing their workforce in response to the pandemic," said Ramez Shehadi, Managing Director for Middle East \& North Africa, Facebook. ${ }^{47}$

Separately, a survey to determine how the pandemic has affected small and medium sized businesses (SMBs) in Egypt, Saudi Arabia and UAE, was conducted by Facebook, the World Bank, and the Organization for Economic Co-operation and Development (OECD). ${ }^{48}$

Although overall sales were down, the survey reported a $\mathbf{2 5 \%}$ increase in digital sales, as a result of SMBs accelerating their digitization and use of social media to promote their goods and services. ${ }^{49}$

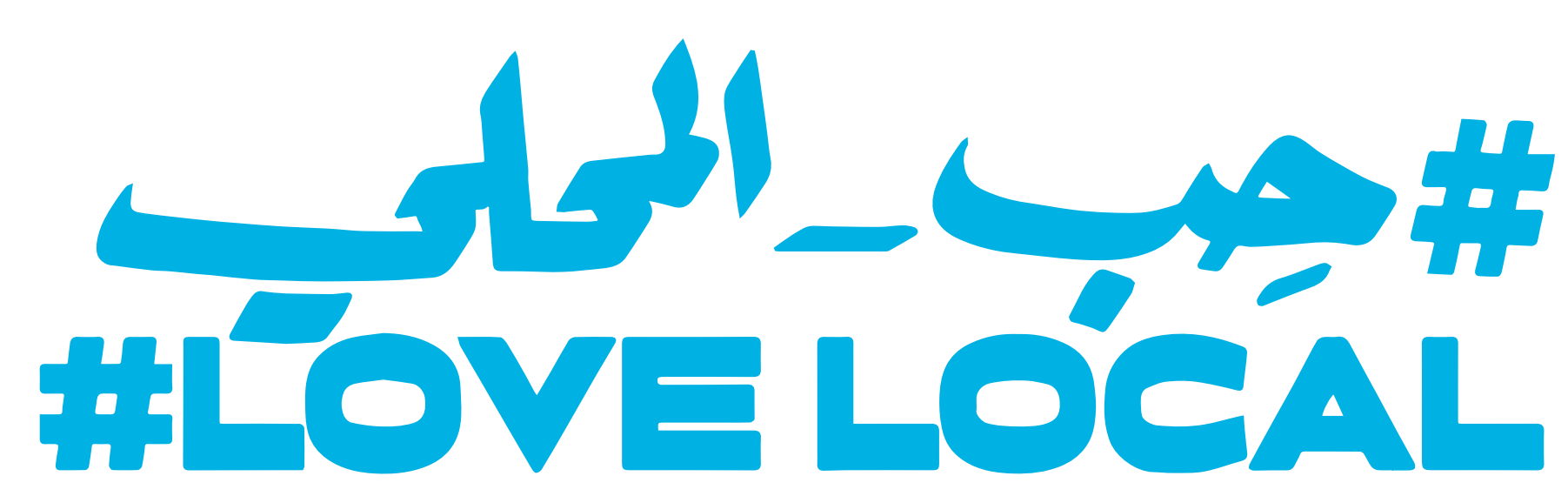


MBC, the Middle East Broadcasting Group, announced an exclusive one-year content partnership with Facebook across the Middle East and North Africa. ${ }^{50}$ With this partnership, the digital department at MBC will share content in the MENA region across various Facebook pages and will include MBC's Ramadan line-up for 2021

Nestlé Middle East previously created a bot for Facebook Messenger during Ramadan back in 2019. Available across the GCC, Nestlé partnered with Zenith MENA and the bot development agency Chatlab to create a bilingual bot communicating in English or Arabic. ${ }^{51}$

Speaking about the impact of the campaign in early 2020, Rainer Mueller, communication director for Nestlé MENA, revealed: "The bot was able to connect with over 7,000 users who opted in and spent over three minutes interacting with the content on the platform, which is almost three times the time spent on our own internet platforms." 52

Users could ask simple questions across five categories: food ideas, general information about Ramadan, health and wellness, entertainment and gifting ideas.

Image: ChatBot via Facebook

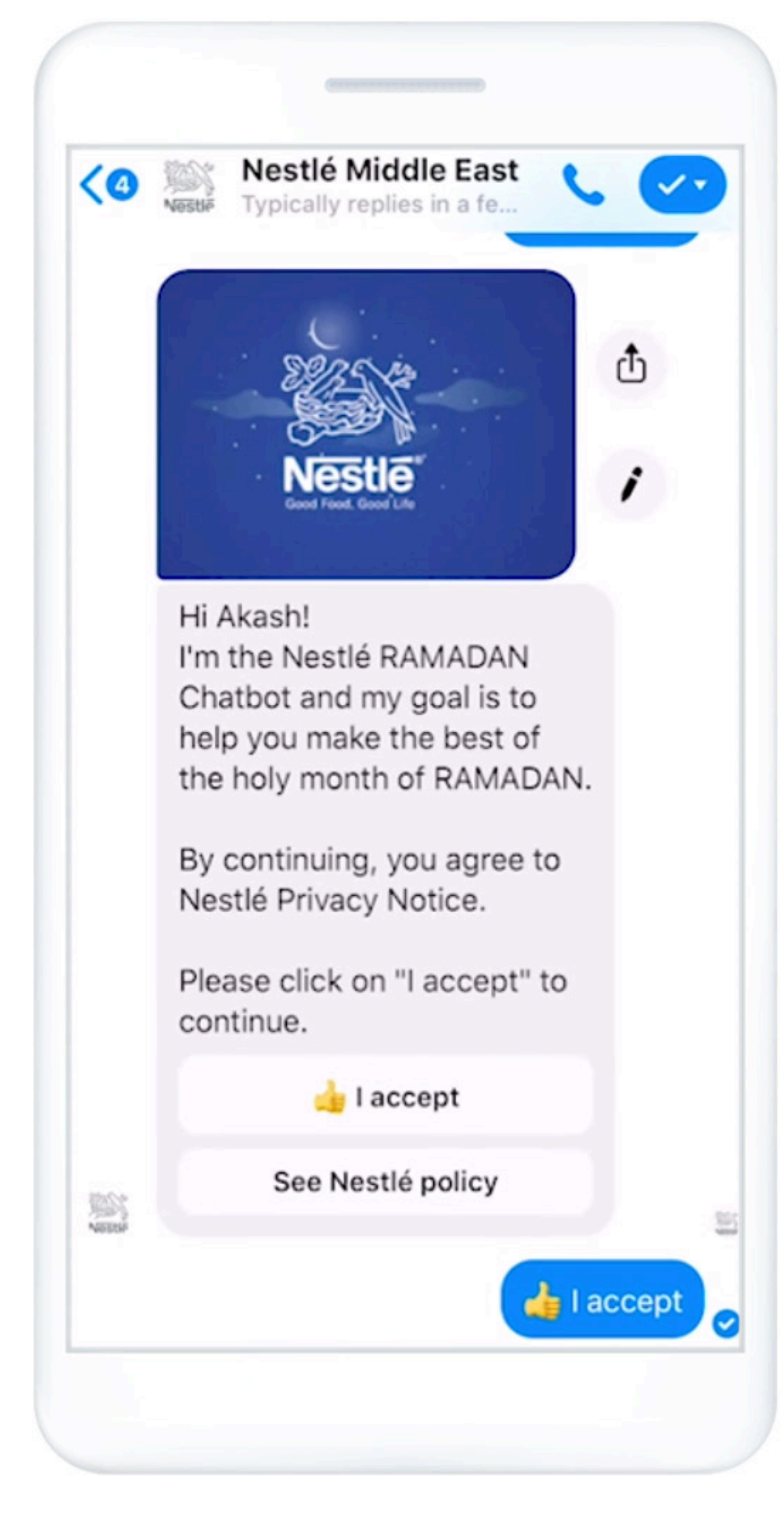

Facebook rolled out a series of content partnerships during Ramadan, including a 10-part series with CNN International. Collaborations included entertainment providers 7AWI, Shoof, Charisma Group and Roya TV, as well as influencers such as Khalid Al Ameri and Ahmad Al Shugairi. ${ }^{53}$

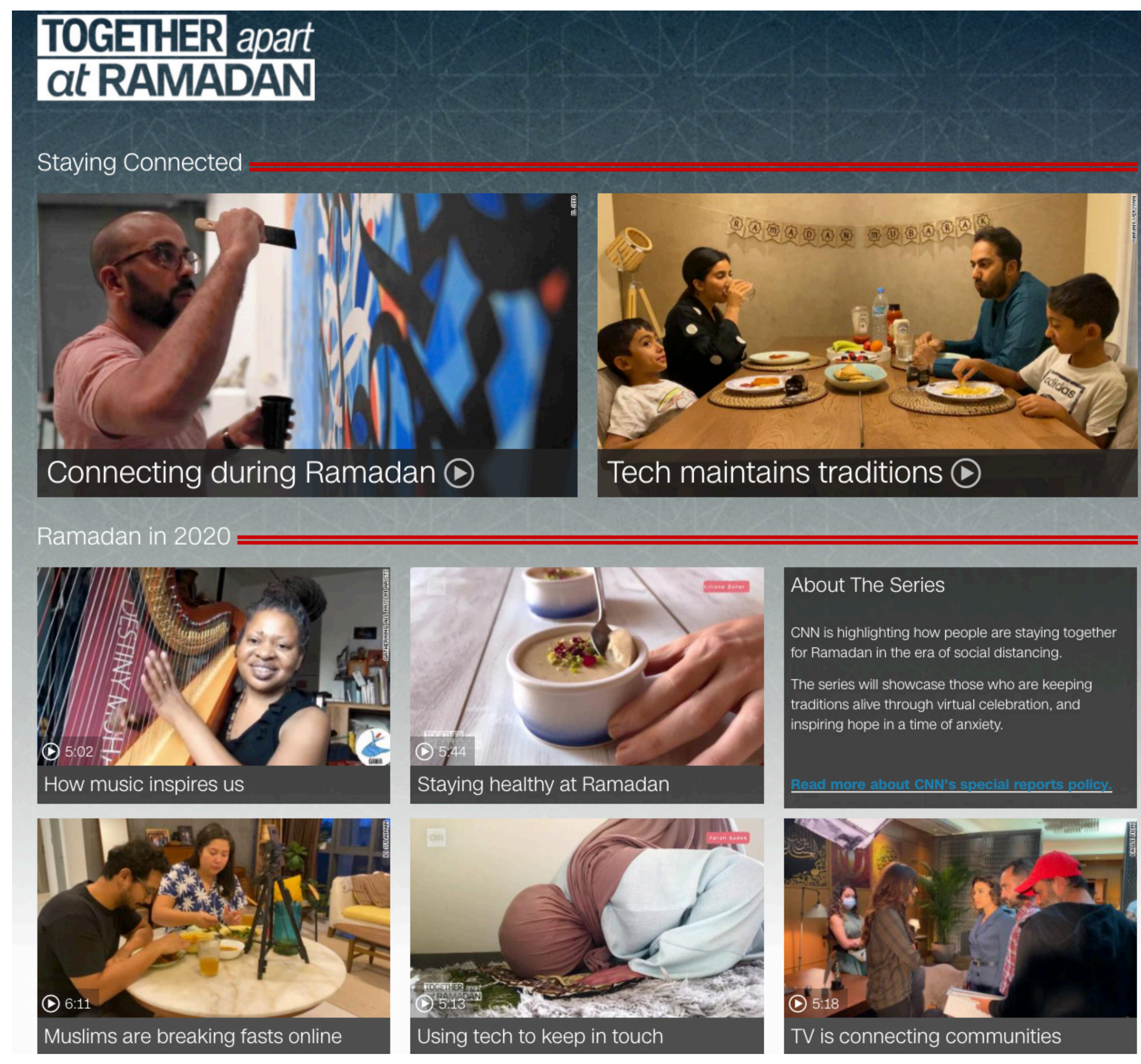

Image: Screenshot of the homepage for CNN and Facebook's Ramadan series "Together Apart" 


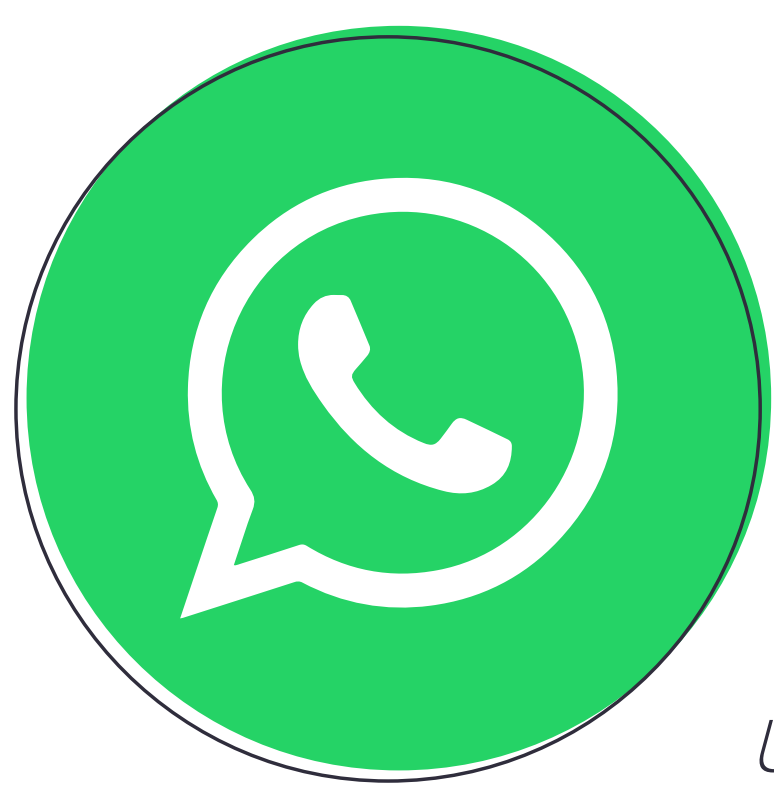

In February 2020, Facebook that the Whatsapp messaging service - which they acquired in 2014 - now had more than 2 billion users worldwide. ${ }^{54}$

Research in late-December 2019 by Northwestern University in Qatar found that three-quarters (75\%) of nationals surveyed in seven nations across the region (Egypt, Jordan, Lebanon, Qatar, Saudi Arabia, Tunisia and UAE) used the service. Since 2017, their data has consistently found WhatsApp to have the highest reach of any social platform in the region. ${ }^{55}$

71\% of Middle East respondents in a 500 person survey run by PwC reported that their usage of WhatsApp and other messaging apps had increased since the outbreak of the pandemic ${ }^{56}$ Similarly, $75 \%$ of the Middle East sample said their consumption of social media such as Facebook, Instagram. Twitter and TikTok had increased as a result of social distancing, "substantially more than the average of $52 \%$ for all (8 other) territories.

Businesses are increasingly using WhatsApp for business communication. ${ }^{5}$ Examples the telecom providers Zain Bahrain ${ }^{58}$ and $\underline{\text { Ooredoo, }},{ }^{59}$ as well as the leisure resort Yas Island in Abu Dhabi,60 all of whom are using the platform for customer relations, and a more conversational experience.
Almosafer, a Saudi based travel company, reported in February 2020 that it was seeing 2,200 WhatsApp conversations a day between customers and their agents Users can harness WhatsApp to make enquiries and get post-booking support. ${ }^{61}$

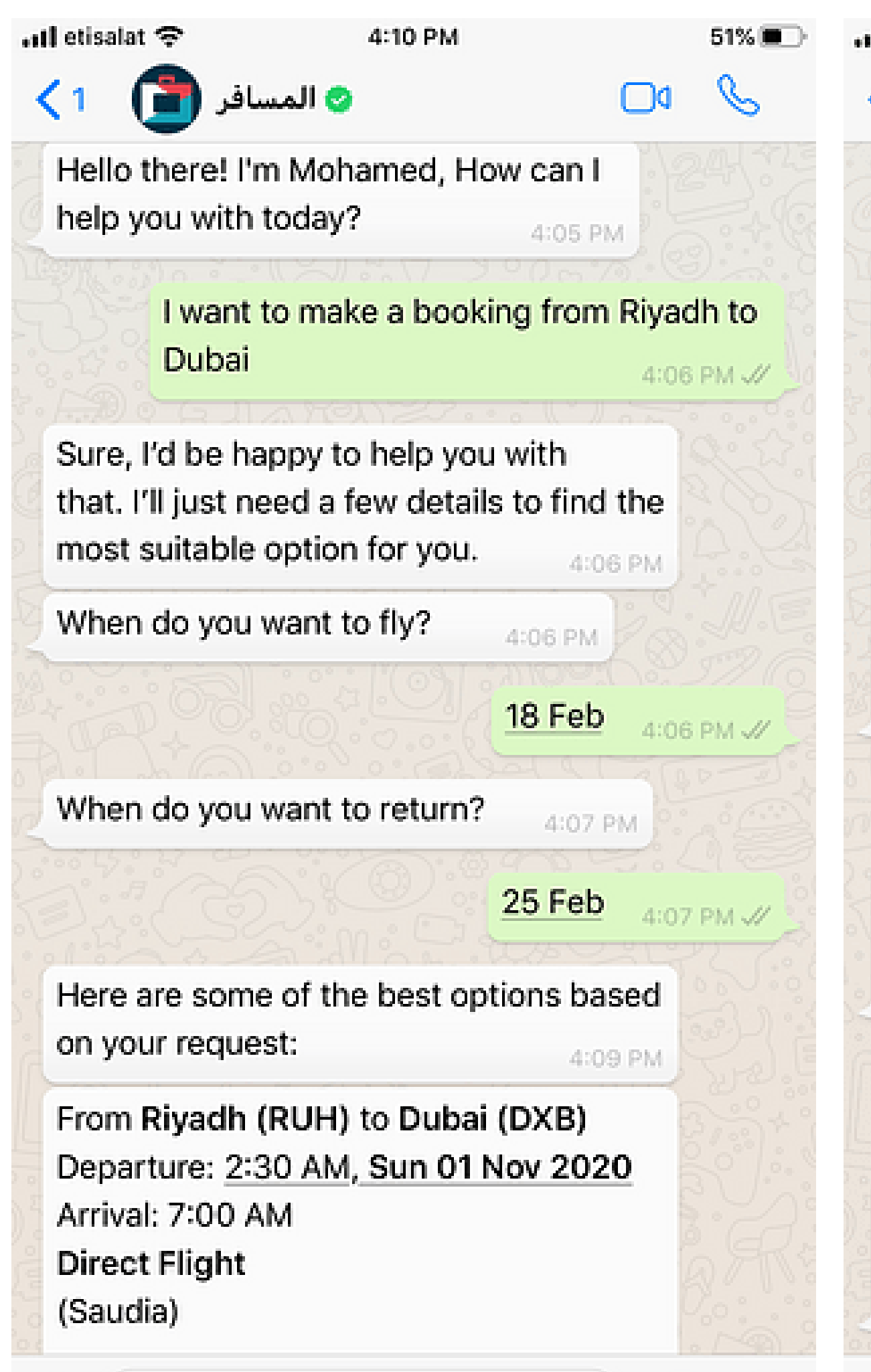

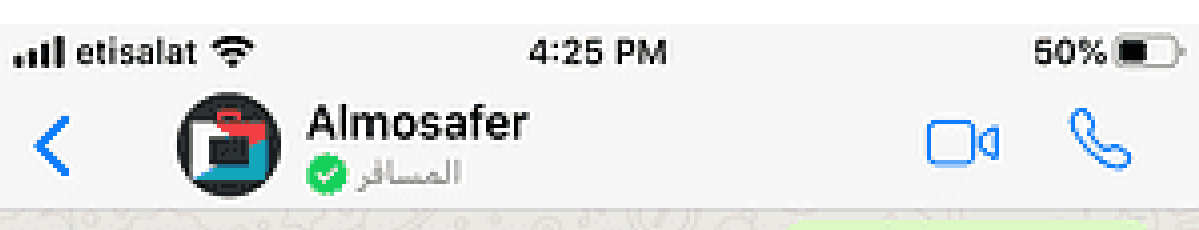

How would you rate your overall satisfaction with the service provided? (Please reply with a rating between 1 and 5)

1) $\pi$

2) 证补

3) 개는

5) vinutiv

What did you like best and how can we further improve your overall experience? $\times$

Your WhatsApp service is awesome

Thank you for your valuable feedback! Looking forward to creating more travel memories in the future! $($ )

$$
+
$$

$+$

Image: Example of a WhatsApp conversation with an Almosafer customer 
The chat app was used by multiple governments to address issues and concerns related to COVID-19. Abu Dhabi's health department launched an automated "Chatbot" allowing citizens to get answers to the most common questions about the virus. ${ }^{62}$

The Ministry of Health in Saudi Arabia also deployed a WhatsApp service, through its contact center 937, enabling users to explore information related to information about the coronavirus, locations of primary health care centers, appointments, blood donation and other services. ${ }^{63}$

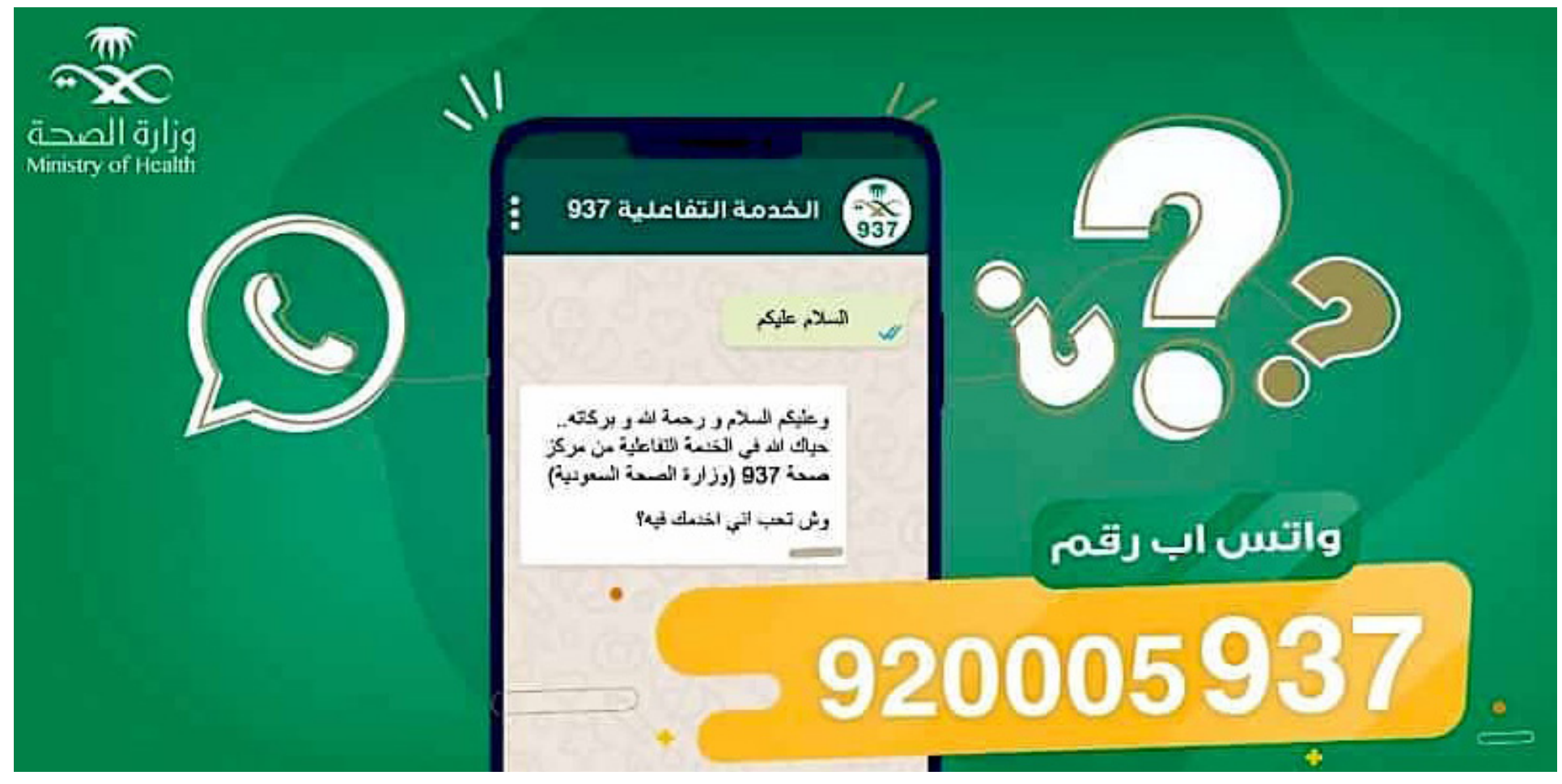

Image: Ad promoting the Saudi Ministry of Health's new WhatsApp Service ${ }^{64}$

UAE Forsan \$ @UAE_Forsan. Jun 14, 2020

The Department of Health Abu Dhabi (DoH) in collaboration with the Abu Dhabi Public Health Center, launches the COVID-19 Home Isolation Programme Smart service on its verified WhatsApp business channel أنت_مسؤول

\#YouAreResponsible

@DoHSocial

Image: Announcement of the Abu Dhabi Department of Health's new Whats App service, via Twitterb5
WhatsApp was the highest ranked brand among a survey of Egyptian women conducted by YouGov. Nearly two-thirds (60.5\%) of respondents had a positive impression of the service. 60 YouTube (4th) and Facebook (5th) were also in the Top 10. It also ranked highly in the other MENA countries covered in their survey.

\section{RANKING OF SOCIAL MEDIA APP BY COUNTRY}

\begin{tabular}{|c|c|c|c|}
\hline & WhatsApp & Facebook & YouTube \\
\hline Egypt 67 & No 1 (60.5\%) & No 5 (47.6\%) & No 4 (54.3\%) \\
\hline KSA68 & No 6 (48\%) & $\begin{array}{c}\text { Instagram No } 10 \\
(44.5 \%)\end{array}$ & No 4 (48.6\%) \\
\hline UAE69 & No 3 (59.8\%) & No 5 (54.2\%) \\
\hline
\end{tabular}

Table: MENA countries featured in YouGov's 2020 Global Women's Impression Rankings ${ }^{70}$

Algeria once again blocked access to a number of social networks - including WhatsApp, Facebook and Twitter - during a period where students were busy sitting exams..$^{71}$ The move, which has happened consistently ${ }^{72}$ since $^{73} 2016$ is designed to stop students from cheating, by discussing answers and sharing papers. 
"Saudi Arabia is developing a secure alternative to the short messaging service WhatsApp," Arab News reports, noting that "the local messaging service will limit the Kingdom's reliance on foreign companies and ensure that any confidential or sensitive data is safe on local servers." 74 The initiative is being led by Saudi engineers and researchers at the King Abdul Aziz City for Science and Technology (KACST).

Meanwhile, in response to COVID-19, a judge in Lebanon interrogated a detainee via WhatsApp video call. "The WhatsApp interrogation was done in accordance with the discretion of the Attorney General," the Lebanese digital news site The961, said. ${ }^{75}$ This unusual move was designed to help reduce in-person contact due to the spread of the coronavirus.

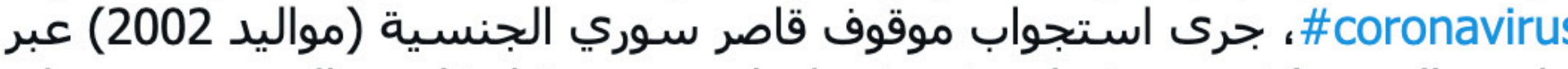

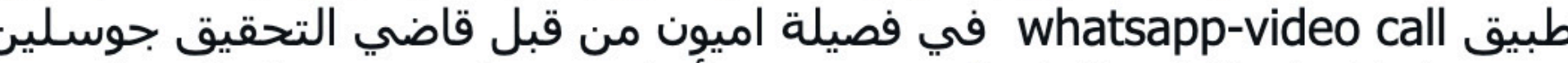

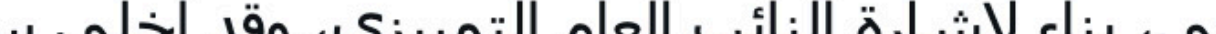

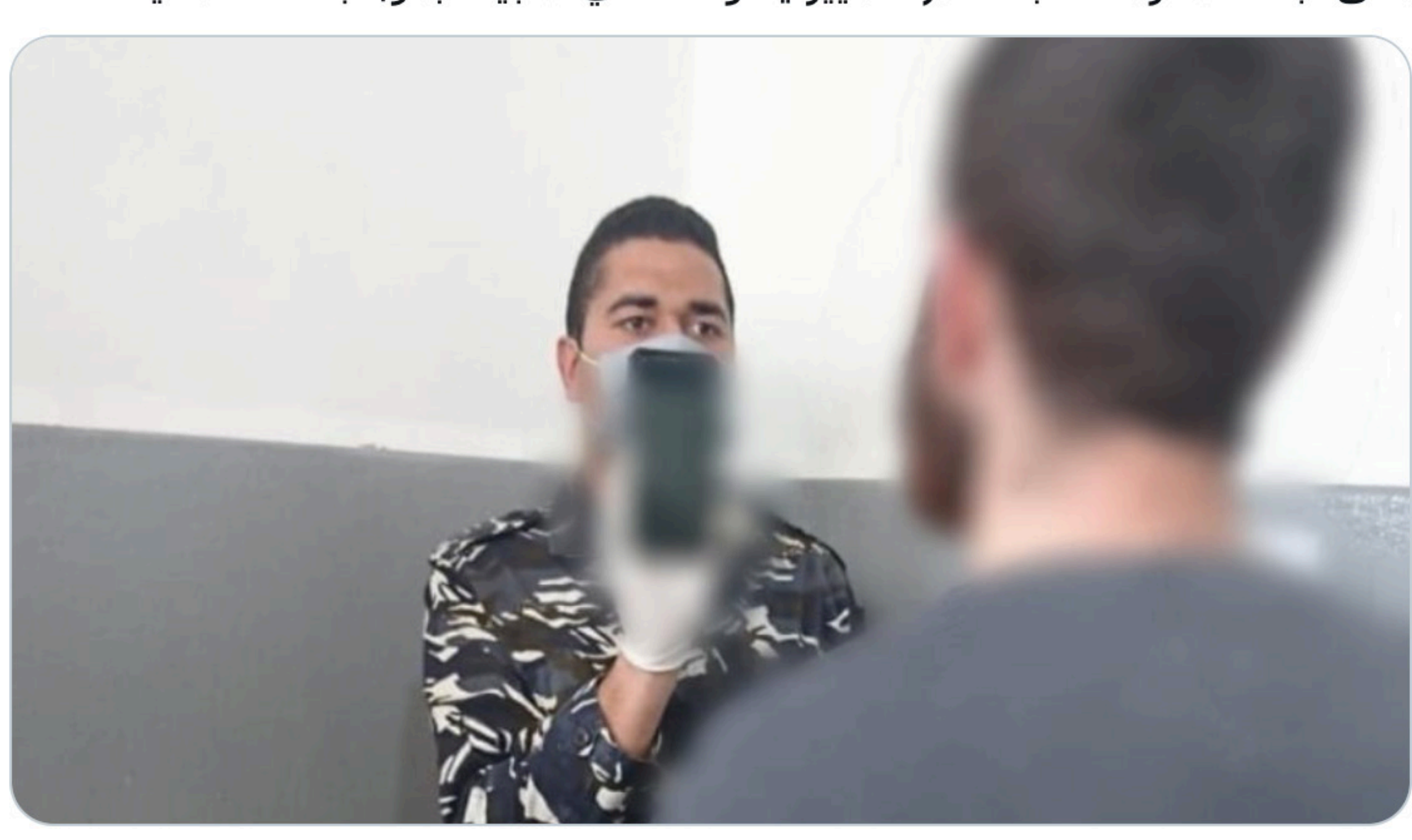

Q 11

$\uparrow\urcorner 40$

O 292

个

Image: Tweet from Lebanon's Internal Security Forces
Louvre Abu Dhabi, working with the agency TBWA, announced the re-opening of the museum in the summer by mimicking a WhatsApp conversation between different works of art. ${ }^{76}$ The 51-second video, which is available with the characters chatting in English, Arabic and French, has been viewed more than 600,000 times on Facebook.

\section{Louvre Abu Dhabio \\ June 23,2020 .}

We're super excited about reopening on the 24 June. In times like this, art helps us focus on positivity and hope. As a mindfu museum, we've been working around the clock so we can offer our communities a safe environment to visit. Good luck to our friends including Musée d'Orsay who opened today and Musée du Louvre opening on 6 July. \#LouvreAbuDhabi \#MindfulMuseum

(1) 20642

42 Comments 102 Shares
$7: 19 \triangleleft$

. II

\section{Louvre Abu Dhabi}

The Bohemian, Young Emir, Bactrian Princess, +2 Today

The Bohemian created this group

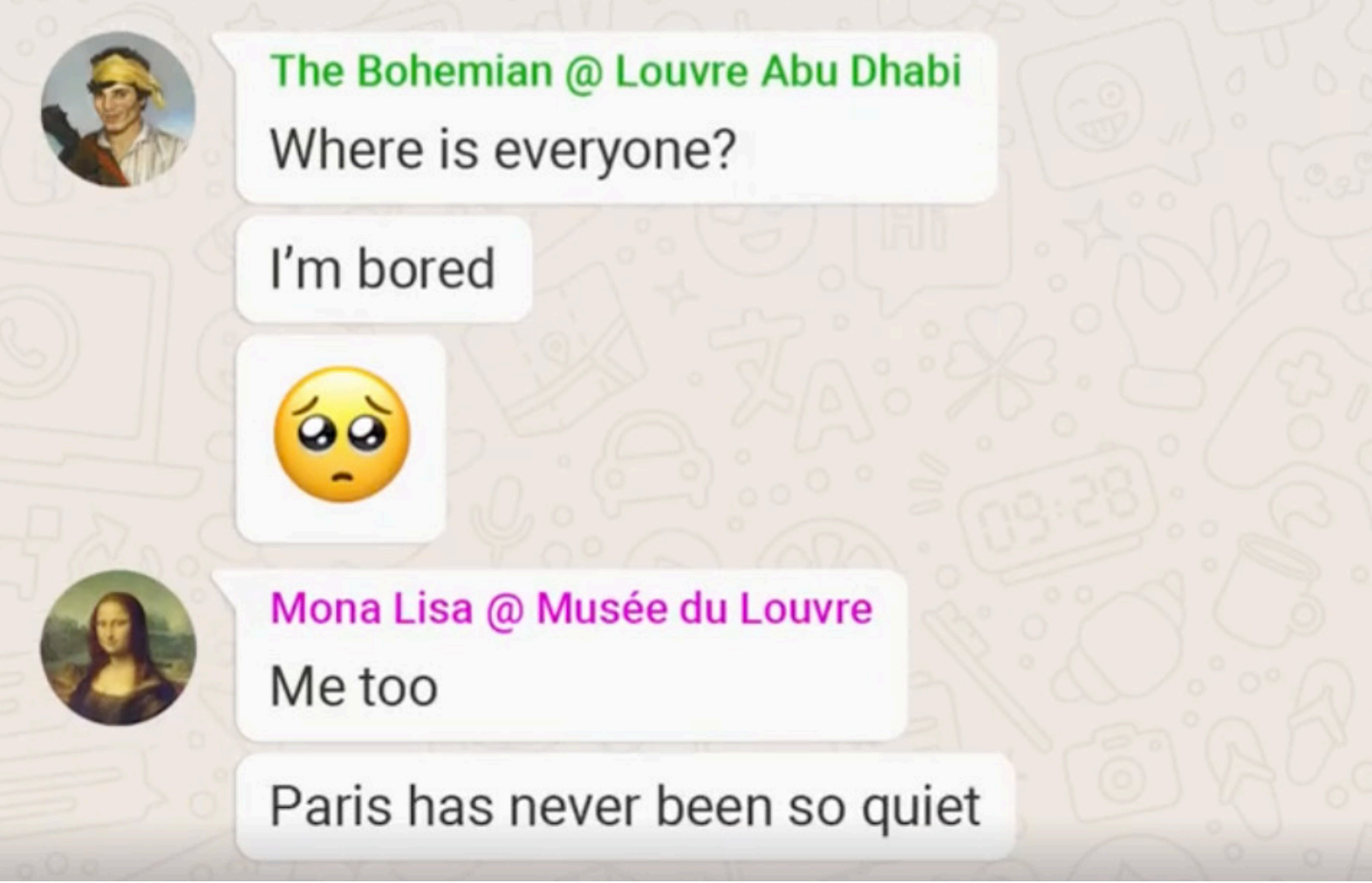

Image: Screenshot via Facebook 


\section{YOUTUBE}

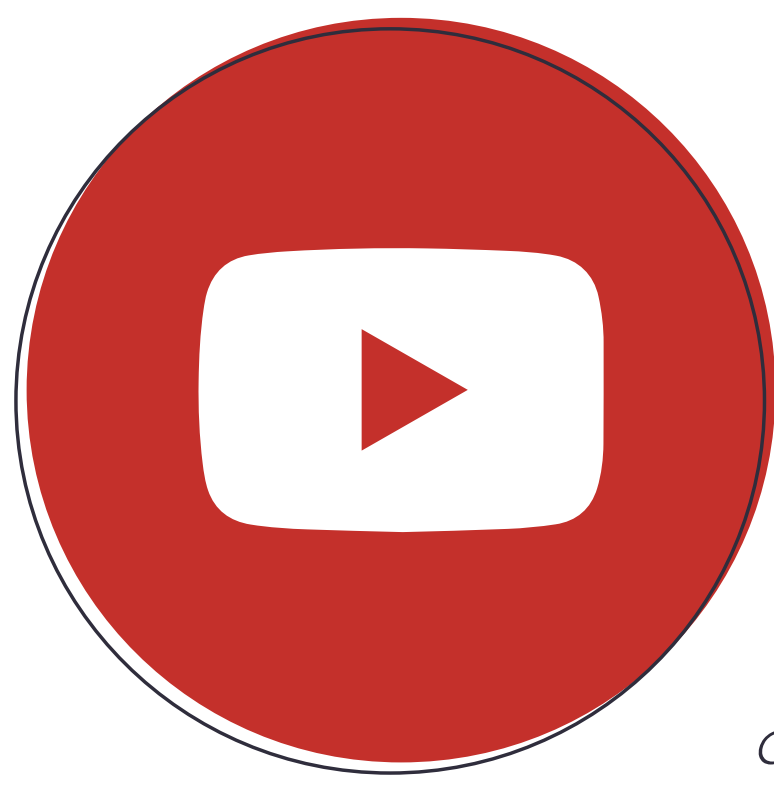

YouTube celebrated its 15th birthday in 2020,"77The first ever YouTube video was uploaded on April 23, 2005. In the past decade and a half, the platform has emerged as a social media behemoth. Over 2 Billion logged-in users now visit YouTube each month

Six YouTube creators grabbed a Guinness World Records title this Ramadan, after 183,544 concurrent viewers joined them for a virtual Iftar, the "most viewers for an Iftar YouTube live stream."79 Participating in the initiative were Mohamed Moshaya, Noor Stars, The Saudi Reporters, Anasala Family, Asrar Aref, and Omar Hussein. ${ }^{80}$
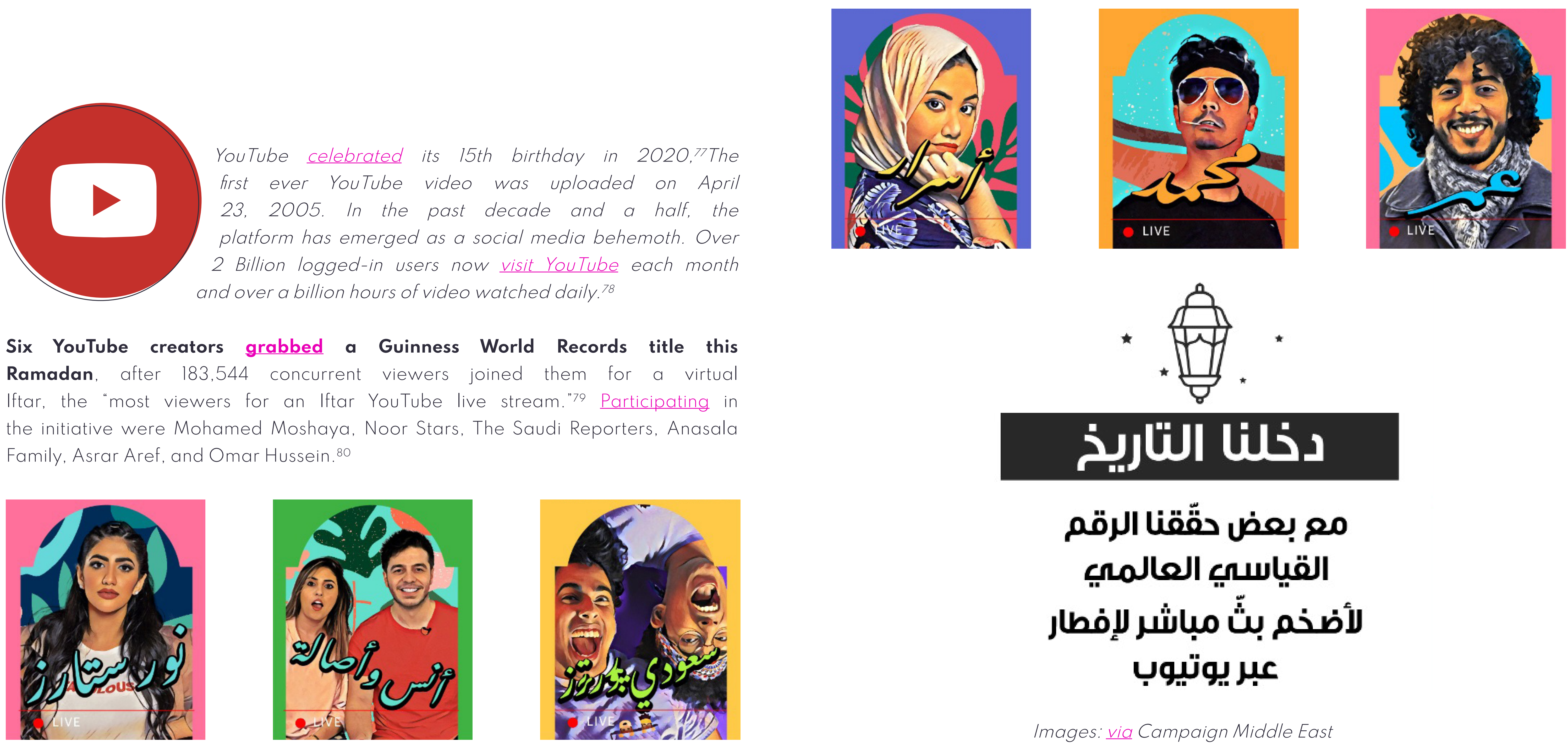

*

\section{دخلة التاريخ}

\section{مع بعض حققّنا الرقم

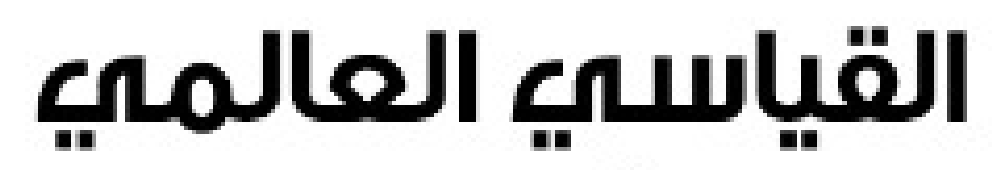 لأضخم بثٌ مباشر لإفطار عبر يوتيوب}


After launching YouTube Premium and YouTube Music across parts of the Middle East in 2019, the service finally launched in Egypt, the region's largest market ${ }^{81}$ All users in Egypt were offered a one free month trial on YouTube Premium, a product with ad-free viewing, offline access and a YouTube Music subscription. Thereafter, YouTube Music subscriptions start at 49.99 EGP (or 74.99 EGP for family plans) and YouTube Premium costing 59.99 EGP (or 89.99 EGP for family plans). ${ }^{82}$

Announcing the service, Liliana Abu Dalu Deira, Director of the Music Partnerships programme forYouTube in the Middle East and North Africa (MENA) region, commented that $\mathbf{7 0 \%}$ of Egypt's Internet users watch YouTube on a daily basis. ${ }^{83}$

\section{YOUTUBE MUSIC MARKETS}

Countries and territories in which YouTube Music is available.

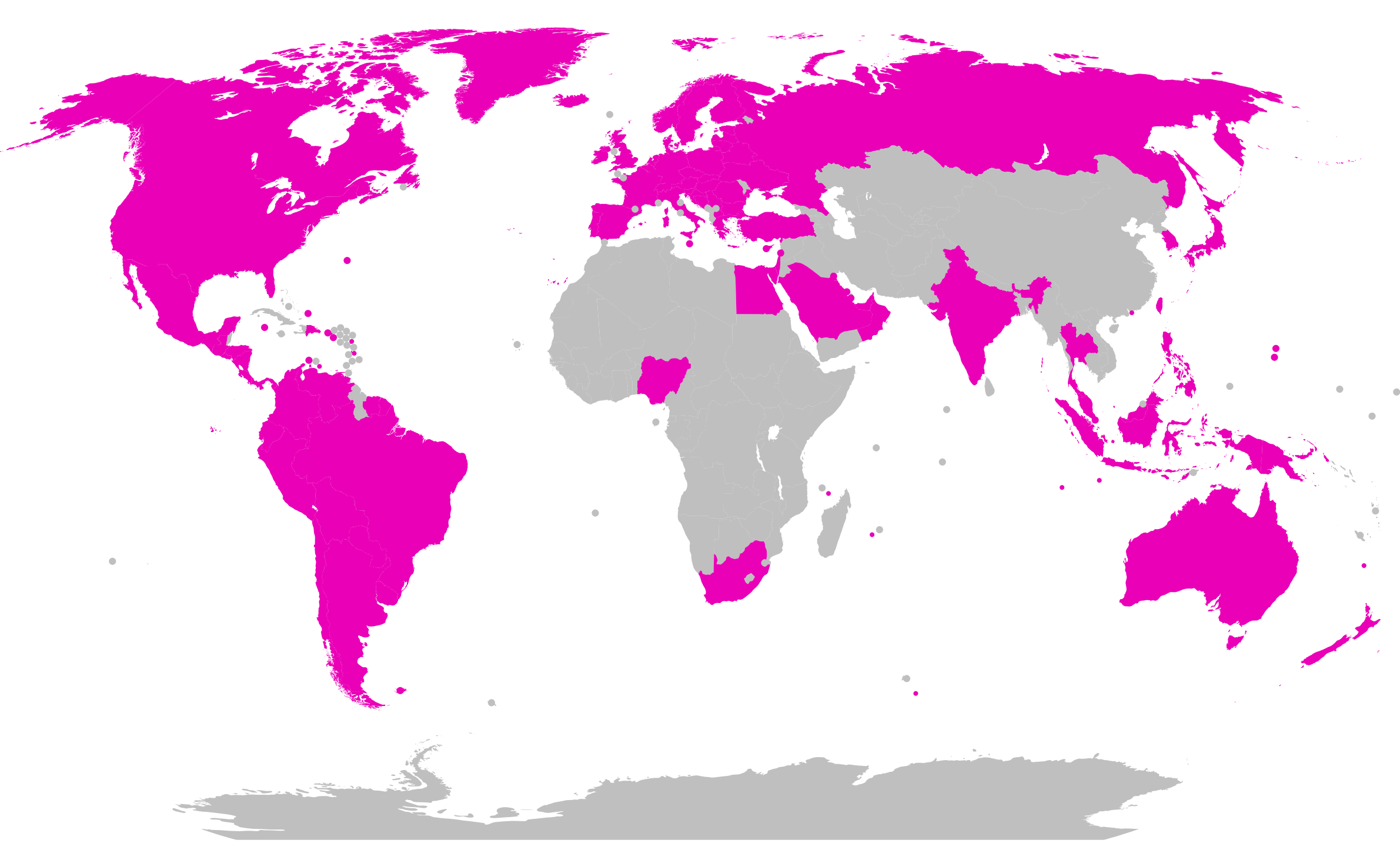

Map: via AndroidCentral
منتجان جديان من YouTube في مصر

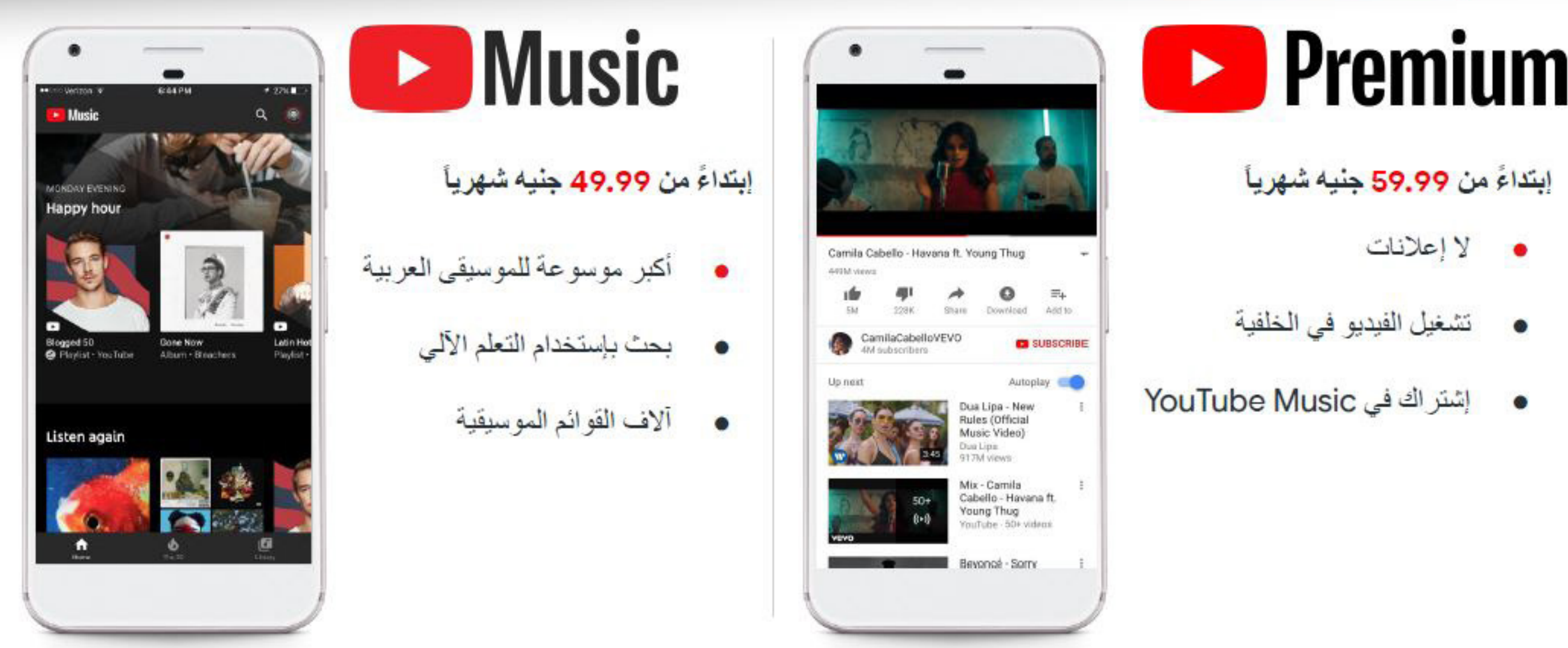

Image: Promotional ad for YouTube Music and YouTube Premium

YouTube terminated 16 channels linked to Iran in April "as part of our ongoing investigation into coordinated influence operations." The platform determined that state-sponsored content was being posted to the network about Saudi-American relations and the U.S. response to COVID-19.84

Earlier in the year, Google deleted the YouTube account for Iran's Press TV UK channel, Middle East Eye reported. ${ }^{85}$ 
"The normalization of ties between Israel and the United Arab Emirates has produced its first musical collaboration: "Ahlan Bik, " or "Helloyou" in Arabic," observed The Times of Israel. 86

Collaborating over Zoom, the song by Israeli singer Elkana Marziano and Emirati artist Walid Aljasim has clocked more than 1.6 million YouTube views since 30th September. The chorus - "I hear you friend far away, far away" - is repeated in Arabic, Hebrew and English, ${ }^{87}$ while the video cuts from Dubai to Tel Aviv.

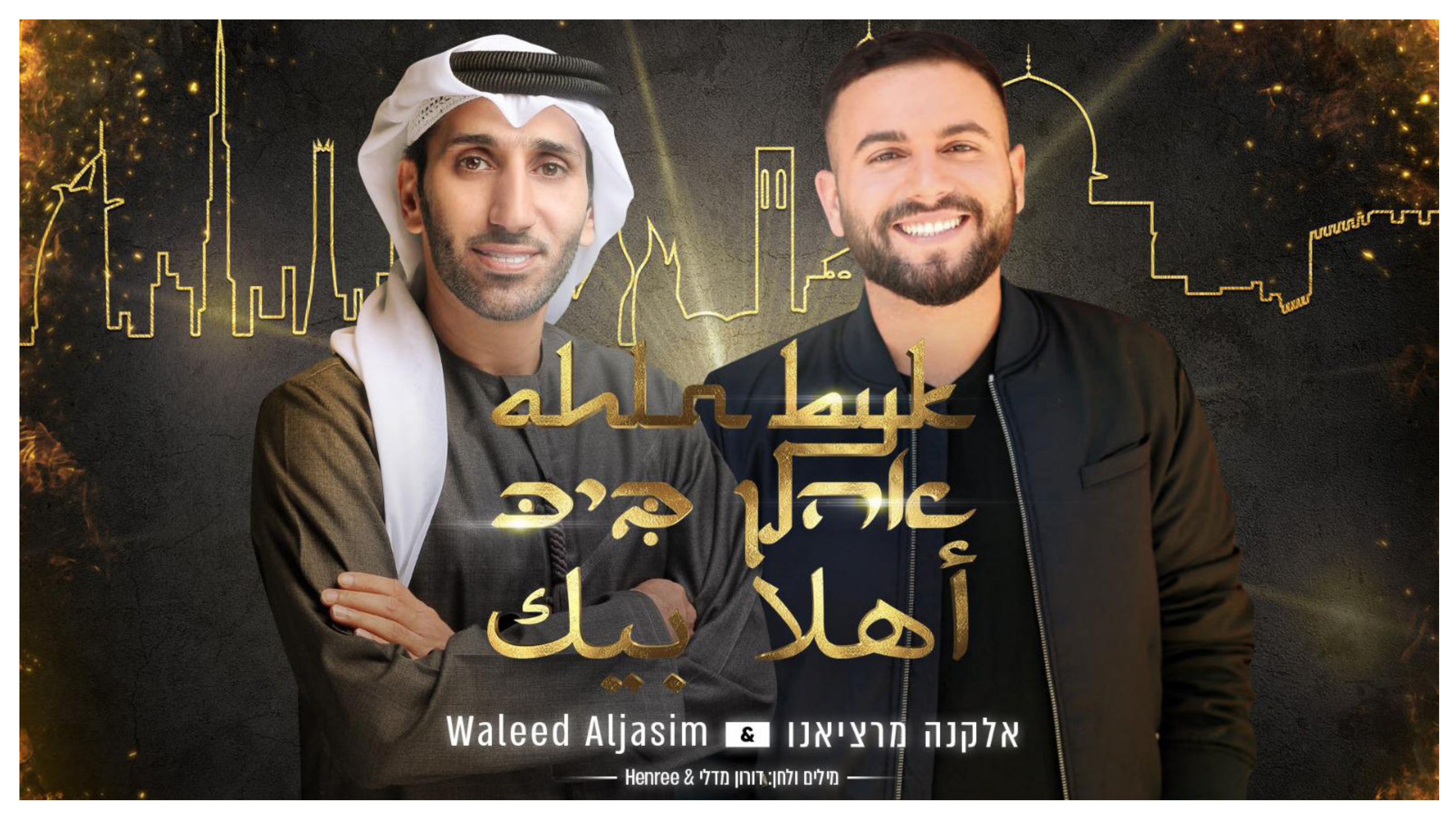

Image: Screenshot via The New Arab
YouTube, like other social media platforms, implemented a range of measures related to COVID-19. In MENA, this included a link to the WHO's website at the top of the page when users searched for COVID-19.88

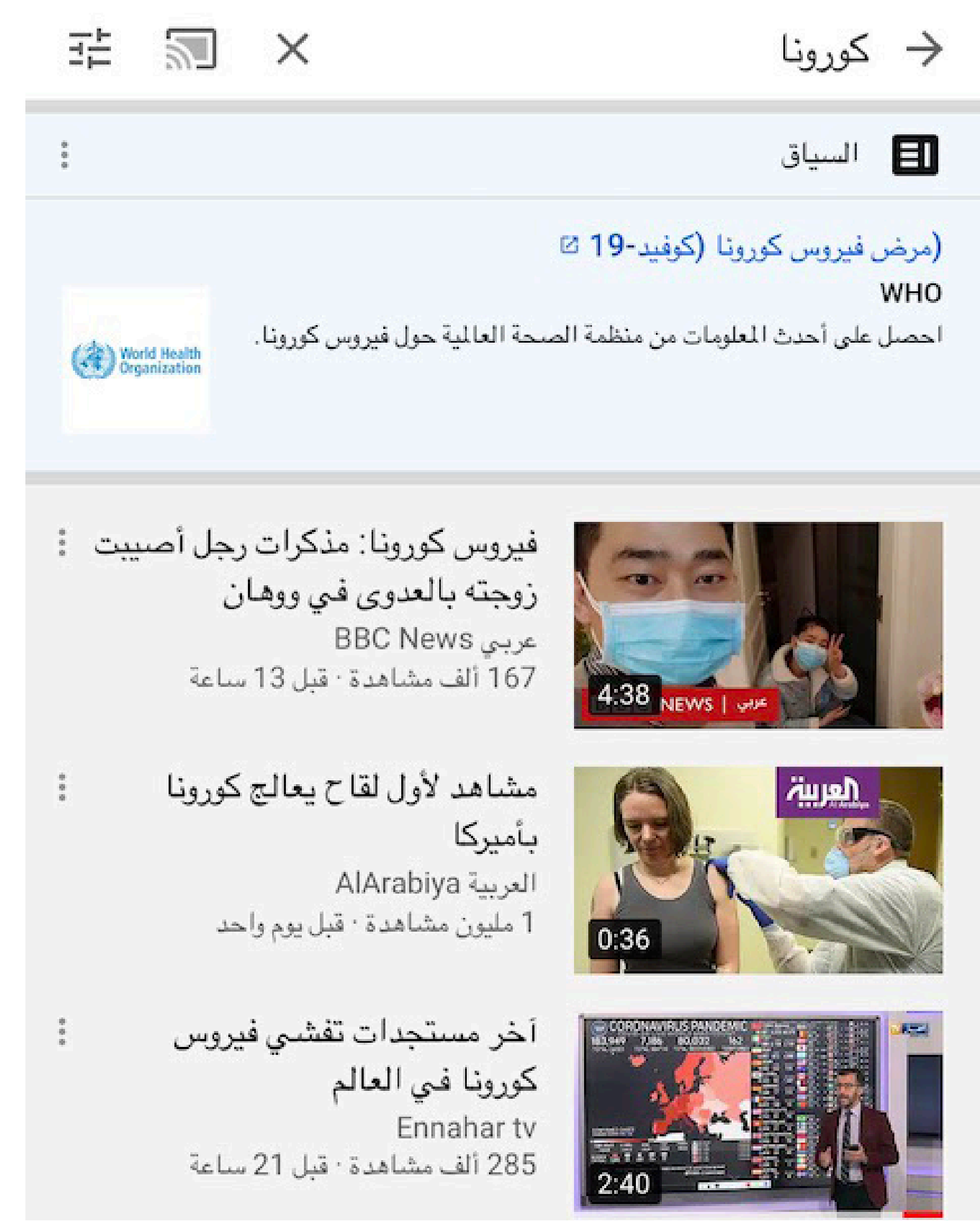

Image: via Google Arabia Blog 


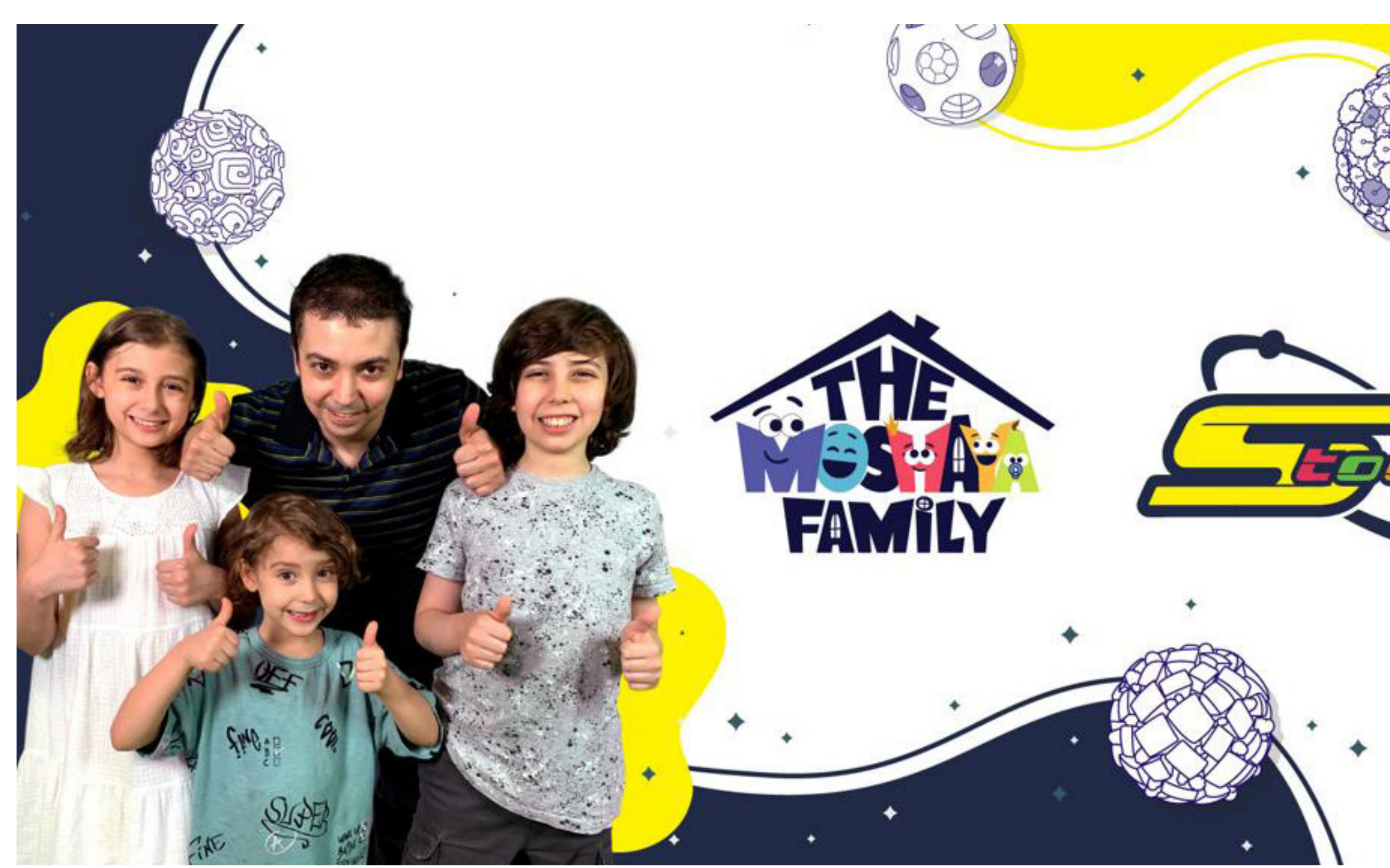

Image: via Animation Magazine.

The Moshaya Family, who run a series of popular YouTube channels, have partnered with Spacetoon, a pan-Arab free-to-air TV channel specialising in animation and children programmes

"Through this agreement, Spacetoon will turn MENA's titan YouTube family channel into a true lifestyle franchise," explains Animation Magazine, "including toys animation series, video games and FMCG (fast moving consumer goods) specially designed to reach and entertain kids and families." 89

The Saudi-based family-friendly content creators, who chart their family trips and adventures on the platform, launched their primary channel a decade ago. By the end of 2020, their main YouTube account has nearly 19 million subscribers and has enjoyed just under 12 billion views.
New Media Academy launched a Youth YouTuber Program in the summer, in partnership with Nas Academy, part of the Nas Daily Group. ${ }^{90}$ The two-week program covered scripting, storytelling, on camera presence and "beating the algorithm." The travel vlogger Nas Daily announced in 2020 that he was opening an office in Dubai (his HQ is in Singapore). ${ }^{91}$ He has more than 18.9 million followers on Facebook, and more than 2 million YouTube subscribers.

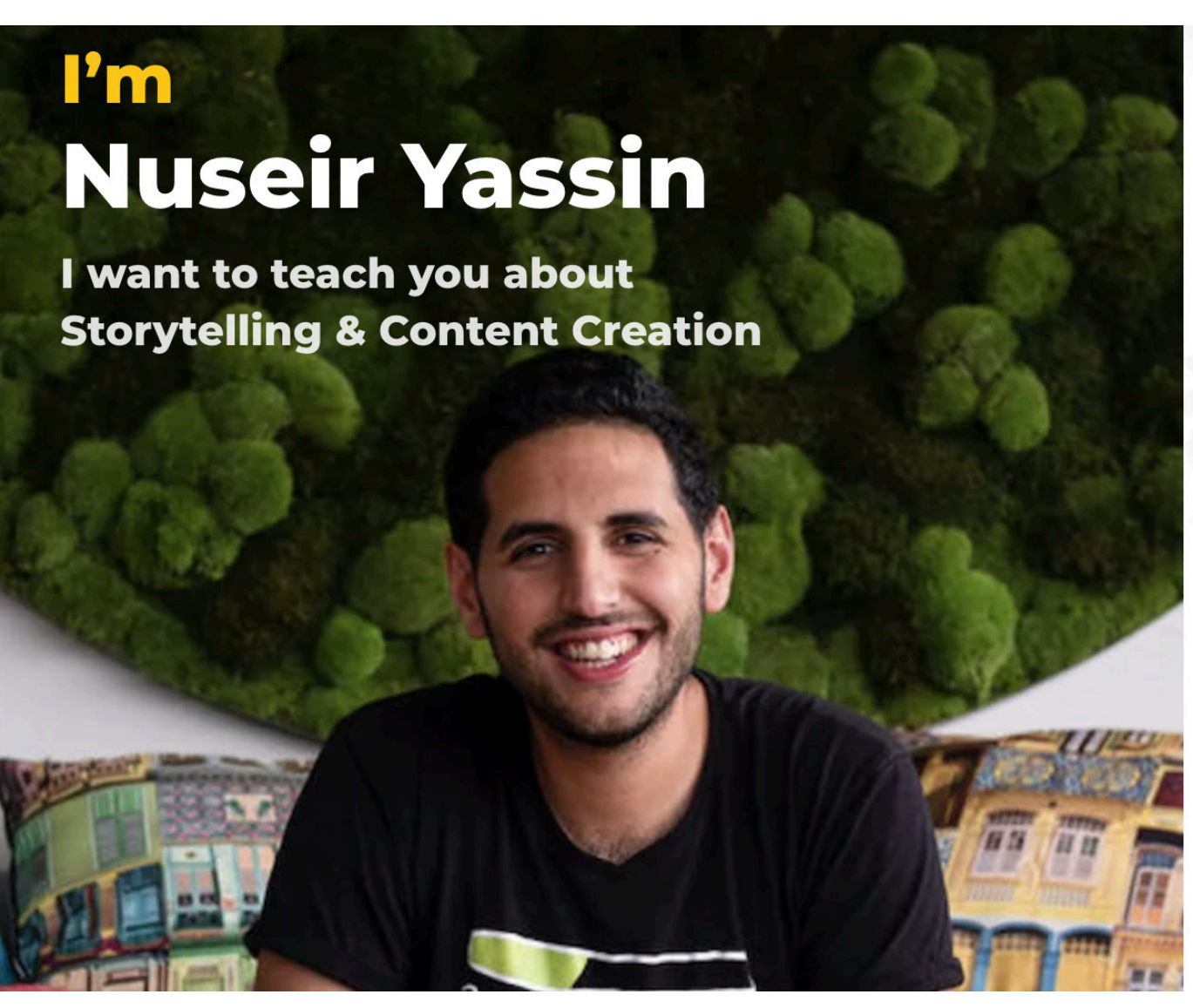

My Videos Have

$9,000,000,000+$

views

Gain

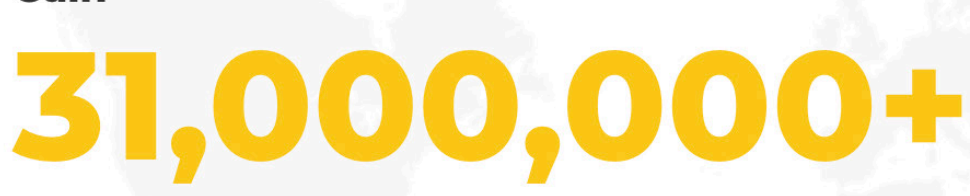

Translated into

10 Languages

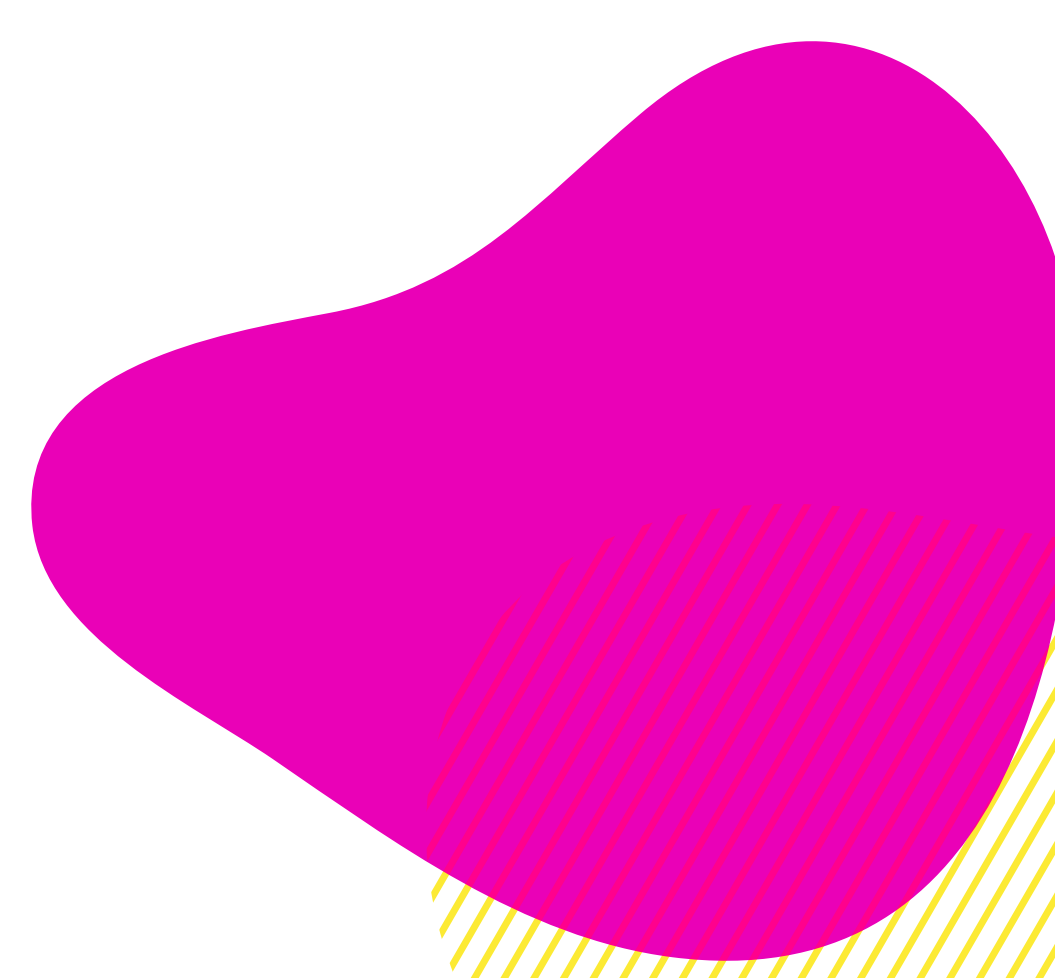


Billed as "the Arab World's first influencer TV show," AYA (As You Are), an Arabic fashion show series, run by an all-female team, premiered on YouTube in January. Recorded on location in 6k, episodes garner around 400,000 views, Digital Studio ME reports. ${ }^{92}$

Each episode features a fashion-related task - such as a professional make-up challenge - judged by a guest influencer. ${ }^{93}$ The \#AYASquad, expanded from four to eight (Haya Al Yassin, Haya Atassi, Noor, Rova, Assia, Marwa, Nadine and Sarah,) comes from across the region. ${ }^{94}$

"It's not hard to see why the AYA Fashion Squad are set to be the stars of the tomorrow," Grazia says. "Each is extremely relatable in their own way - bold, confident and representing the thoughts, beliefs and attitudes of a generation at the beginning of their journeys as role models of the future." 95

\section{THE ARAB WORLD'S FIRS}

\section{INFLUENCERTV SHOW /}

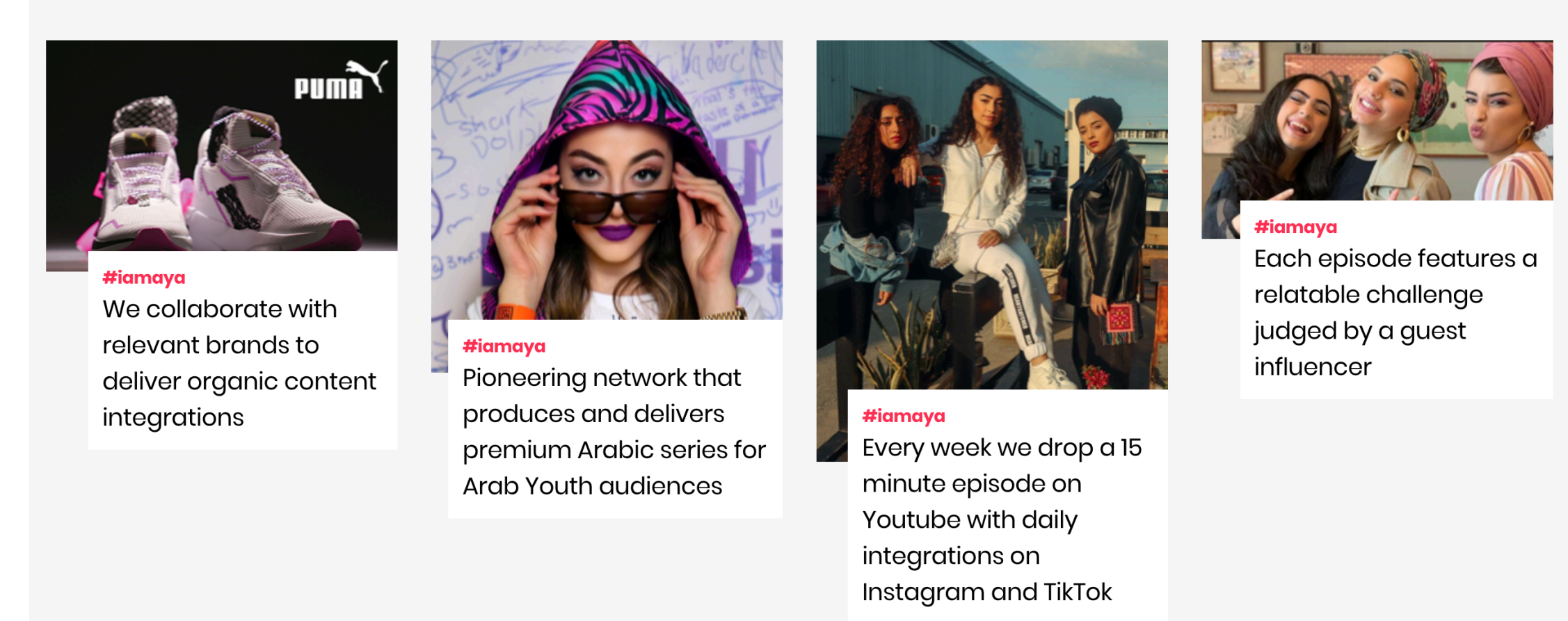

Image: Screenshot via IAmAYA
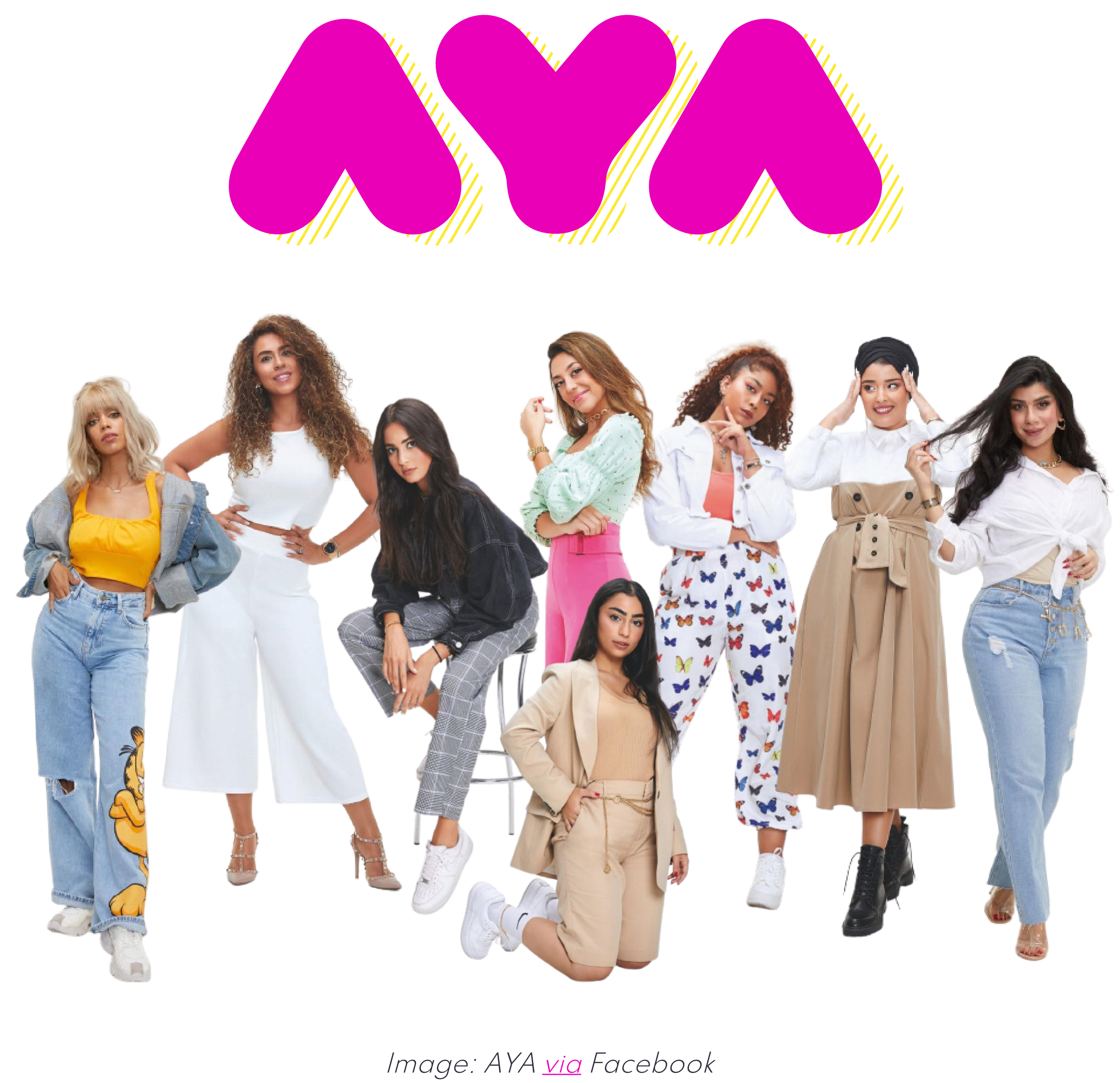

Image: AYA via Facebook 


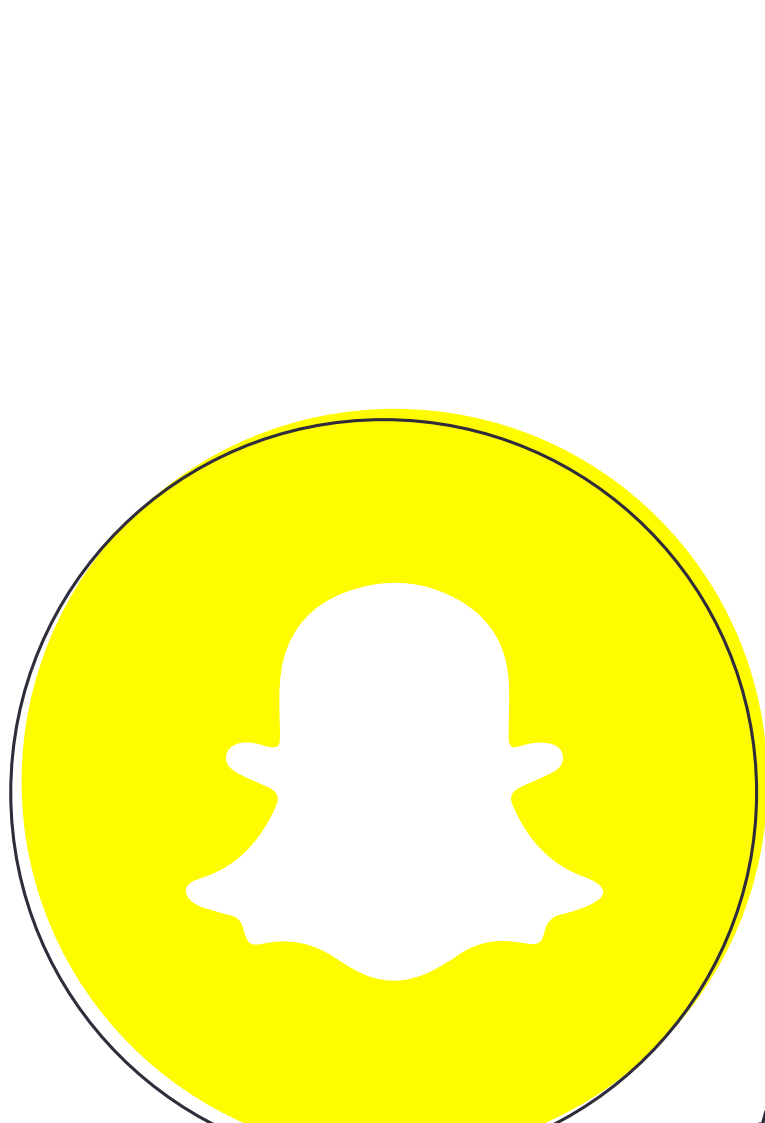

Globally, Snapchat now reaches 249 million users a day (up $18 \%$ on this time last year) ${ }^{96}$ with the MENA region - and in particular Saudi Arabia - a key market for the company.

"It goes without saying that Saudi Arabia is one of the most interesting markets that all eyes are on for the past five years; it's one of our biggest economies, Abdullah Alhammadi. Snapchat's regional business lead for the Middle East and North Africa market, told Arab News in December 2020.97

Snapchat now reaches $\mathbf{6 7}$ million unique users in the region each month, up $\mathbf{3 8 \%}$ year-on-year (as of October 2020). The app reaches $60 \%$ of $13-24$-year-olds in UAE and 90\% of 13-34-year-olds in Saudi Arabia. Arabian Business observed that over $85 \%$ of MENA daily users interact with Lenses every day. ${ }^{98}$

Four MENA countries - Saudi Arabia (17.9 million users), Turkey (9.7m), Iraq (9.6m) and Egypt $(8.9 \mathrm{~m})$ are in the 13 largest national markets for the app worldwide Each of these countries continues to see considerable growth in terms of Snapchat users.

Countries and territories with the greatest potential Snapchat advertising reach.

\begin{tabular}{|c|c|c|c|c|}
\hline$\#$ & COUNTRY & REACH & QOQ & QOQ \\
\hline 01 & U.S.A. & $101,900,000$ & $+0.5 \%$ & $+500,000$ \\
\hline 02 & India & $49,800,000$ & $+047 \%$ & $+16,000,000$ \\
\hline 03 & France & $22,150,000$ & $+7 \%$ & $+1,500,000$ \\
\hline 04 & U.K. & $19,150,000$ & $+8 \%$ & $+1,500,000$ \\
\hline 05 & Saudi Arabia & $17,900,000$ & $+3 \%$ & $+550,000$ \\
\hline 06 & Mexico & $15,700,000$ & $+3 \%$ & $+500,000$ \\
\hline 07 & Germany & $13,600,000$ & $+8 \%$ & $+1,050,000$ \\
\hline 08 & Brazil & $11,200,000$ & $-9 \%$ & $-1,150,000$ \\
\hline 09 & Philippines & $10,750,000$ & $+19 \%$ & $+1,750,000$ \\
\hline 10 & Turkey & $9,700,000$ & $+8 \%$ & $+750,000$ \\
\hline 11 & Iraq & $9,600,000$ & $+10 \%$ & $+900,000$ \\
\hline 12 & Canada & $9,400,000$ & $0 \%$ & {$[U N C H A N G E D]$} \\
\hline 13 & Egypt & $8,900,000$ & $+15 \%$ & $+1,150,000$ \\
\hline 14 & Indonesia & $8,650,000$ & $+35 \%$ & $+2,250,000$ \\
\hline 15 & Pakistan & $8,200,000$ & $+30 \%$ & $+1,900,000$ \\
\hline
\end{tabular}

Table: Largest markets for Snapchat globally via We Are Social and Hootsuite 
Snapchat launched 9940 new shows specifically for the month of Ramadan Snapchatters in the UAE, Saudi Arabia, and Kuwait, spent 77 minutes a day on the app during Ramadan 2020. In Q3 2020, Snap revealed that the total daily time spent watching shows on Snapchat Discover increased by more than $\mathbf{5 0} \%$ year-over-year. ${ }^{100}$

\section{"In Saudi Arabia, more people} watch Snapchat Discover content every day than any of the top ten TV channels, both before and during Covid-19" 10

- Hussein Freijeh Regional Director of Snap Inc. MENA
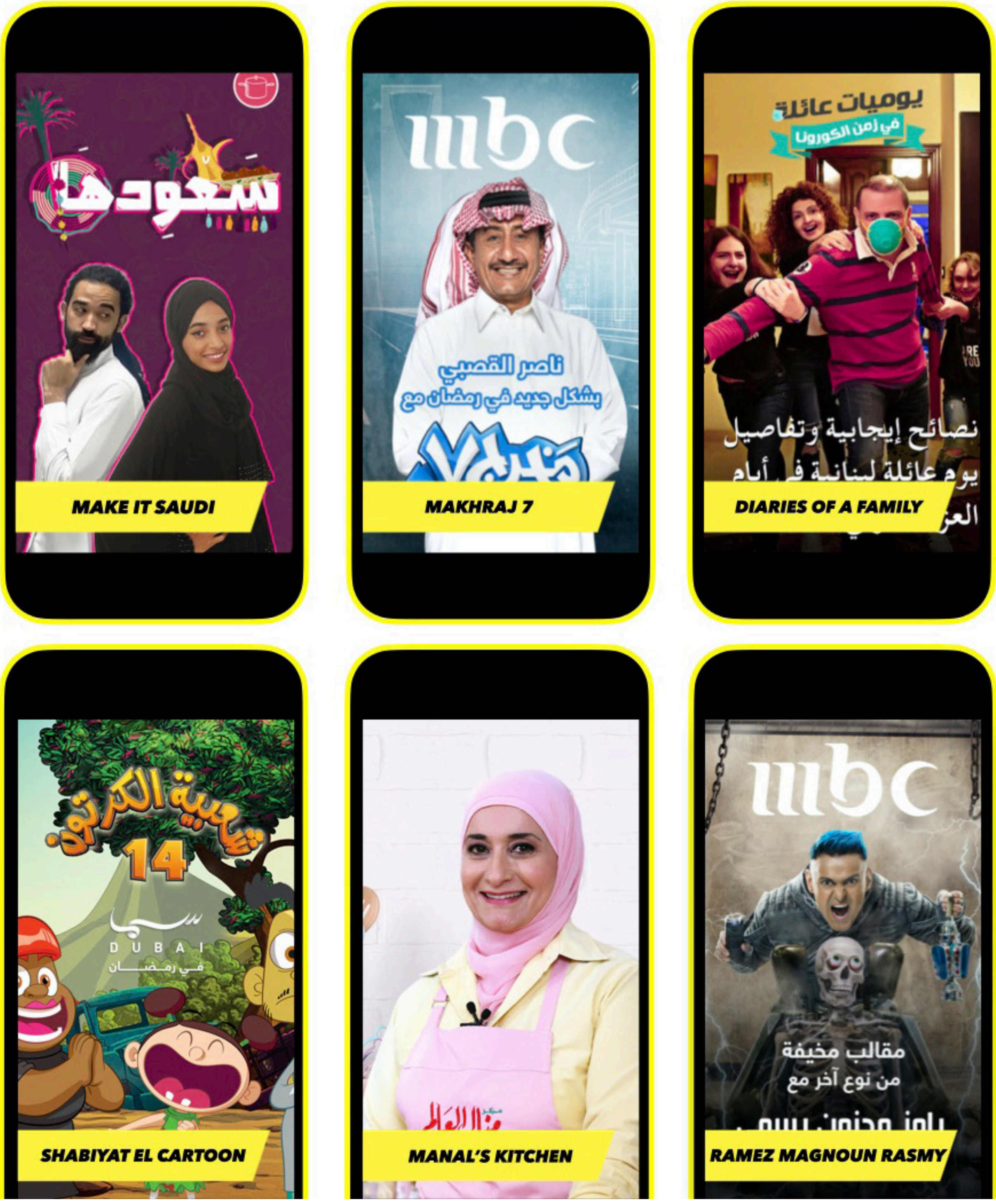

Image: Examples of Snapchat's exclusive Ramadan shows 
Rotana, one of the apps Discover partners, reaches an average of nearly 10 million Snapchatters in the Middle East each month. ${ }^{102}$

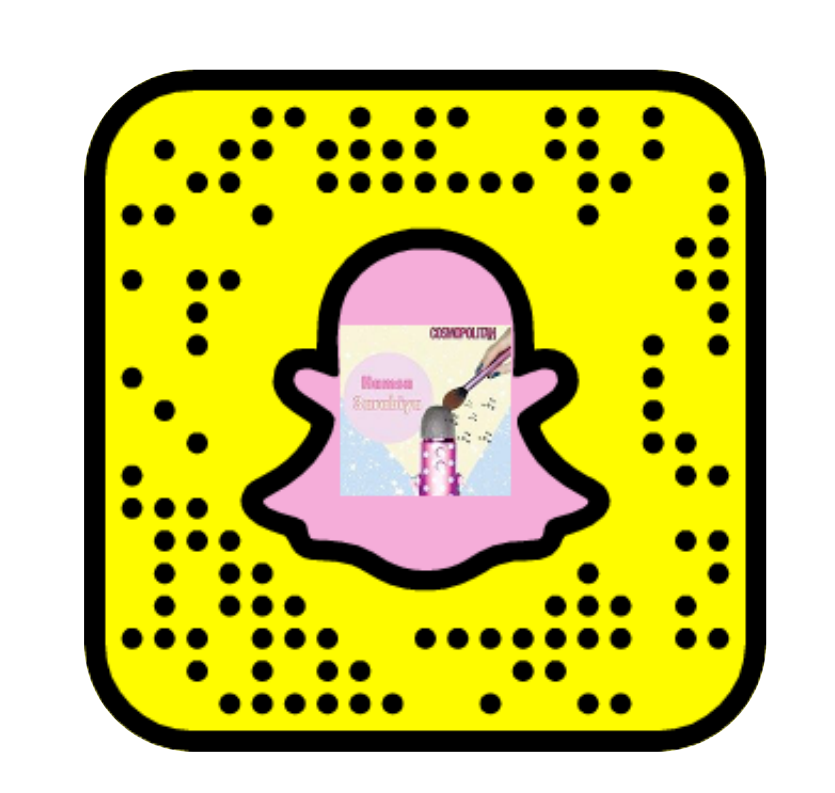

One of the new propositions to emerge on Snapchat during the year was an ASMR Arabic Snapchat series, Hamsa 3arabiya (aka "Whispers of Arabia") launched by Cosmopolitan. The series offers beauty tips using "auditory whispering, tapping, scratching and squelching to provide an overall sense of calm." 103

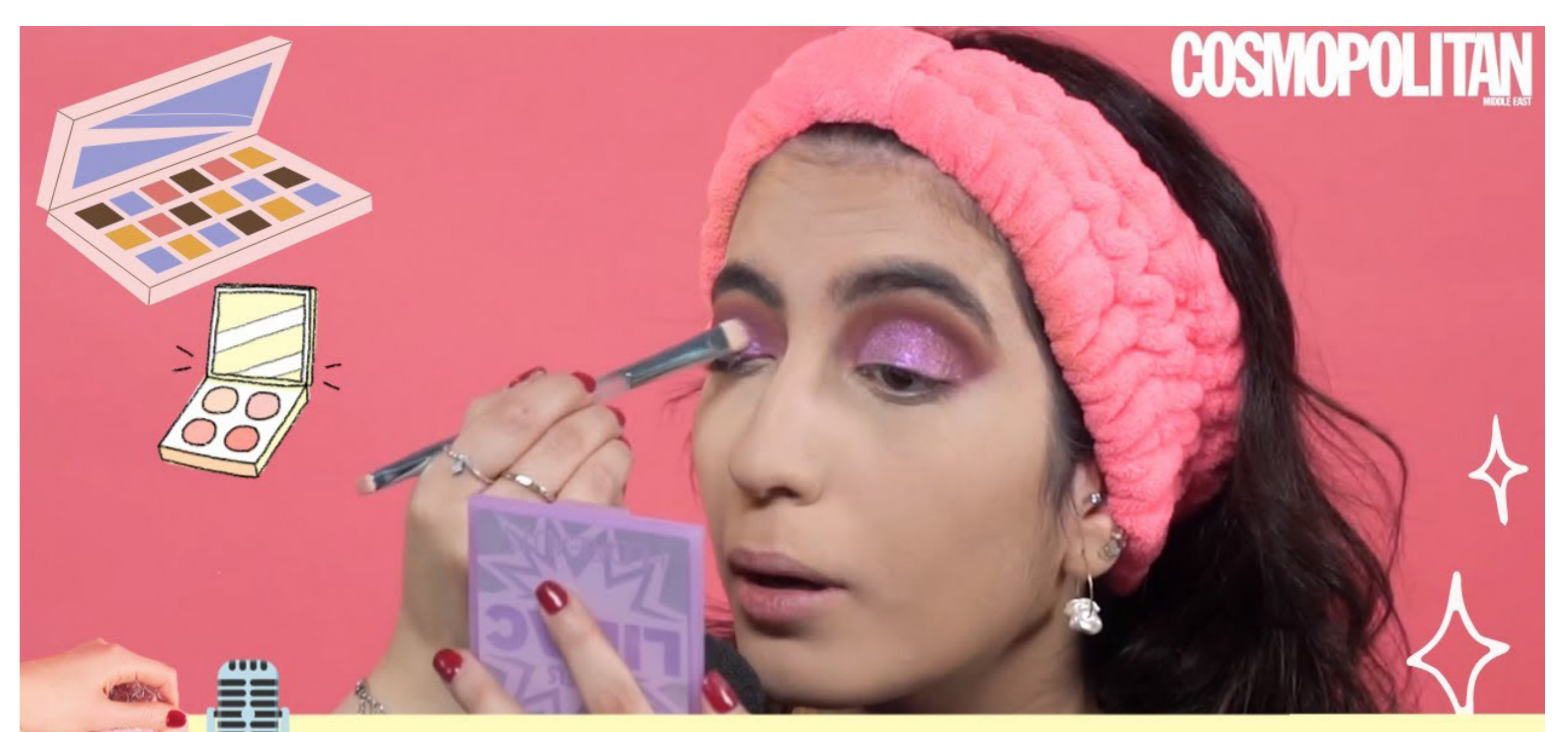

\section{HAMSA 3 ARABIYA ASMR}

Images: Snapcode \& screenshot of Cosmpolitan's Snapchat show, Hamsa 3arabiya
In time for Ramadan, 104 Snapchat revealed 105 a new AR experience designed to encourage donations to the United Nations Foundation's COVID-19 Solidarity Response Fund

Available in select markets, such as UAE and Saudi Arabia, the lenses allowed Snapchatters to scan real-life objects like an AEDIO/SARIO note to show how a potential donation could support the WHO's immediate response efforts

Discussing the launch, Snap's Hussein Freijeh, said: "This campaign also comes as we are getting ready to welcome the holy month of Ramadan and celebrate the spirit of giving. We believe that everyone can play a meaningful role in stopping the spread of COVID-19, and that it is our responsibility to support initiatives that can make that happen.

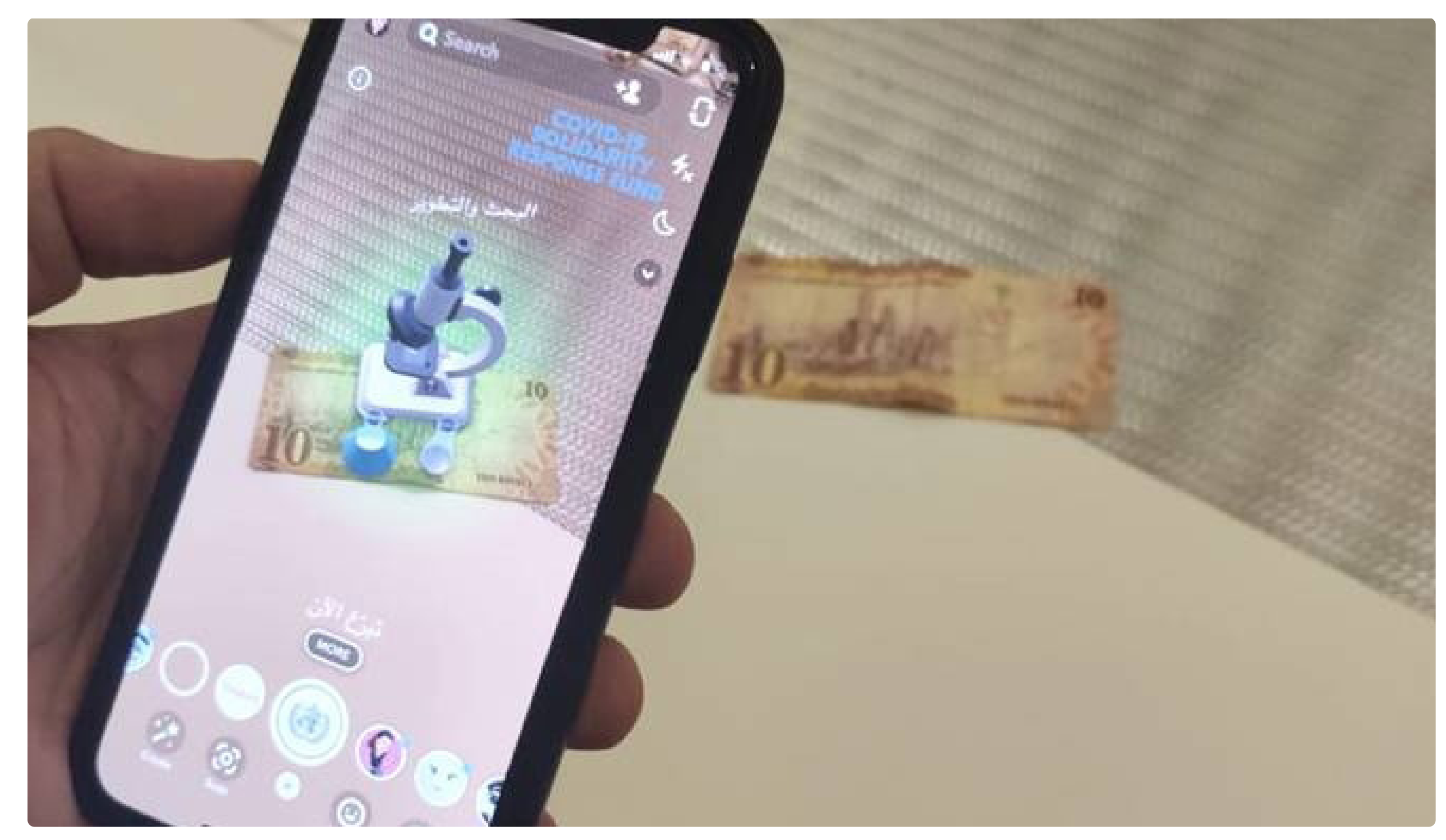

Image: via Saudi Gazette 


\section{3}

Dubai Tourism partnered with Snapchat in the first wave of the COVID-19 pandemic, to allow Snapchatters to virtually visit some of the emirate's best known landmarks

More than 9.2 million people in the UK and France used the lenses, as part of Dubai Tourism's "Till We Meet Again" campaign, ${ }^{106}$ designed to remind people of Dubai's potential as a holiday destination once COVID restrictions were lifted. ${ }^{107}$
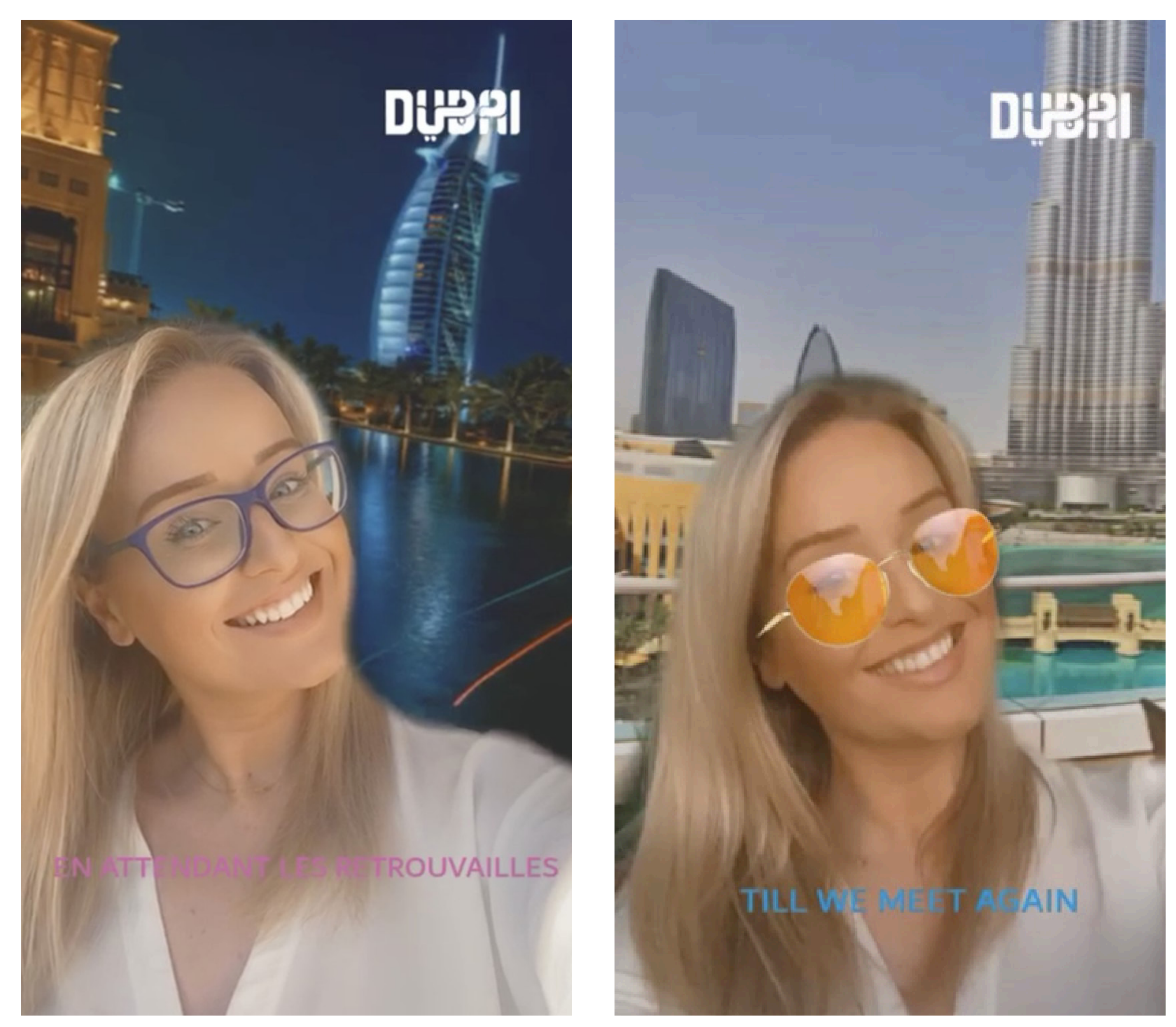

Images: Examples of Snapchat lenses used for the "Till We Meet Again" campaign, via Twitter

\section{Dotof}

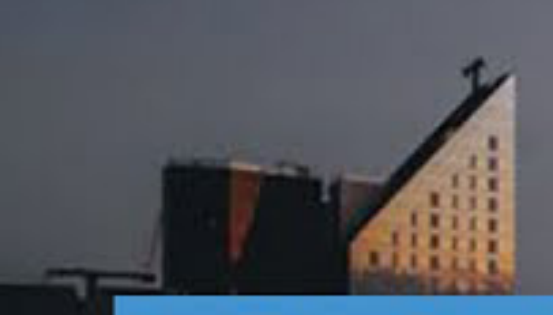

TILL WE

MEET AGAIN

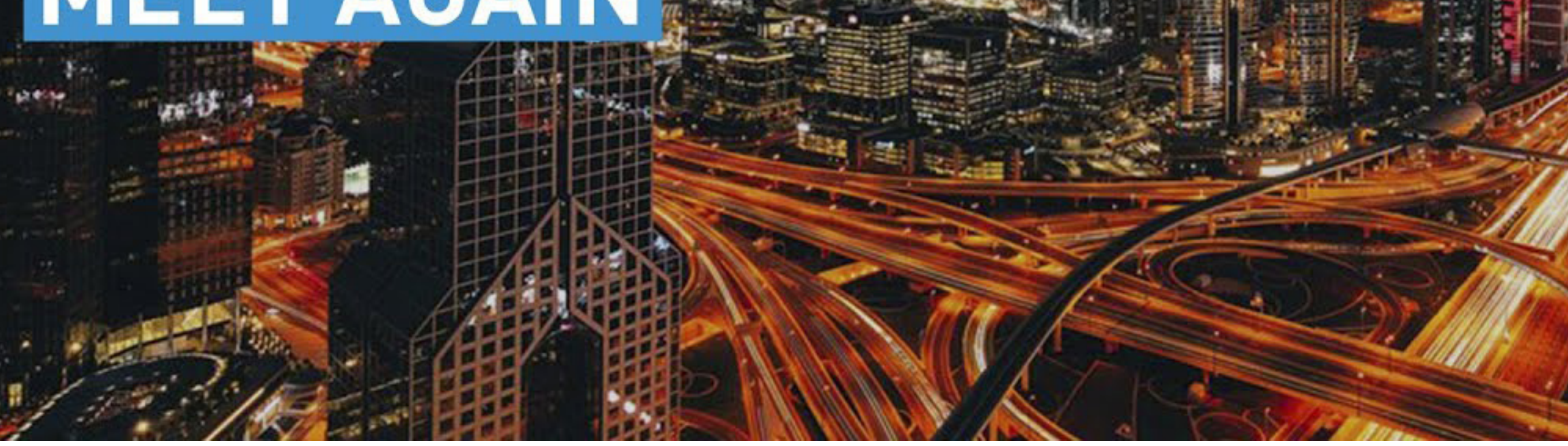

Image: Screenshots of the "Till We Meet Again" campaign ad, via YouTube

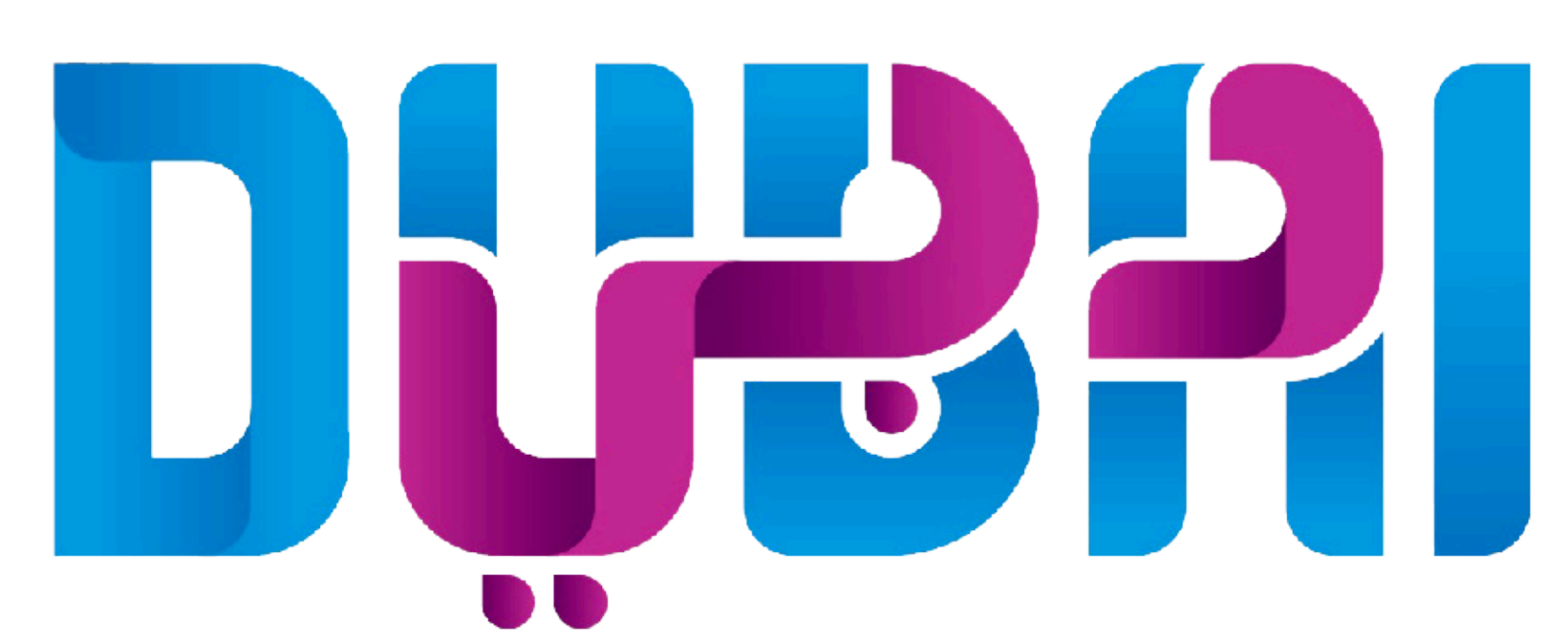




\section{INSTAGRAM}

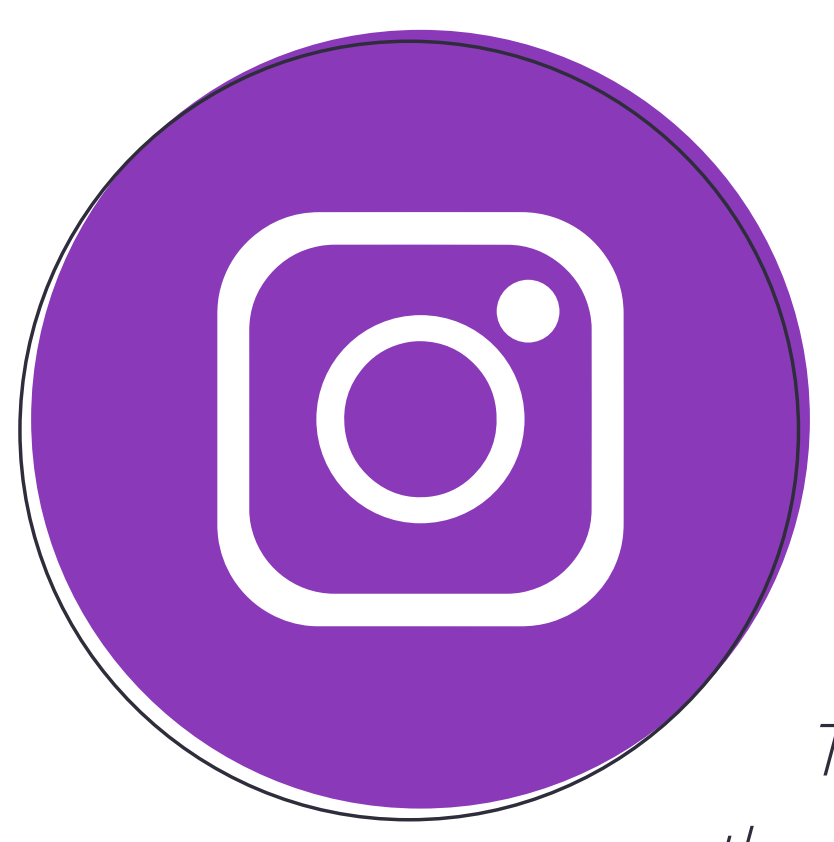

Instagram is now ten years old, celebrating its birthday on 6th October. In the past decade the service has grown from a fledginly start-up to one of the biggest social networks in the world, ${ }^{108}$ with over I billion users a month. ${ }^{100}$

The service is continuing to evolve, offering new functions such as the new "Reels" feature and an increasing focus on online shopping. "Io

The Middle East is home to some of the biggest markets for Instagram in the world Three MENA nations - Turkey 6th (at 44 million), Saudi Arabia 16th (15 million) and Egypt 20th (14 million) - are all in the Top 20 for largest audiences, by country.

Looking at a different metric, percentage of the population using Instagram, and even more MENA nations are present in the Top 20. More than half of people online in Kuwait (4th), Turkey (5th), Bahrain (9th), and Israel (17th) are using the visual social sharing app."'l

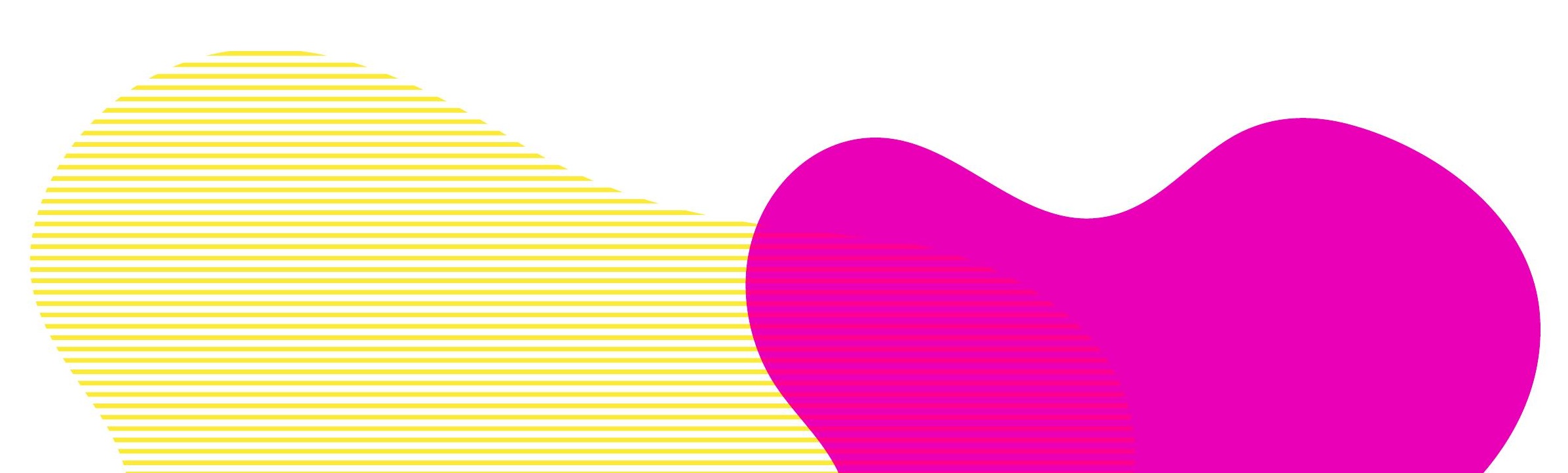

INSTAGRAM ELIGIBLE AUDIENCE REACH RATE RANKING

Countries and territories with the highest levels of potential Instagram advertising reach compared to population (aged 13+)

\begin{tabular}{|c|c|c|c|c|}
\hline$\#$ & COUNTRY & $\% 13+$ & REACH & QOQ \\
\hline 01 & Kazakhstan & $72 \%$ & $10,000,000$ & $+6 \%$ \\
\hline 02 & Brunei & $71 \%$ & 250,000 & $+4 \%$ \\
\hline 03 & Iceland & $67 \%$ & 190,000 & $+6 \%$ \\
\hline 04 & Kuwait & $66 \%$ & $2,300,000$ & $+5 \%$ \\
\hline 05 & Turkey & $66 \%$ & $44,000,000$ & $+5 \%$ \\
\hline 06 & Cayman Islands & $65 \%$ & 36,000 & $+0 \%$ \\
\hline 07 & Guam & $63 \%$ & 84,000 & $+4 \%$ \\
\hline 08 & Sweden & $63 \%$ & $5,400,000$ & $+2 \%$ \\
\hline 09 & Bahrain & $61 \%$ & 880,000 & $+7 \%$ \\
\hline 10 & Chile & $60 \%$ & $9,500,000$ & $+3 \%$ \\
\hline 17 & Israel & $56 \%$ & $3,700,000$ & $+6 \%$ \\
\hline
\end{tabular}

Table: Largest markets for Instagram, based on \% of online population, via We Are Social and Hootsuite 
As Instagram expands its eCommerce potential, Social Networkers in Saudi Arabia and Egypt are among those most likely to say that adding a "buy button" on social networks would increase their likelihood of purchasing a product. Nonetheless, with fewer than one in five users in those countries open to this idea, this suggests that social commerce still has some way to go before it becomes mainstream.

\section{A "BUY" BUTTON ALONE ISN'T ENOUGH}

Percent of each social platform's visitors/users who say a "buy" button would most induce them to buy

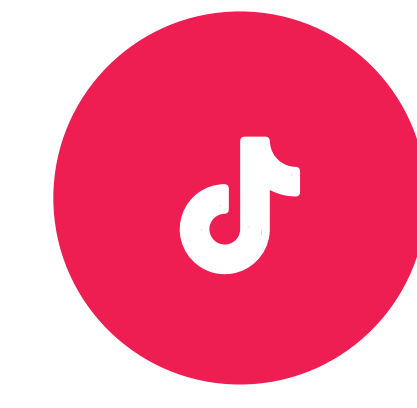

$19 \%$

TikTok

Users

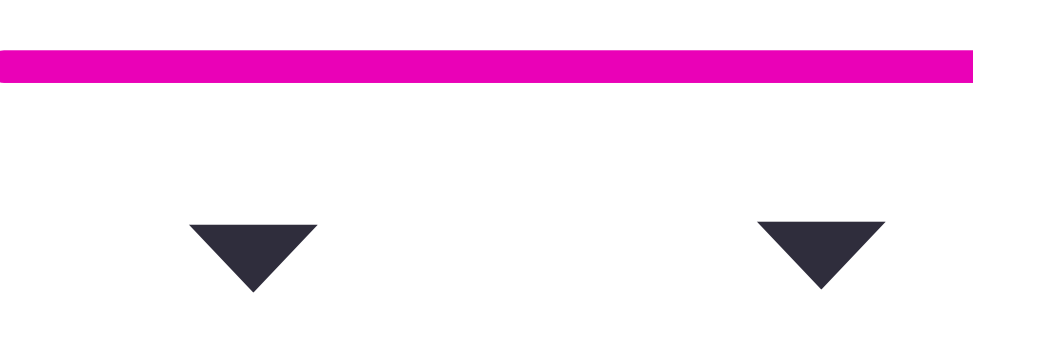

Vietnam

Saudi Arabia

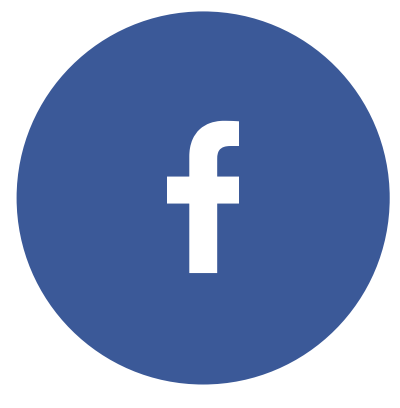

$16 \%$

Facebook

Users

Top Countries

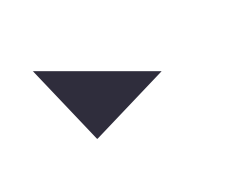

Egypt

$18 \%$

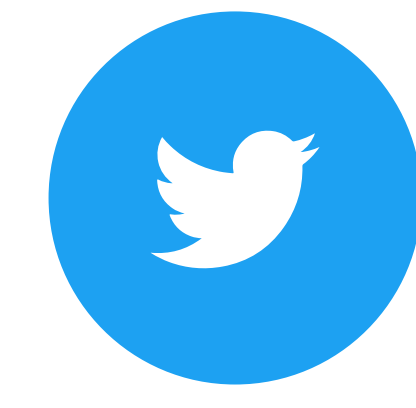

$15 \%$

$13 \%$

Twitter

Users

Snapchat

Users

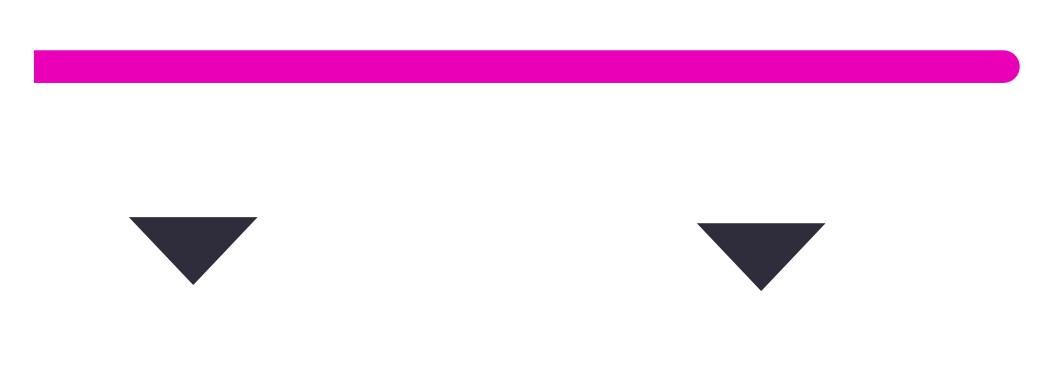

China

$17 \%$

Thailand

$17 \%$

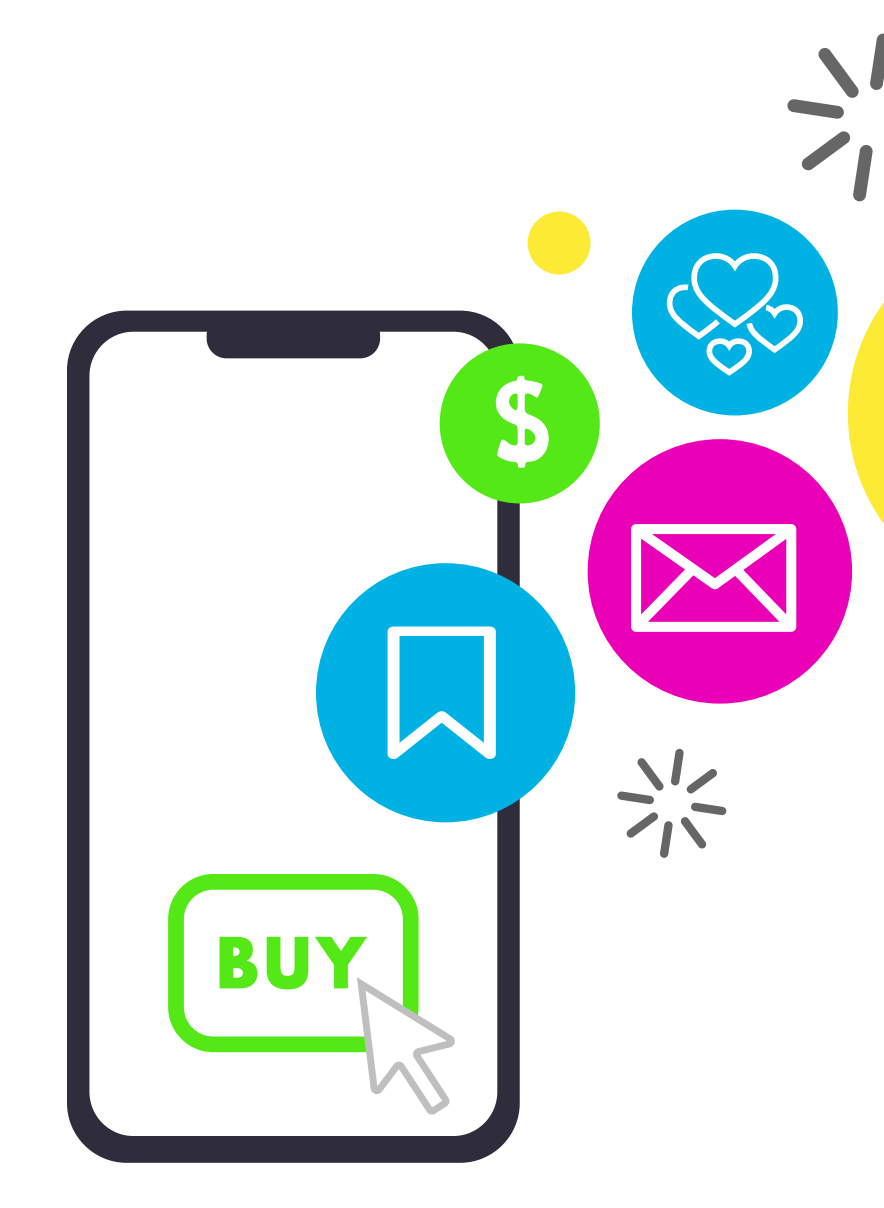

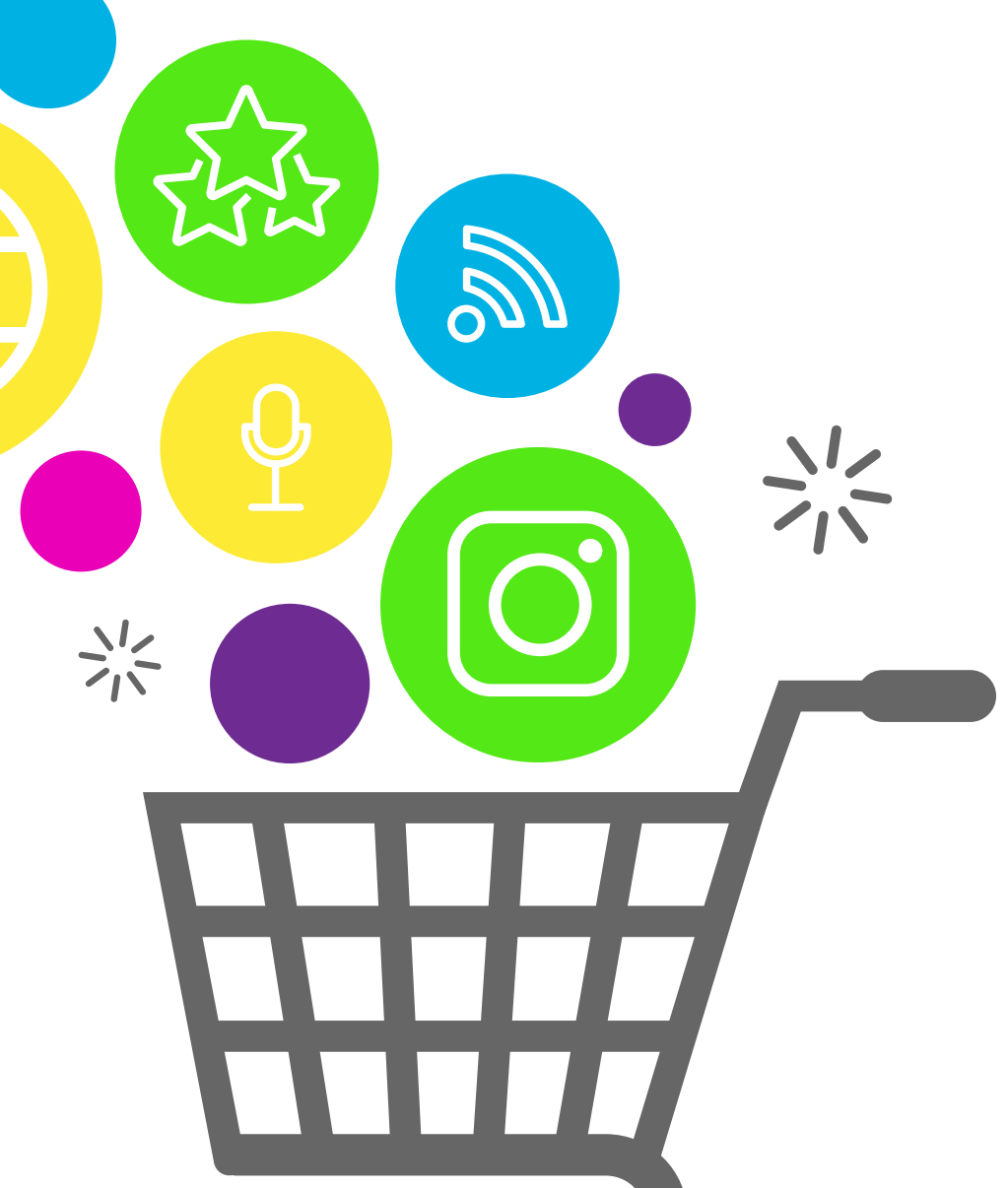

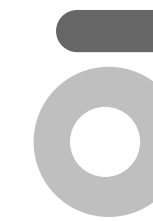

Iranian Instagram star Sahar Tabar has been jailed for 10 years, the Guardian reported, "charged with corruption of young people and disrespect for the Islamic Republic." "I2 Tabar had previously been arrested in 2019 on blasphemy charges,"13 before being released earlier in the year after contracting COVID-19.114

Three men were arrested in Iran over the summer for allegedly selling babies on Instagram, CNN reported, citing the semi-official ISNA (Iranian Students' News Agency) news agency. 115 
Instagram apologized to the supermodel of Palestinian origin, Bella Hadid, after she criticized the platform for deleting a post she shared that showed a picture of her father's passport with the birthplace listed as Palestine. 116

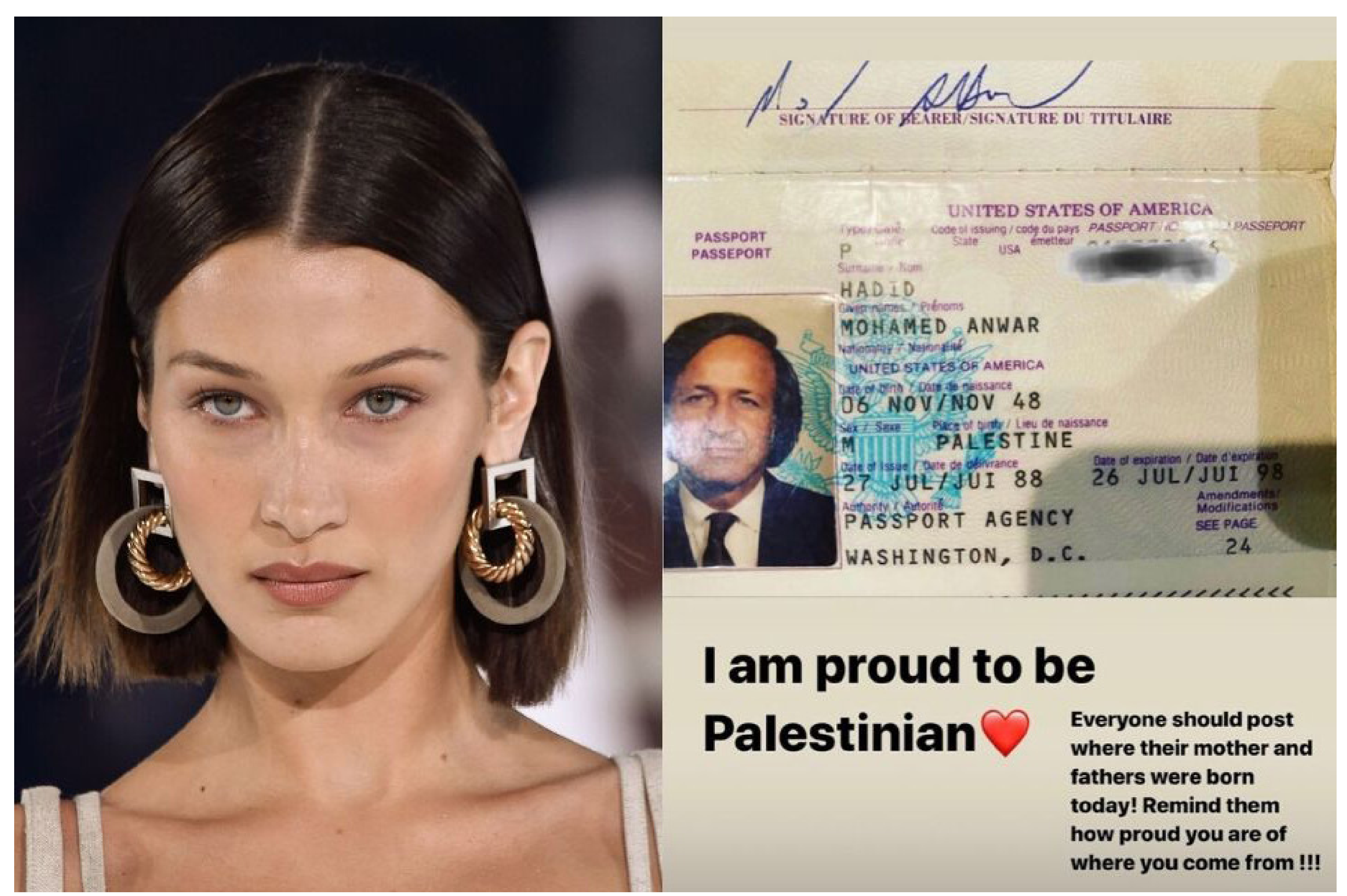

Image: Screenshot via Al-Jazeera/AFP of Hadid's post which was captioned: "Are we not allowed to be Palestinian on Instagram? This, to me, is bullying."

"To protect the privacy of our community, we don't allow people to post personal information, such as passport numbers, on Instagram. In this case, the passport number was blurred out, so this content shouldn't have been removed," an Instagram spokesperson said. "We've restored the content and apologised to Bella for the mistake.
Egyptian authorities ordered the arrest of a group of men accused of being involved in a gang rape in 2014, after the incident was highlighted on an Instagram account (@assaultpolice) designed to fight sexual violence.177 The account has nearly a quarter of a million followers

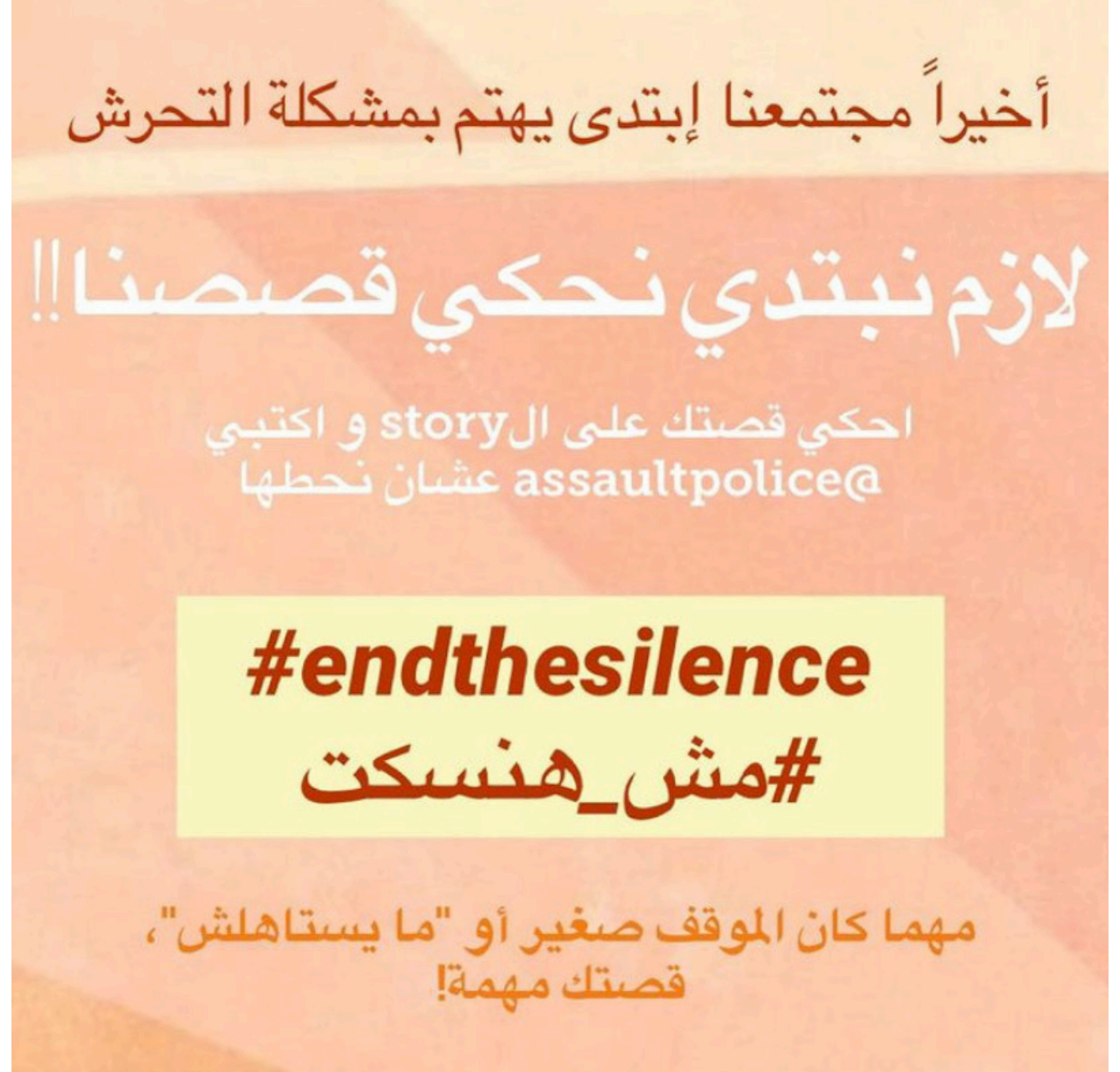

$0 \bigcirc \nabla$

2,717 likes

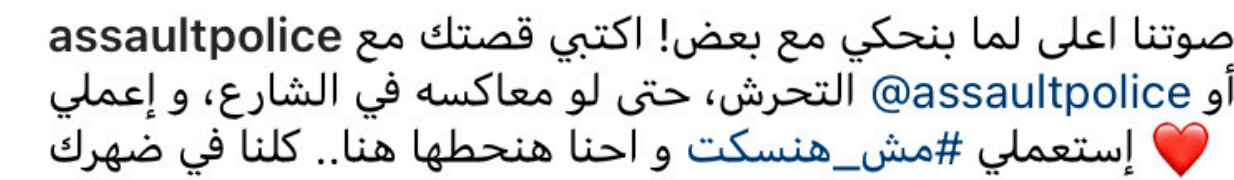

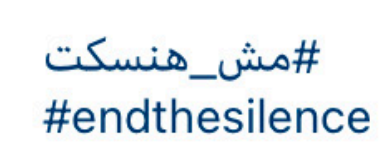

ఐ

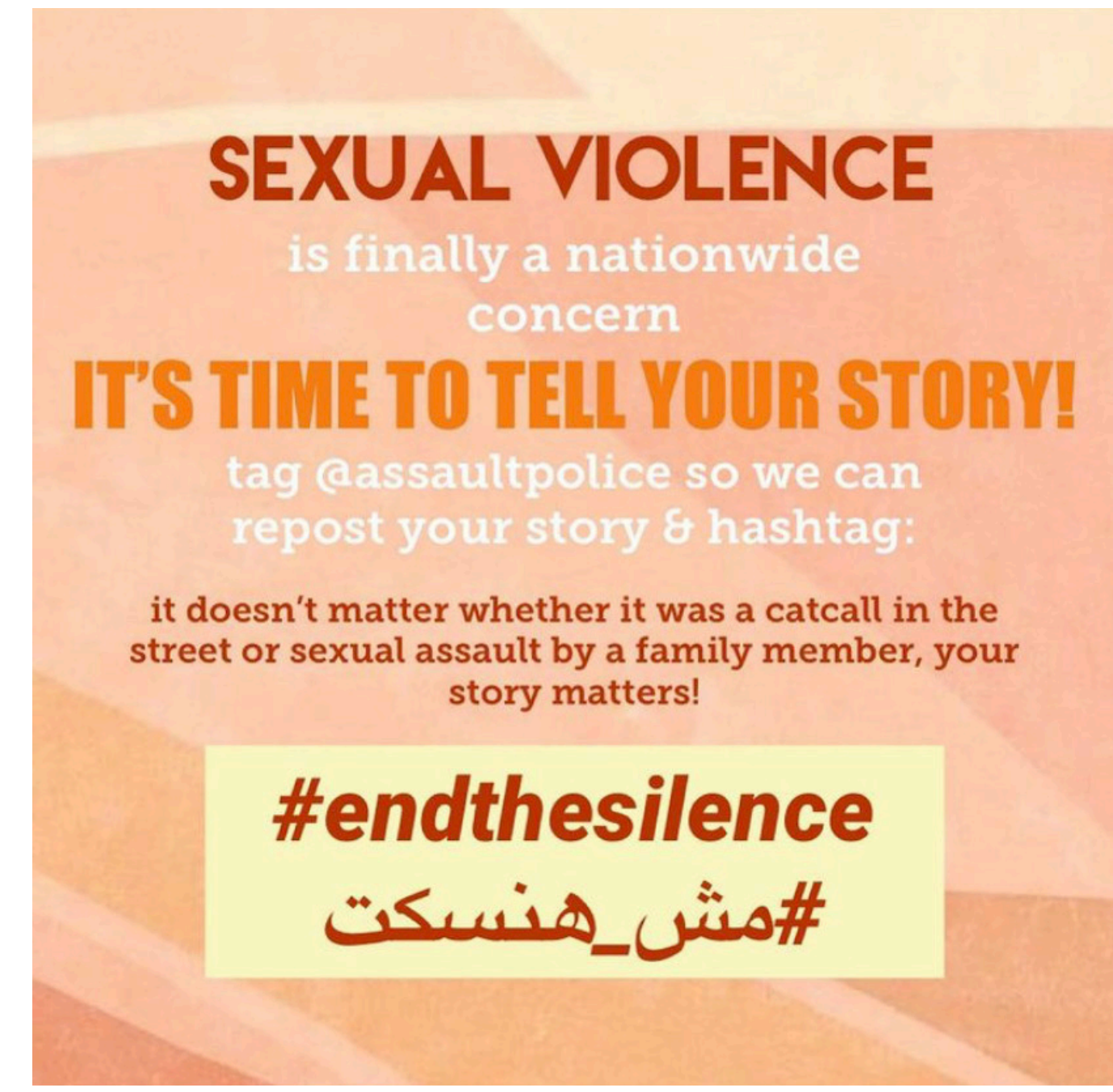

$\bigcirc \bigcirc \nabla$ 2,573 likes

togaltpolice Our voices are louder when we speak together! Share your story with sexual harassment or assault on your story using these hashtags, and mention us
Qassaultpolice if you want us to repost your story. IT's @assaultpolice if you want us to repost your story. IT'S
TIME TO SPEAK OUT! \#endthesilence

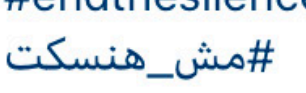

Images: in Arabic and English, on the Assault Police Egypt's account, encouraging Instagram users to share their stories of sexual assault and harassment 
To celebrate the start of the new football (soccer) season in Saudi Arabia, Instagram created a new voice activated AR filter. Part of its \#TherelnSpirit campaign, users press record and make noise to activate the filter and its effects. ${ }^{118}$

"The campaign achieved 3,400 filter impressions a day and 1,116 English or Arabic posts shared with the hashtag across Instagram and other social platforms," Instagram reported. "In total, the \#thereinspirit campaign achieved an estimated 72 million reach across the MENA region and widespread media coverage." "119

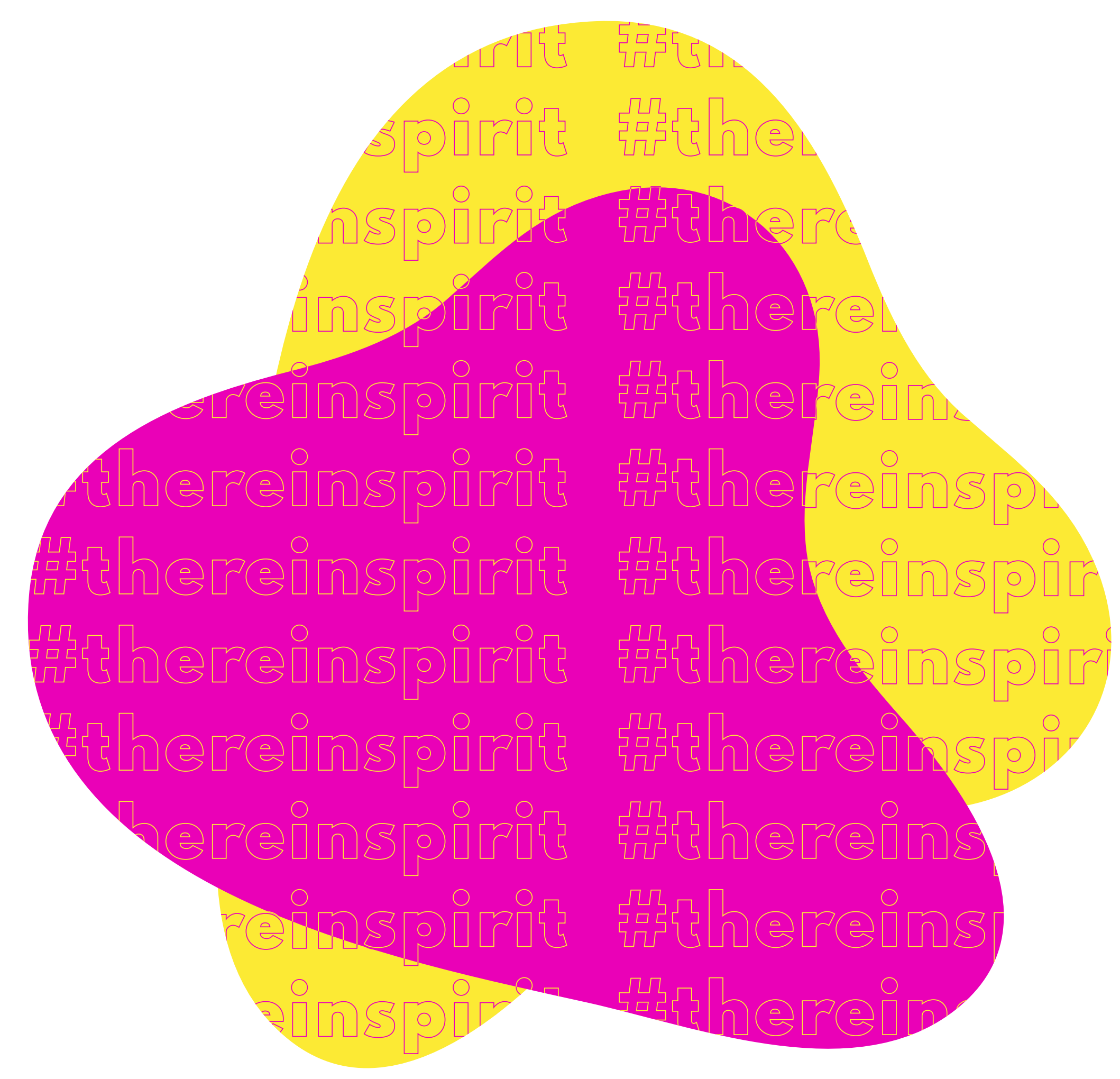

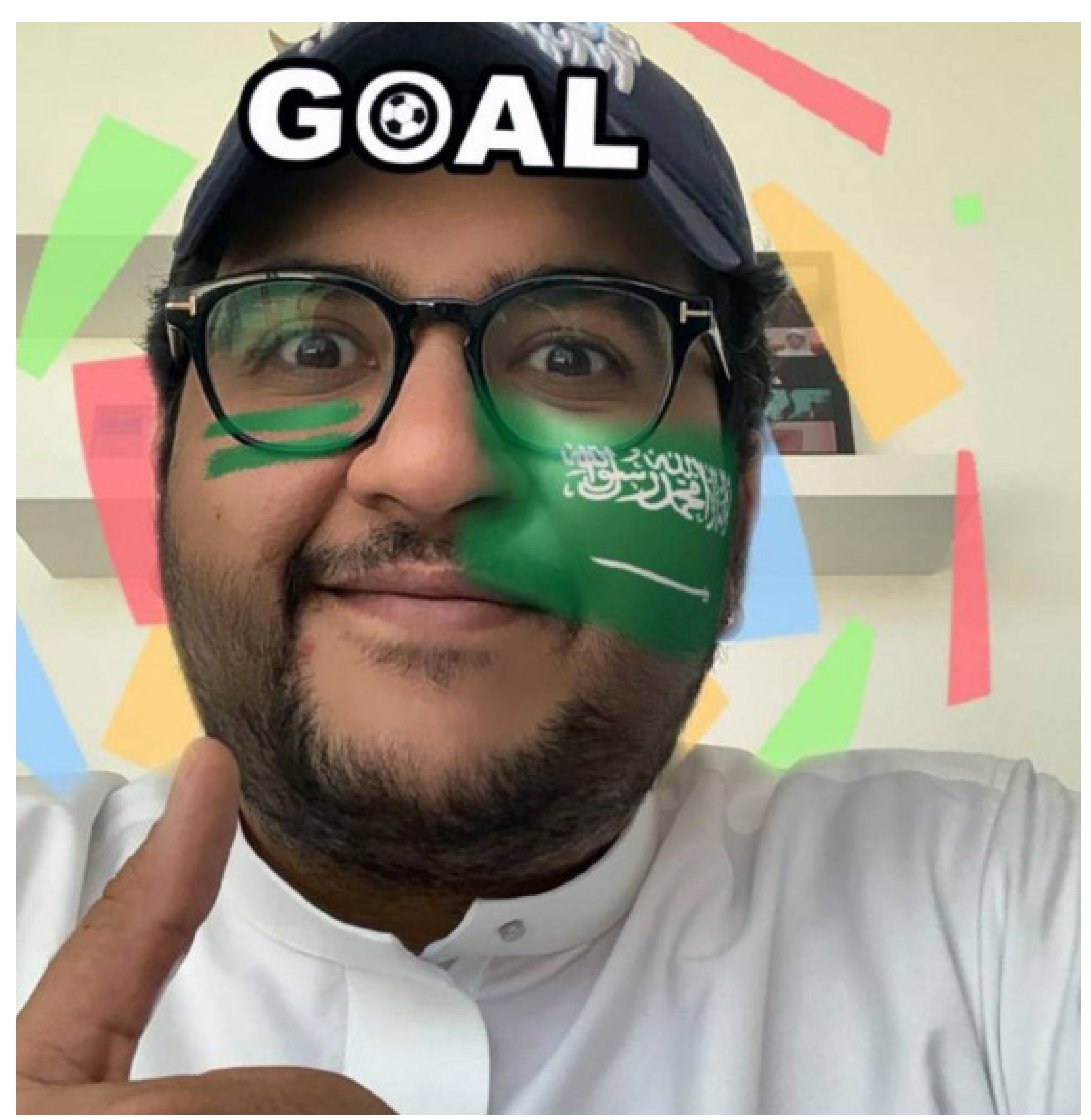

Image: via Saudi Gazette 
The @nescafearabia Instagram grid was turned into a building, with different balconies showcasing stories of how people are connecting during the time of COVID. Using the hashtag \#StayCloseFromFar users were asked to submit their stories, with each story that was added to the virtual building accompanied by its own individual illustration. ${ }^{20}$

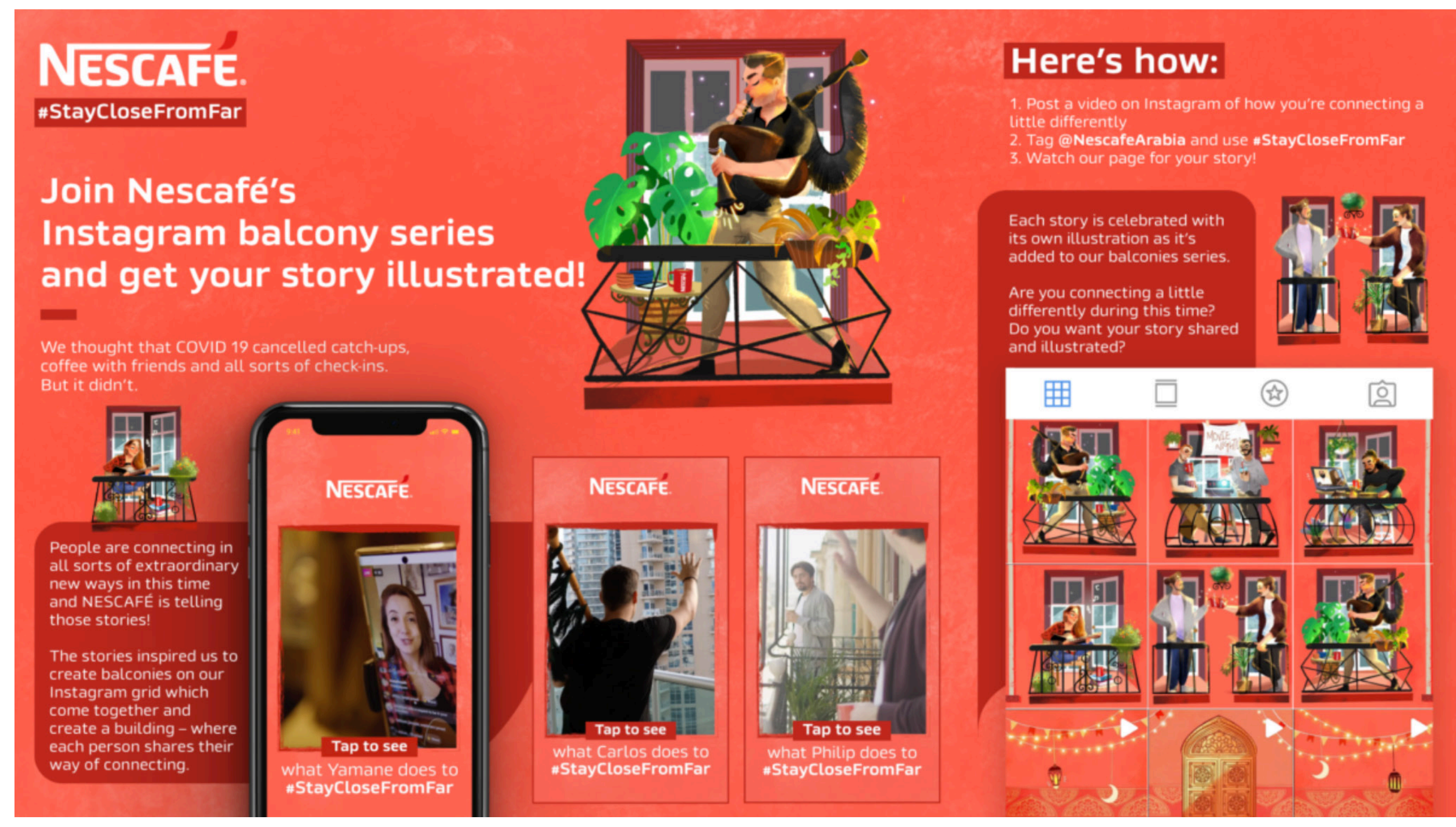

Image: via FAB News

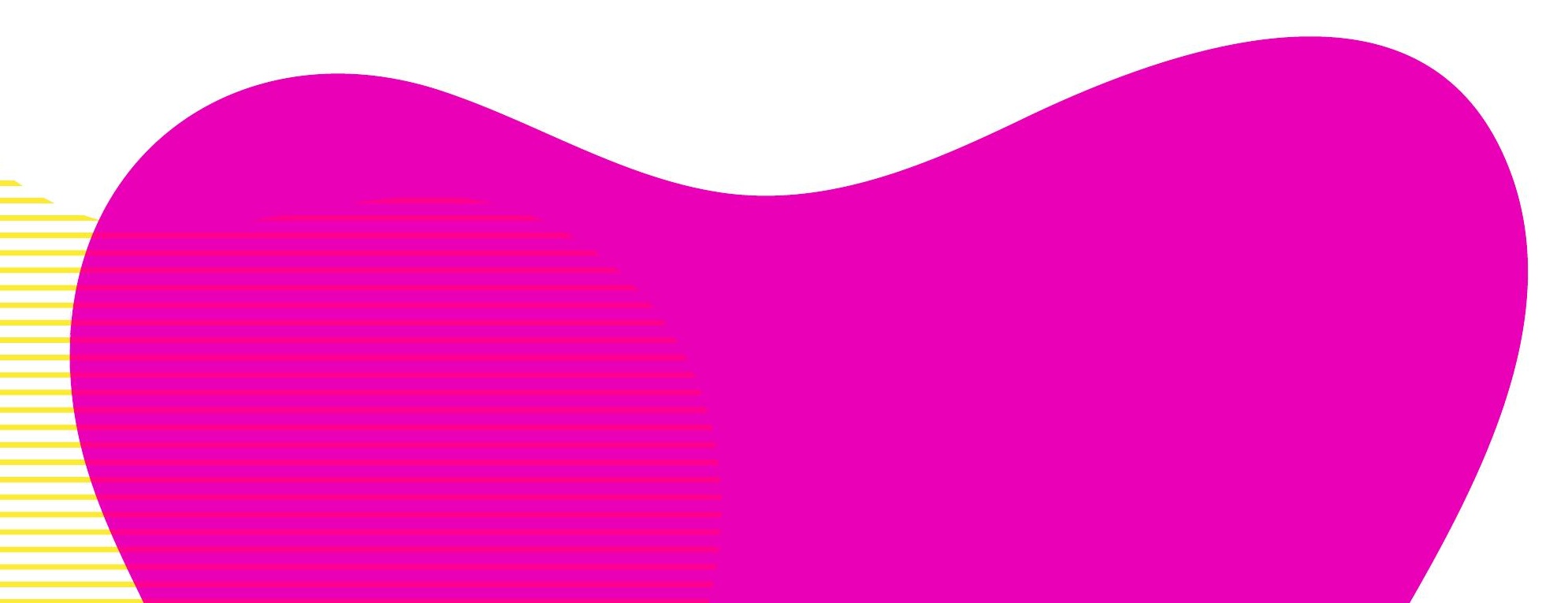

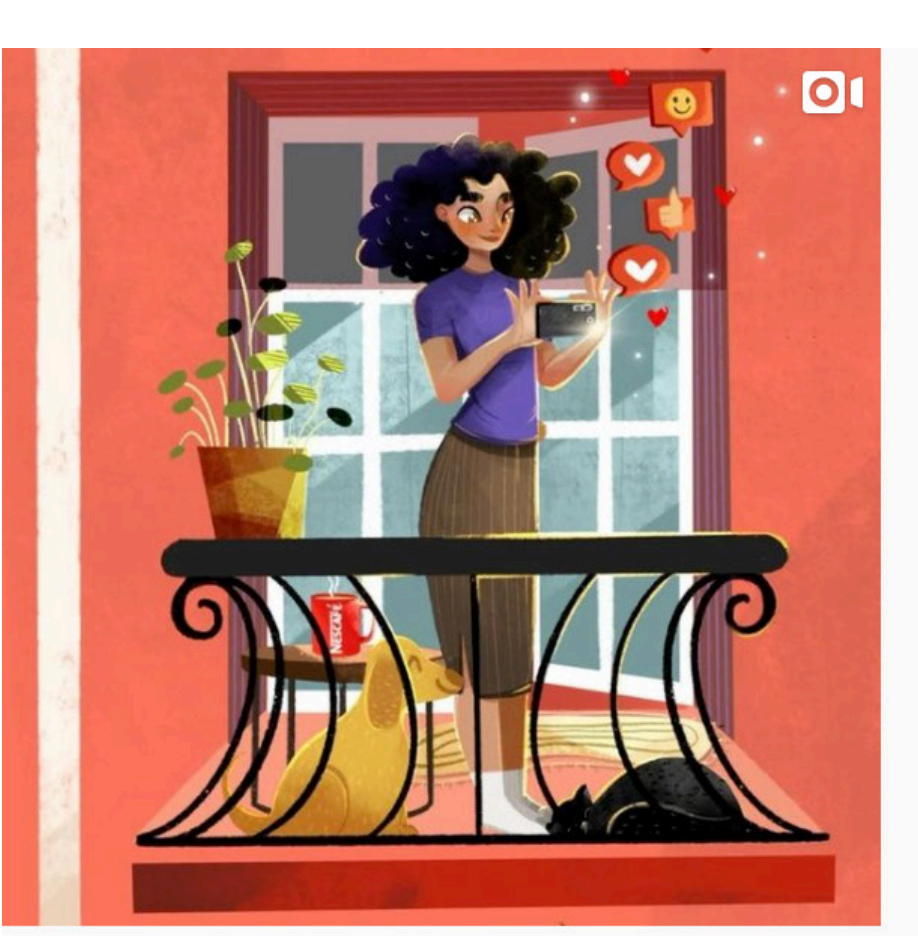
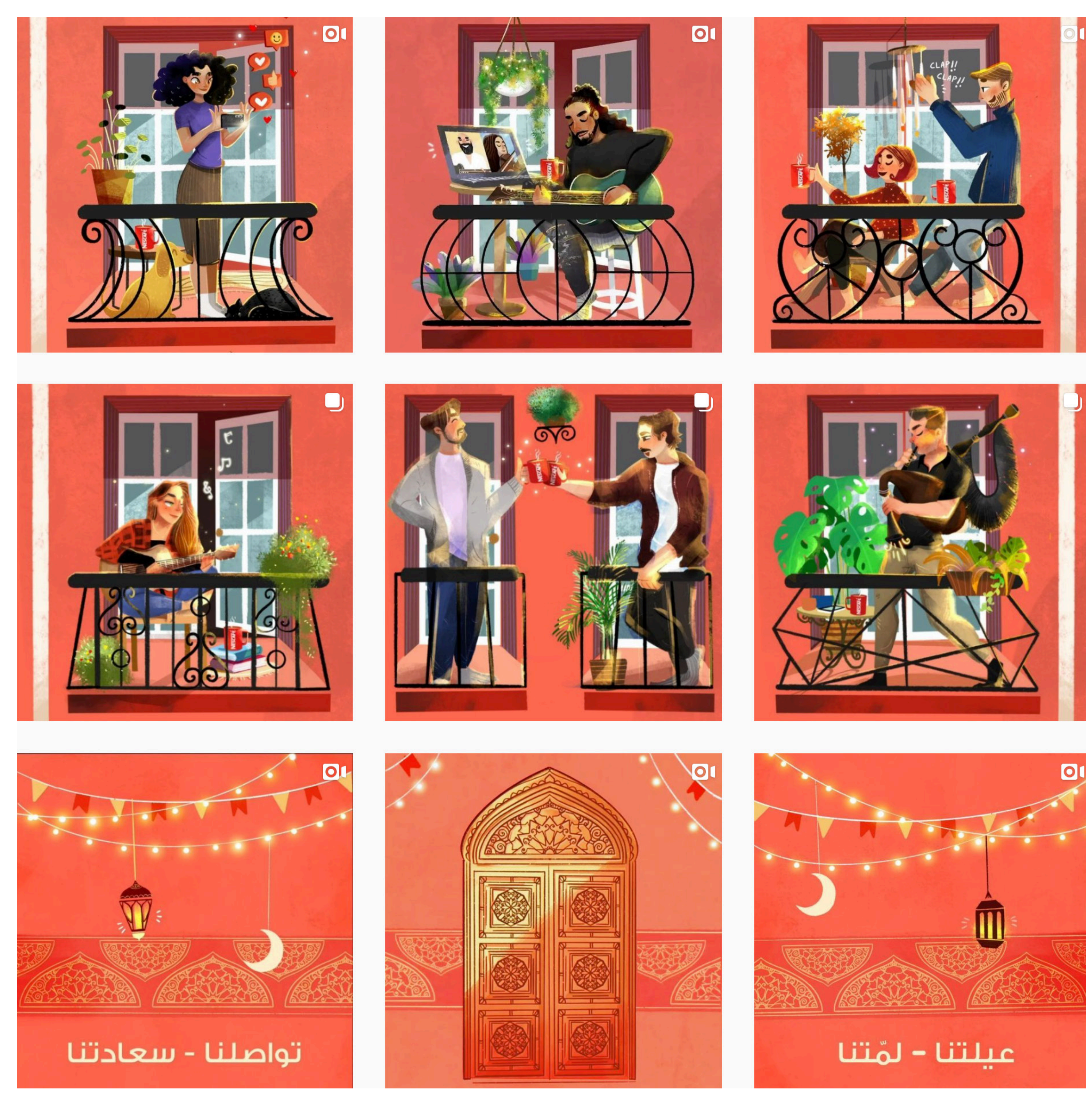

Image: \#StayCloseFromFar posts via Instagram 


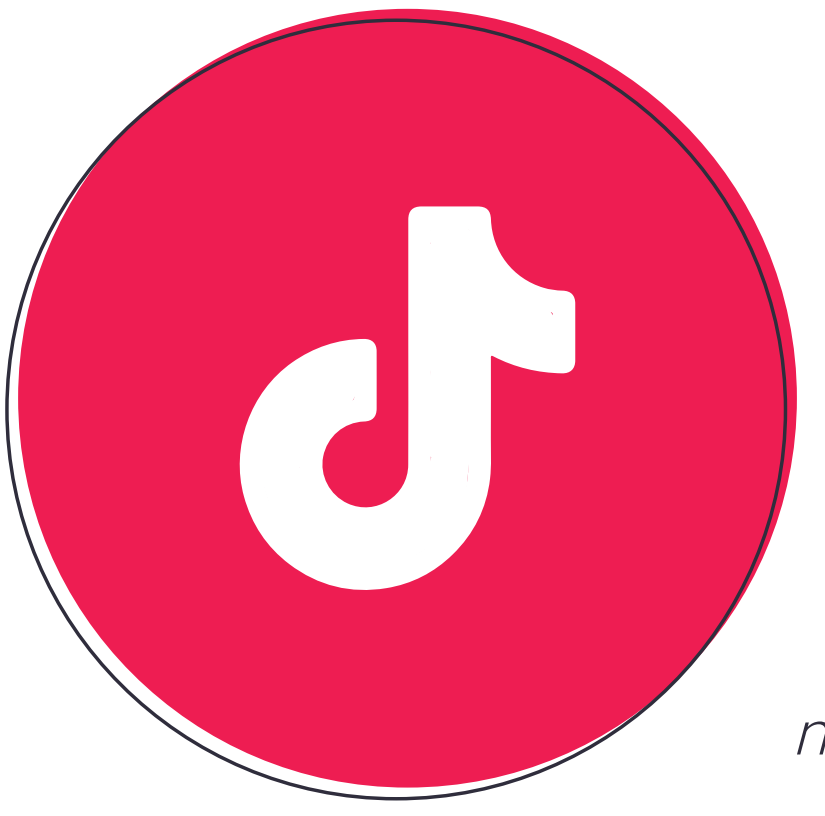

"Can we really talk about 2020 without mentioning TikTok?" asked the research company GlobalWeblndex during summer 2020. The company pointed out how time spent on social media had risen during the start of the pandemic. "Nearly every social media platform has seen a boost in monthly engagement," they observed.

One reason for TikTok's growth - which in MEA is behind other regions during this period - lies in the fact that "the social platform has certainly given people an outlet for creativity during lockdown, offering a platform for light-hearted content at a time it was needed most." 121

"TikTok is seeing phenomenal growth across the GCC, with the app consistently ranking among the top downloads in regional Apple App and Google Play Stores," an August 2020 report from Anavizio Data Solutions revealed. 122

\section{THE EXPLOSION OF TIKTOK}

Percent outside China who say they visited TikTok in the last month. 000\% = change between Q3 (2019) \& Q2 (2020)

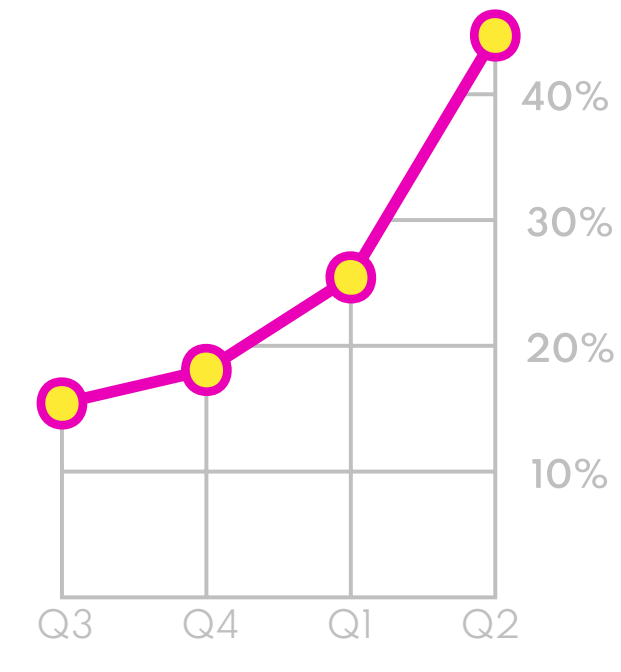

Latin America

$+185 \%$

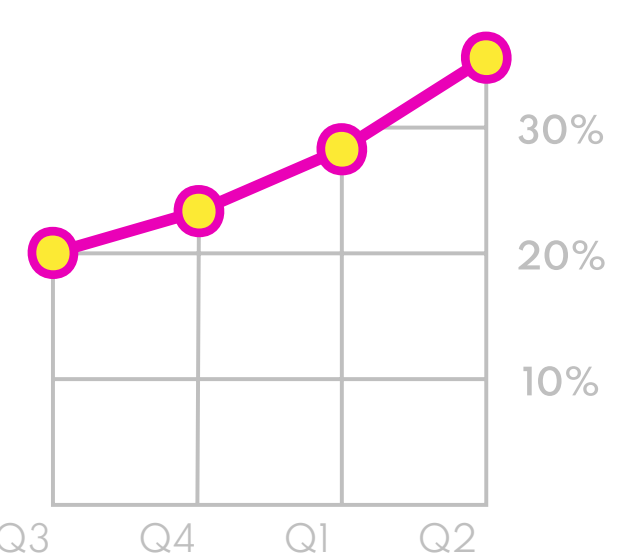

Middle East \& Africa $+72 \%$

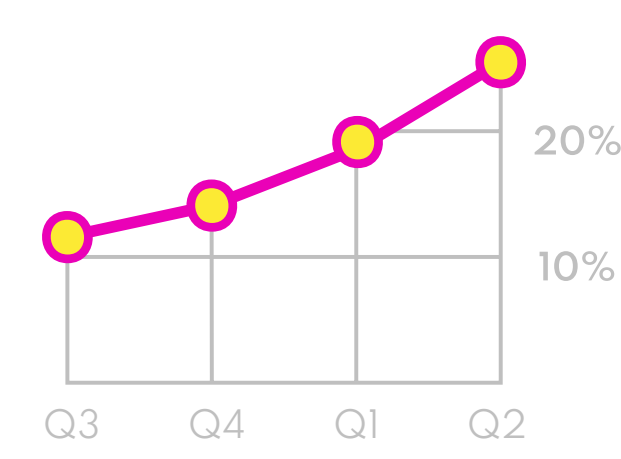

North America $+123 \%$

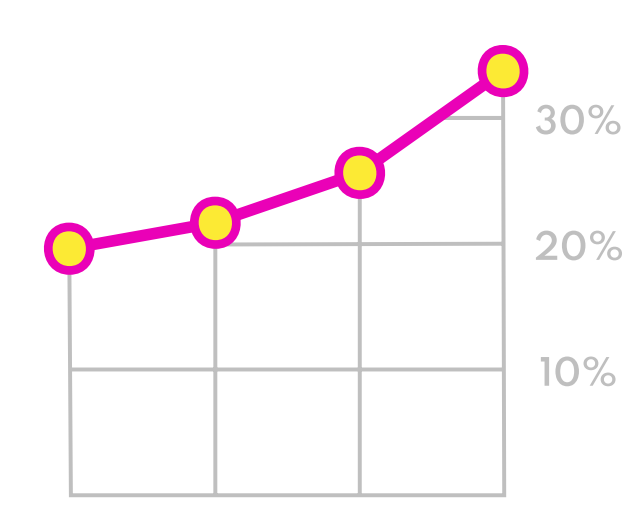

Global (exl. China) $+72 \%$

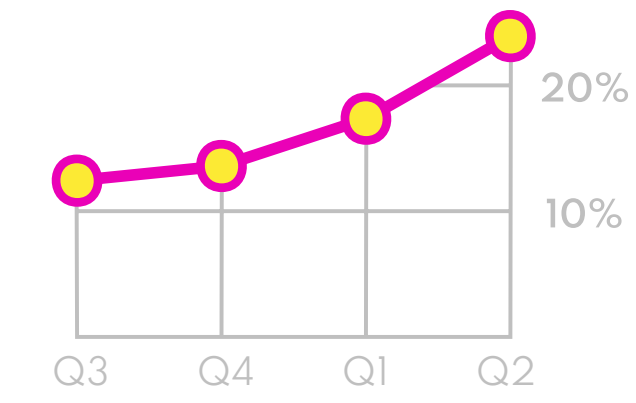

Europe

$+93 \%$

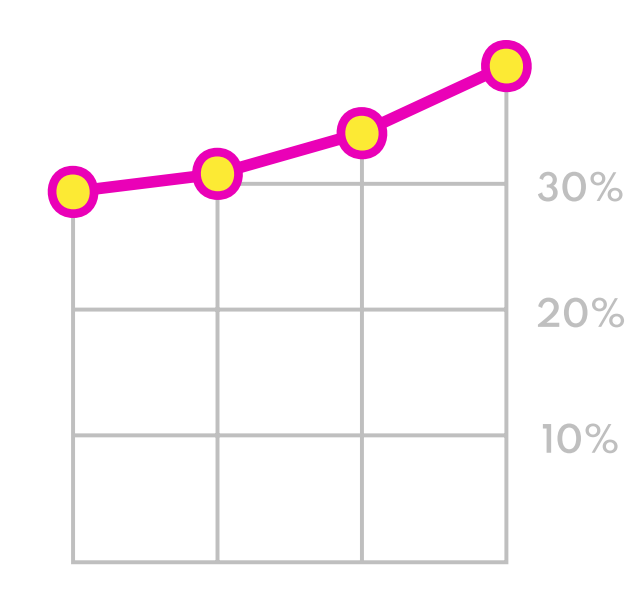

Asia Pacific (exl. China) $+36 \%$ 
Between February and August 2020, top influencers grew their fanbase by average of $65 \%$, with the highest engagement rates seen in Bahrain, Oman and Saudi Arabia.

"New influencers have emerged organically on TikTok," the authors note rather than crossed over from more established social media channels such as Instagram. Huda Kattan "is one of the few celebrities or influencers to have successfully crossed over.

\section{TOP 3 INFLUENCERS IN THE GCC}

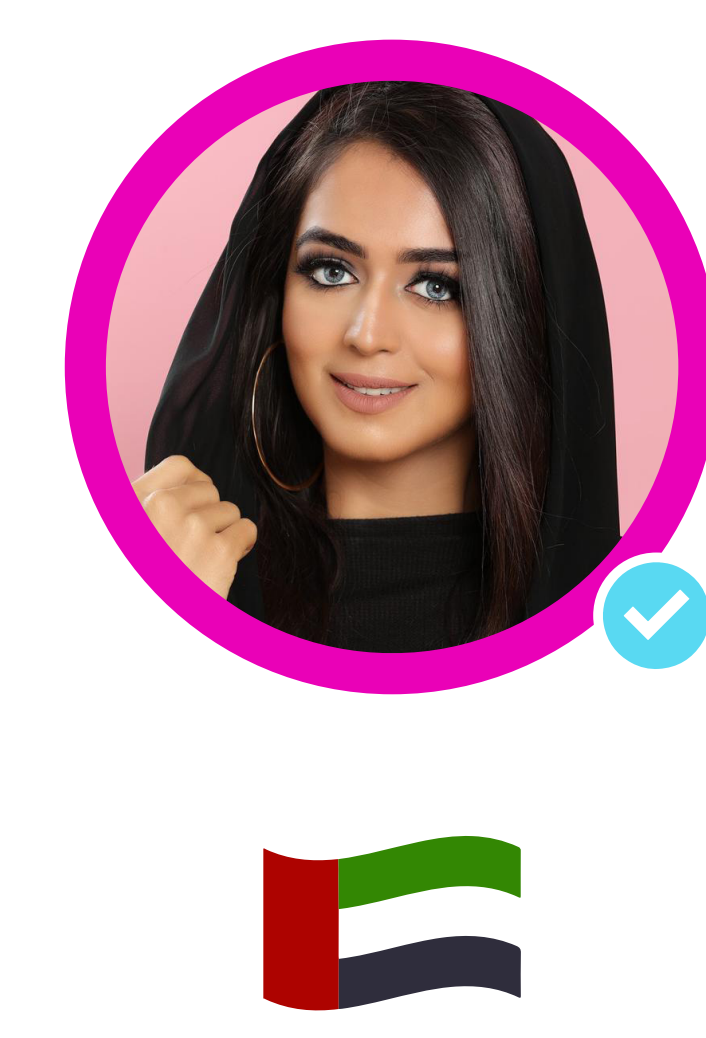

@jumana_khan_ $8.4 \mathrm{M}$

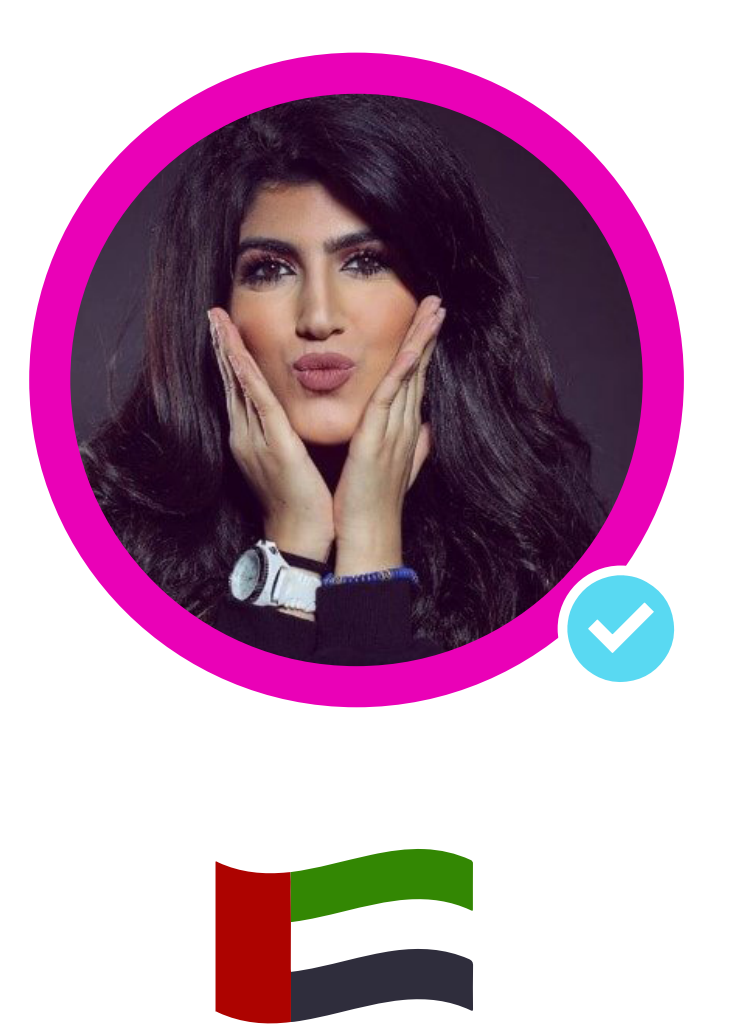

@sarahhmiladd $6.6 \mathrm{M}$
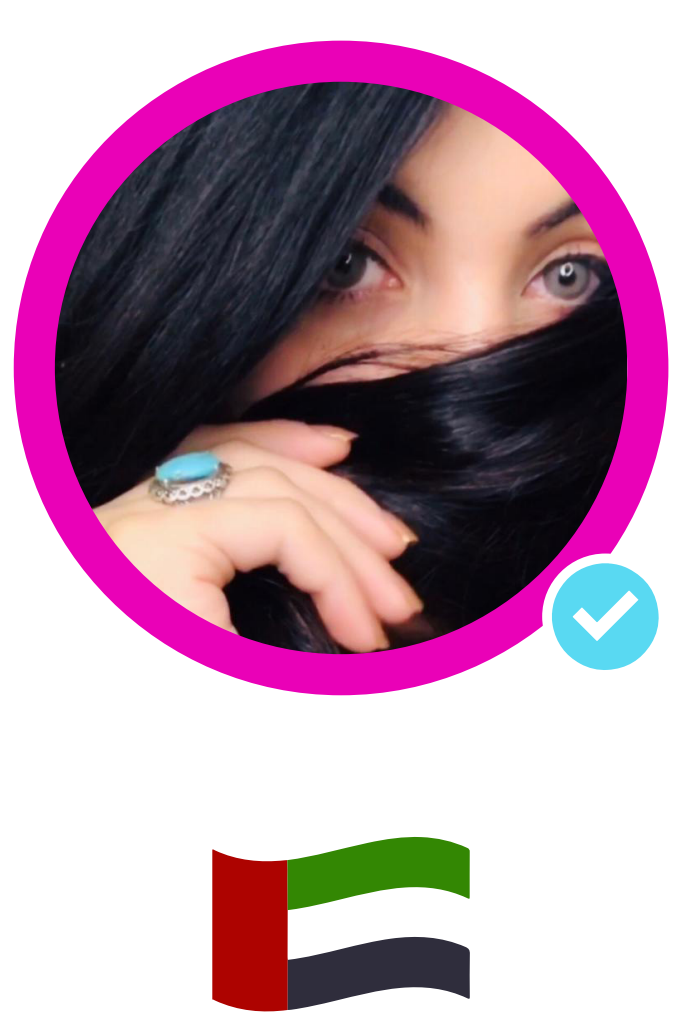

@xzayx89

$5.2 \mathrm{M}$
Chart: The Top 3 TikTok influencers in the GCC, as of August 2020

TikTok users are more willing to click on an ad with a higher intent to purchase than other networks, according to a new study from TikTok for Business in partnership with the UAE research company, Feedback Market Research. ${ }^{123}$
The study found that $68 \%$ of users in Egypt, $66 \%$ in KSA and $65 \%$ in UAE say an ad on TikTok has persuaded them to proceed with a purchase. On other channels that drops to $48 \%$ in KSA and $51 \%$ in UAE and Egypt.

Five Egyptian young women were sentenced to two years in prison and a fine of nearly $\$ \mathbf{2 0 , 0 0 0}$ for violating the country's family values with their TikTok and Instagram posts, the BBC $\underline{\text { said. }} .124$

Their videos "show them dancing, singing and clowning about," the New York Times noted, observing that "the clips are tame by social media standards, and nothing that would raise the eyebrow of a broadcast censor in the West." 125

The sentences were overturned in early 2021, the Egyptian newspaper Al-Ahram reported. ${ }^{126}$

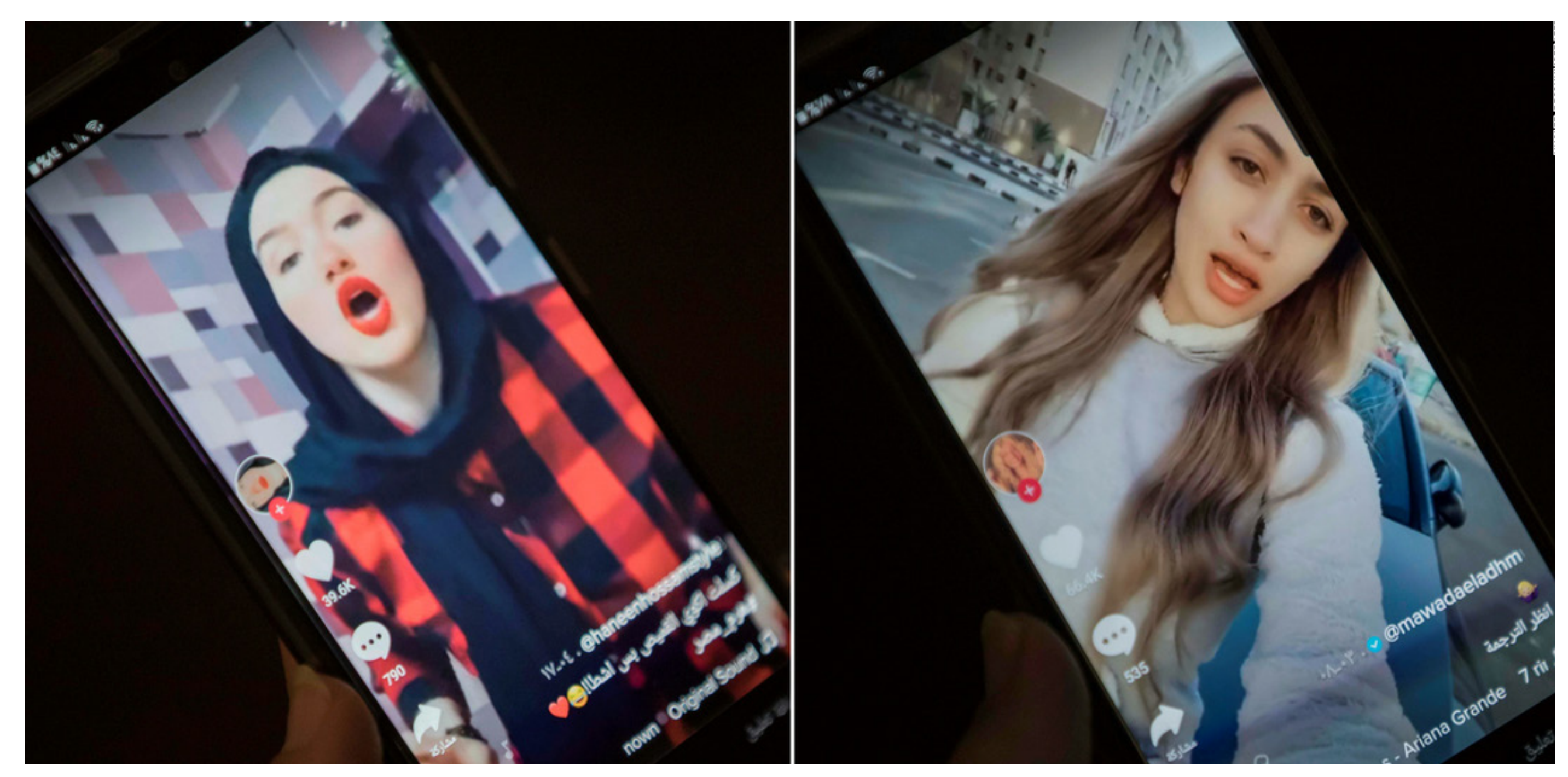

Image: Haneen Hossam (left) and Mowada al-Adham (right). Image via CNN. 


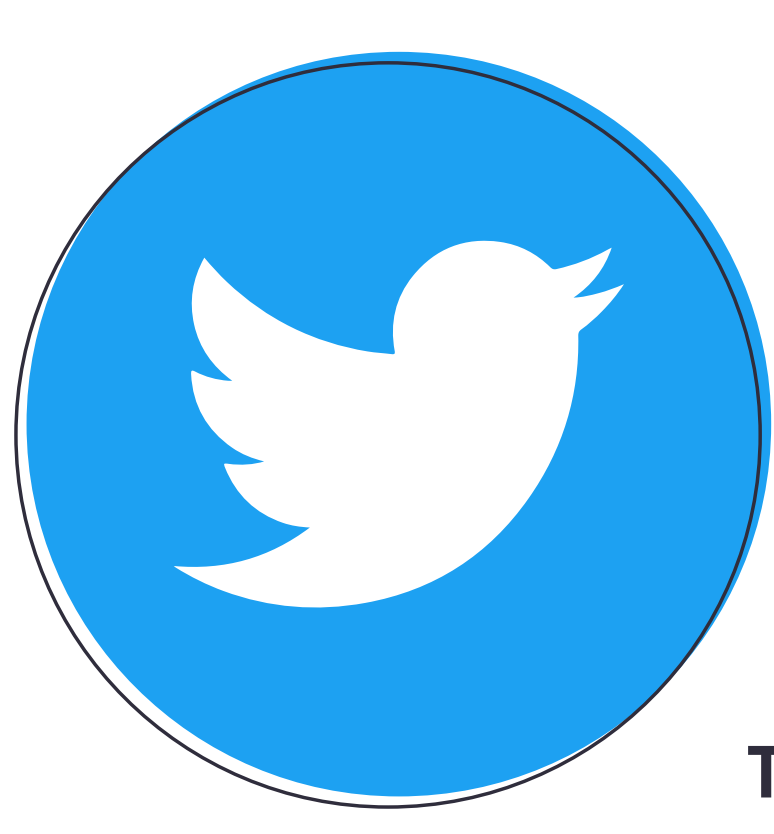

In recent years. Twitter has seen some decline in usage in the Middle East as audiences have moved to other newer social media platforms. ${ }^{127}$ However, it continues to play an important role in some of the biggest markets in the region.

Turkey (6th), Saudi Arabia (8th) and Egypt (18th) are all in the Top 20 countries with the highest audiences for Twitter; and in each market, numbers continue to increase.

The Lebanese pop artist, Elissa, is the Arab world's most influential user on Twitter and the only Arab figure to make the list of 50 most powerful international influencers. ${ }^{2}$

In a report published by Brandwatch, Elissa (@elissakh) is ranked at number 45, just behind @TheRock (actor Dwayne Johnson at No 44) and a head of former US First Lady a MichelleObama (No 50).129 The pop star has just over 15 million followers on Twitter and nearly 17 million on Instagram.

\section{TWITTER REACH RANKINGS}

Countries and territories with the greatest potential Twitter advertising reach

\begin{tabular}{|c|c|c|c|c|}
\hline$\#$ & COUNTRY & REACH & QOQ & QOQ \\
\hline 01 & U.S.A & $68,700,000$ & $+10 \%$ & $+6,150,000$ \\
\hline 02 & Japan & $51,900,000$ & $+6 \%$ & $+2,800,000$ \\
\hline 03 & India & $18,900,000$ & $+11 \%$ & $+1,900,000$ \\
\hline 04 & Brazil & $16,650,000$ & $+6 \%$ & $+950,000$ \\
\hline 05 & U.K. & $16,650,000$ & $+9 \%$ & $+1,400,000$ \\
\hline 06 & Turkey & $13,450,000$ & $+6 \%$ & $+750,000$ \\
\hline 07 & Indonesia & $13,200,000$ & $+18 \%$ & $+2,000,000$ \\
\hline 08 & Saudi Arabia & $12,350,000$ & $+3 \%$ & $+350,000$ \\
\hline 09 & Mexico & $10,650,000$ & $+2 \%$ & $+250,000$ \\
\hline 10 & France & $7,900,000$ & $+11 \%$ & $+800,000$ \\
\hline 18 & Egypt & $3,700,000$ & $+4 \%$ & $+150,000$ \\
\hline
\end{tabular}

Table: Twitter reach rankings, via Hootsuite and We Are Social 
Twitter suspended the account of the Iranian Petroleum Minister, Bijan Zanganeh in November. "The account was suspended for violation of the Twitter rules against impersonation," Bloomberg wrote, citing an email from a spokesperson for the socia media company, which they commented did not provide "any more details." 130

The social network also removed 130 accounts linked to Iran which they said they were attempting to interfere with conversation around the first American presidential debate. ${ }^{13}$

In April, the micro-blogging site removed 5,350 accounts associated with Saudi Arabia and 2,541 Egyptian accounts it said were involved in pushing pro-government messaging. ${ }^{132}$

Twitter launched their "Topics" feature in Arabic, enabling users to follow specific subjects on the network. ${ }^{133}$ The service, as of March 2020, was available in English, Japanese, Spanish, Portuguese, Arabic and Korean
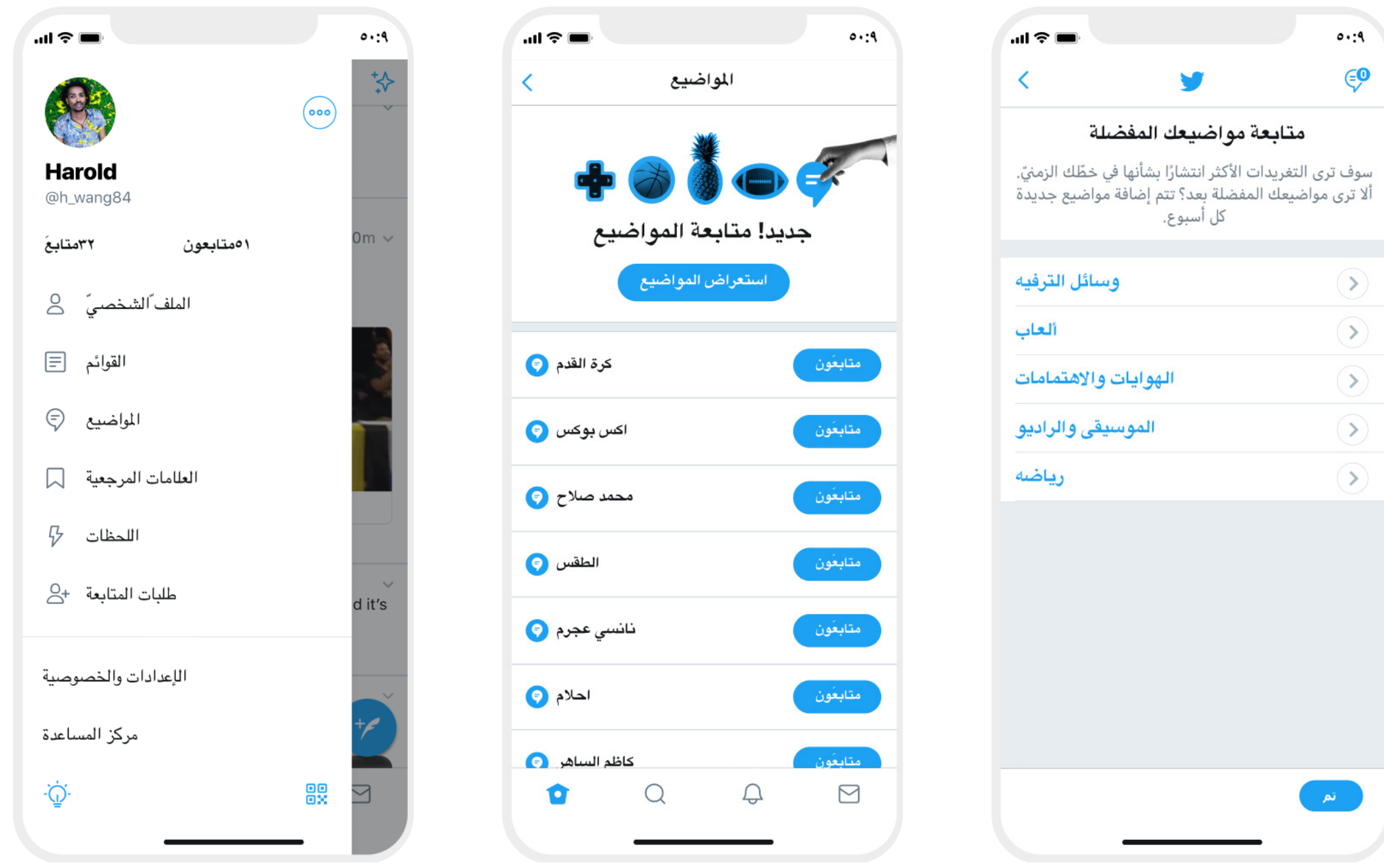

Twitter MENA

@TwitterMENA

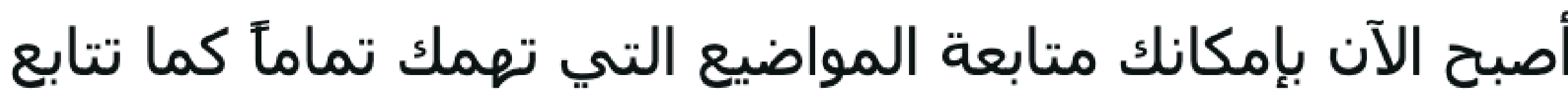

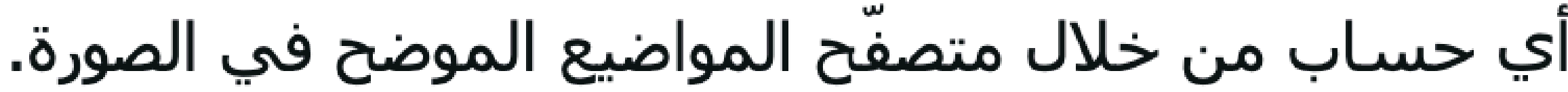

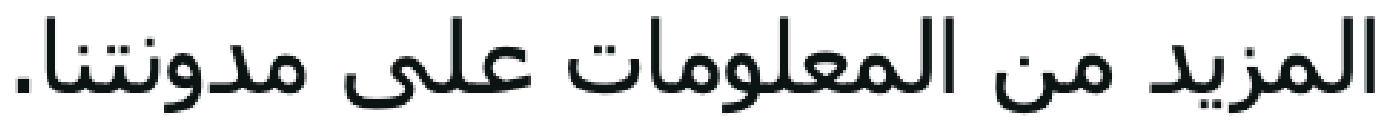
blog.twitter.com/ar/topics/prod...

Translated from Arabic by Google

Now you can follow the topics that interest you just as you follow any account through the Topics Browser shown in the picture. More information on our blog.blog.twitter.com/ar/topics/prod...

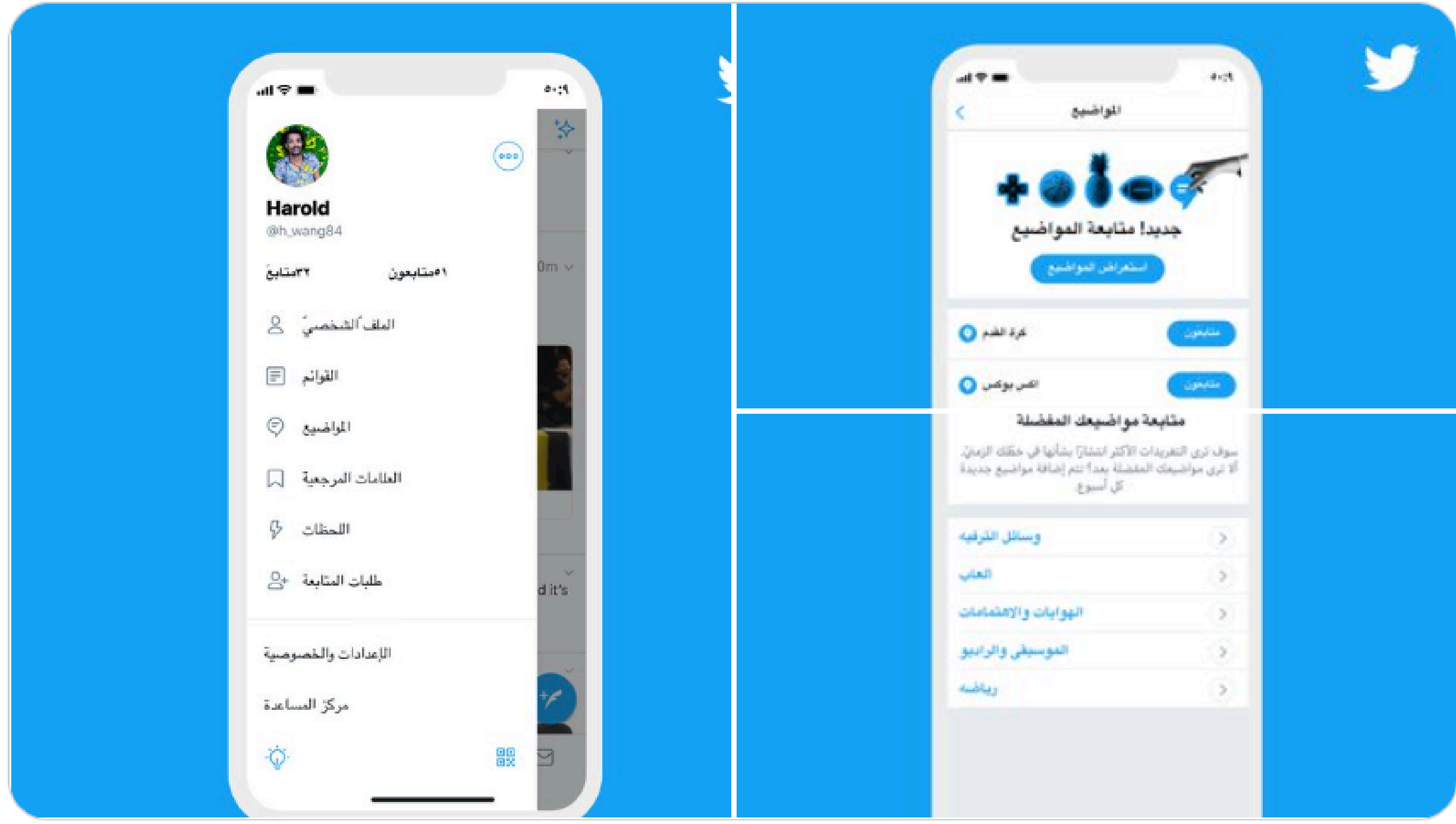

Images: Showing how the "Topics" feature works, via Twitter 


\section{TRENDING HASHTAGS}

Although news about COVID-19 dominated social media in 2020, there were many other events - globally and in the region - which attracted a lot of attention on social media.

Here are three examples of non-COVID related stories which trended in the Middle East last year, including stories originating from MENA and one that resonated within it

\section{THE ABRAHAM ACCORDS}

The hashtag \#Palestine_Charter in Arabic circulated on social media criticising the recent signing of the Abraham Accords, undertaken by the United Arab Emirates, Bahrain, Morocco, and Sudan. The online charter, which was signed more than 200,000 times, called for the liberation of occupied Palestine and denounced normalization with Israel. 134

'Normalization Is Betrayal' and 'Gulf people against normalization' in Arabic were other trending hashtags rejecting the Arabs' states normalization relations with Israel. 135

Elsewhere, the Israel-Morocco normalization deal was also condemned by some Moroccans online using the hashtag \#MoroccansAgainstNormalization, ${ }^{136}$ reflecting the decades-long animosity and lack of diplomatic ties between different Arab States and Israel.
(1). ․․․․

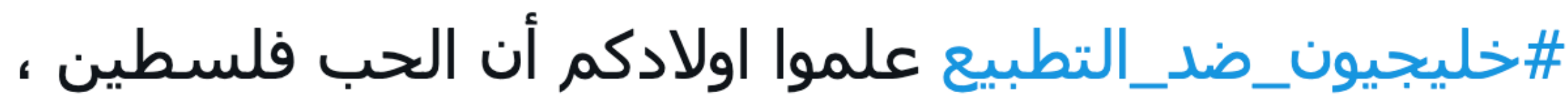

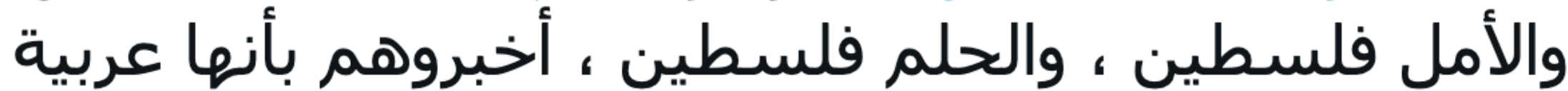
مسلمة من الضفة وحتى غزة الأبية عاصمتها القدس نولنه نوروهم

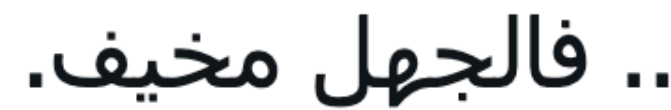

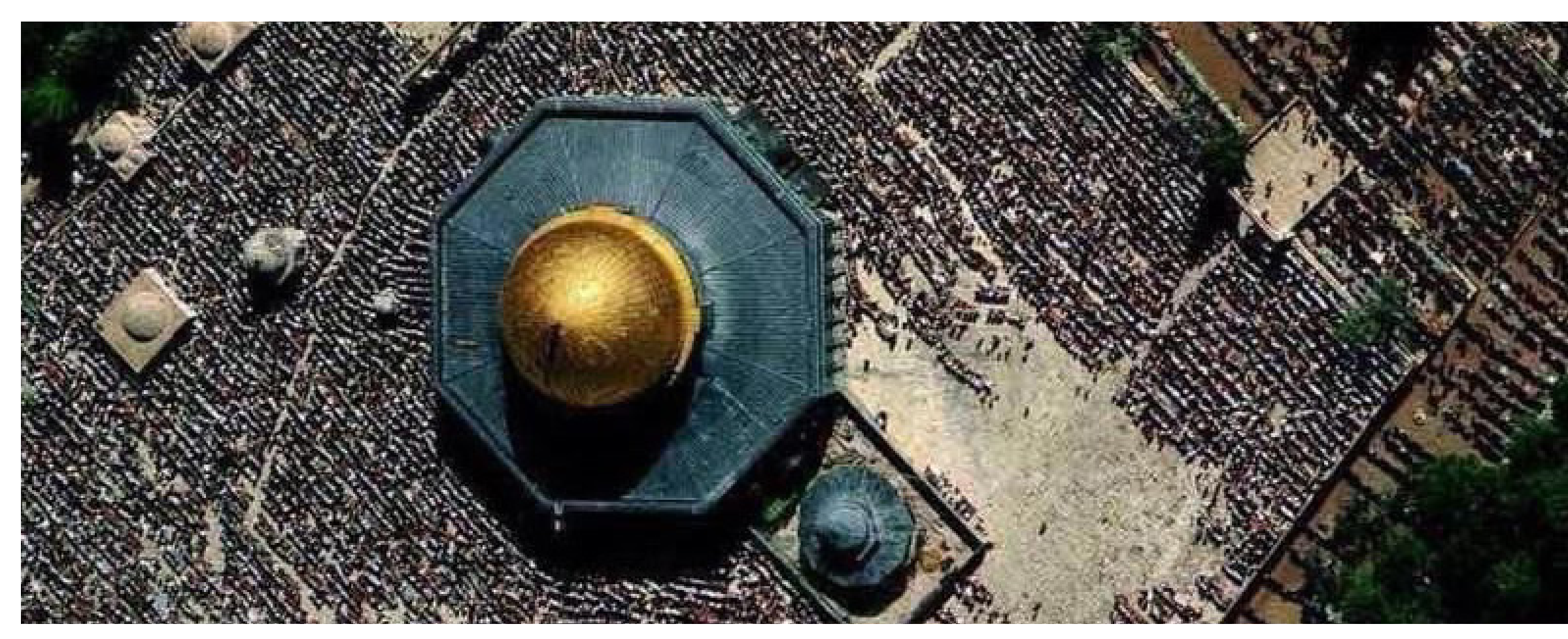

A Tweet using the hashtag Gulf people against normalization. Image: via Twitter

Citing research by Israel's Strategic Affairs Ministry, the Israeli newspaper Haaretz reported that "Ninety Percent of Arabic Social Media Chatter About Israel-Gulf Deals [is] Negative." 137 


\section{BEIRUT EXPLOSION}

On August 4th 2020, an horrific explosion in Beirut, the Lebanese capital, killed over 200 people and injured thousands. It was described as one of the biggest non-nuclear explosions ever recorded, Reuters says. ${ }^{138}$

Footage of the blast and its impact went viral on social media. Meltwater, the media monitoring and social listening platform, reported in November that there had been more than 600000 global social media mentions related to the 'Lebanon explosion. '139

As videos and images of the blast went viral on the internet, so did support from - and for - Lebanon

Through social media, hundreds of Lebanese offered shelter - using the hashtag \#OurHomesAreOpen in Arabic and English - to those who were displaced by the tragic event. ${ }^{140}$

The hashtags \#PrayForLebanon, \#PrayForBeirut, \#BeirutBlast and \#Lebanon were also trending. However, there were concerns that misinformation ${ }^{141}$ around the causes, ${ }^{142}$ impact and support for the country could be seen across social media. ${ }^{143}$

Many local Lebanese expressed their anger through the hashtag \#HangThem in Arabic blaming the government's negligence and corruption for the explosion. ${ }^{144}$

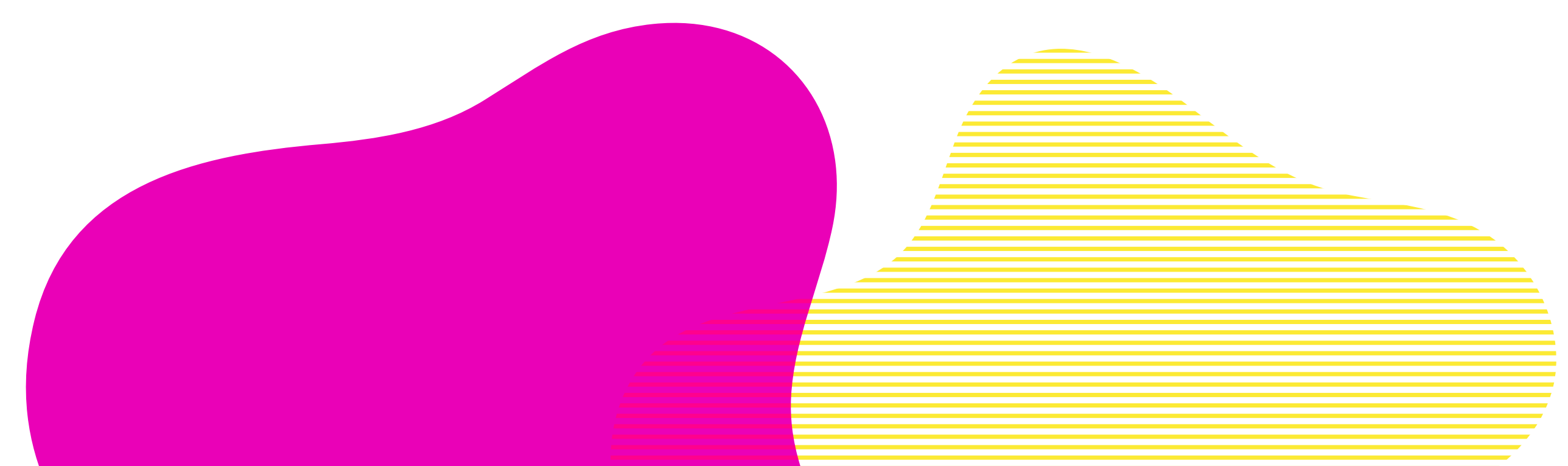

Abir Ghattas

AbirGhattas

Follow @thawramap, they are building a map with all shelters from the posts on the following hashtags

\#Lebanon \#Beirut

\#ourhomesareopen

\#بيوتنا_مفتوحة \#

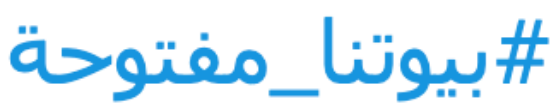

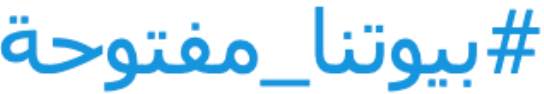

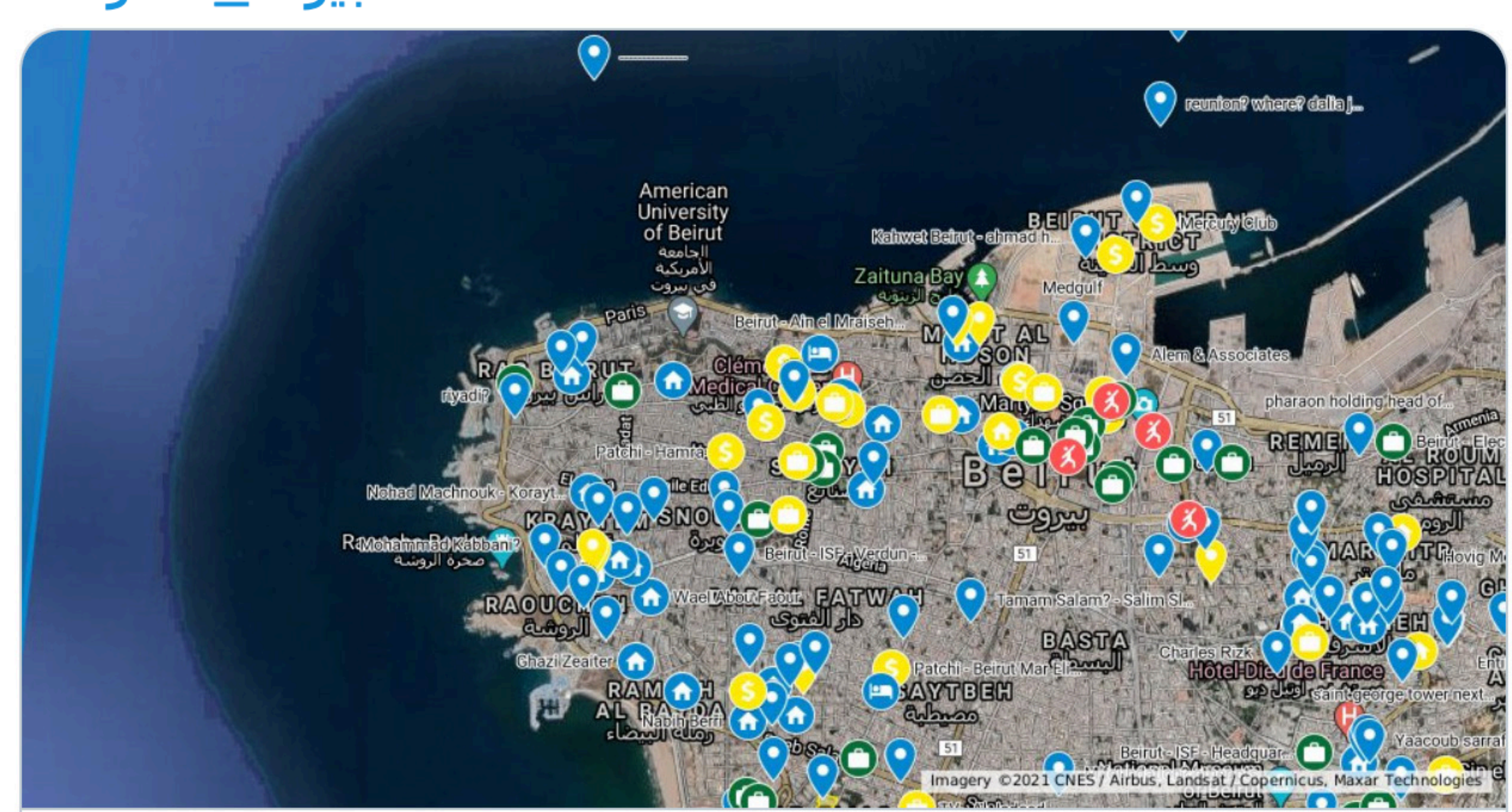

Thawra Map - Google My Maps

Instagram: thawramap

$\mathcal{S}$ google.com

A tweet that shows buildings with shelters. Image: via Twitter 
The growth of the Black Lives Matter Movement, following the killing of George Floyd in May, spread beyond the USA to encompass numerous countries, ${ }^{145}$ including those in the Arab world. ${ }^{140}$

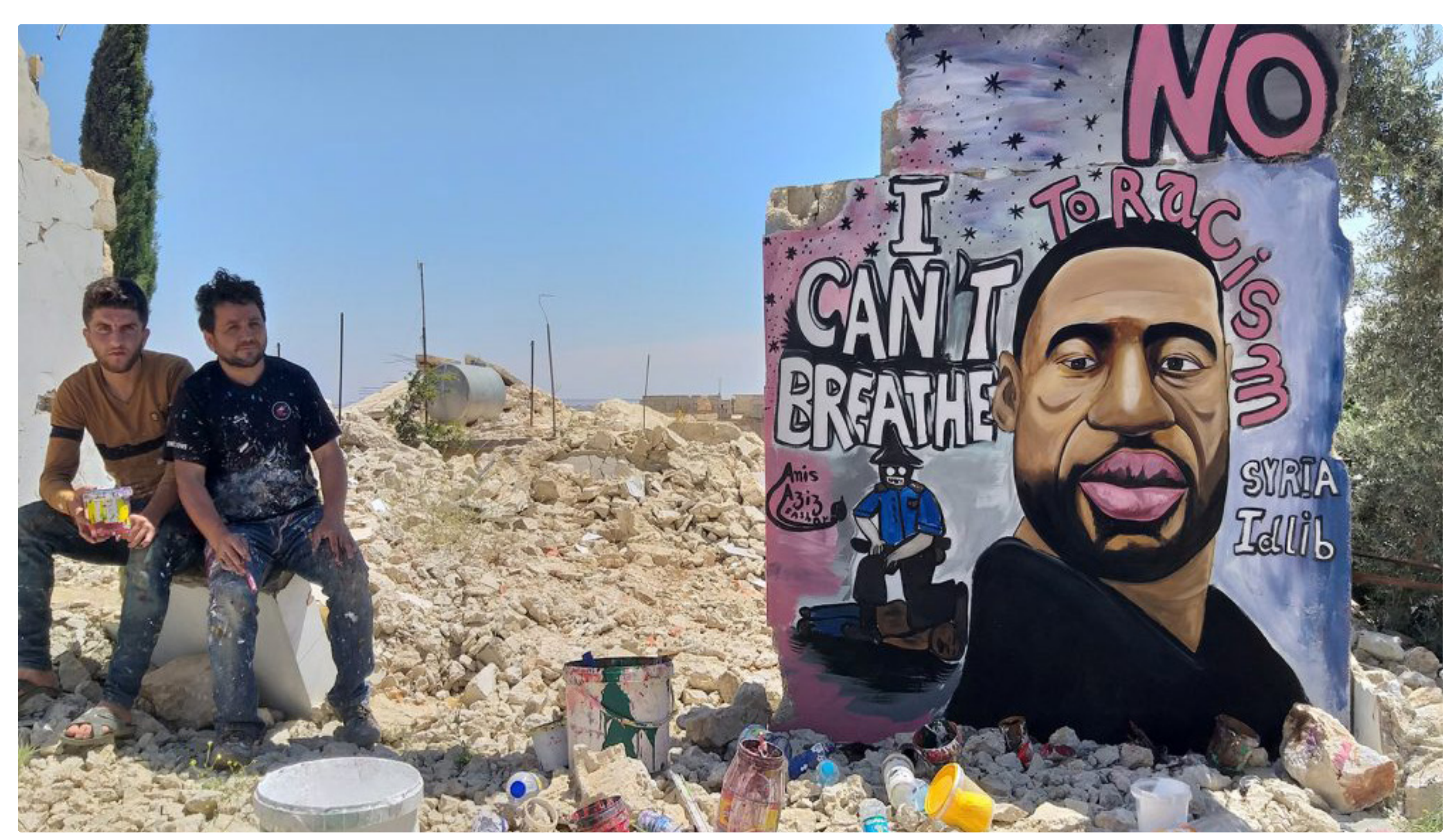

Image: George Floyd in Idlib, Syria by Aziz Asmar via Mohamad Jamalo/Reuters and Atlantic Council

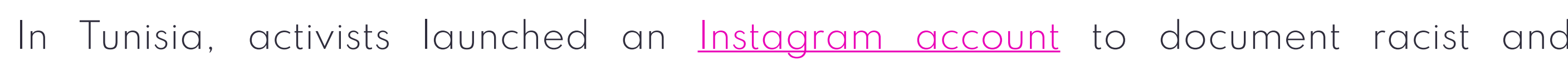
discriminatory acts against black people in the Arab world and to raise awareness

Others, ${ }^{147}$ including the Saudi beauty vlogger Abeer Sinder ${ }^{148}$ and the Palestinian actress and film director Maryam Abu Khaled also shared their experiences. ${ }^{149}$

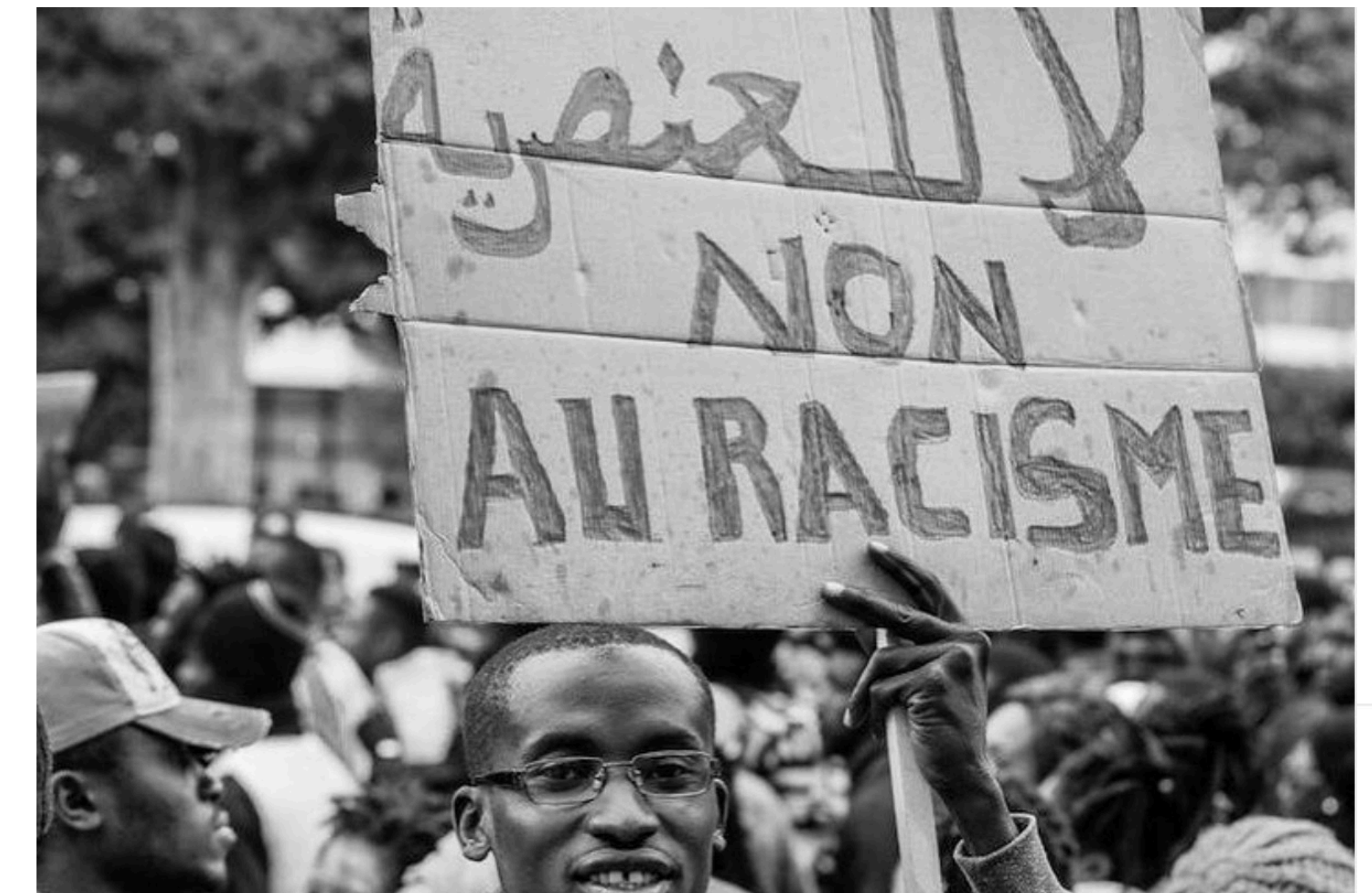

(3) blacklivesmattertunisia

La violence raciste institutionnelle contre les Noirs n'est pas seulement un problème américain, c'est aussi un probleme récurrent en Tunisie et dan

M'nemty et l'ATSM ont lancé une invitation à manifester devant le thêatre heures.

In Tunisia and in North Africa, there is racism's

$\bigcirc \bigcirc \nabla$ ఐ

The hashtags \#BlackLivesMatter in Arabic and English and the hashtag \#BLM were trending during June, resulting in media coverage $^{150}$ across the region $^{151}$ and internationally. ${ }^{152}$
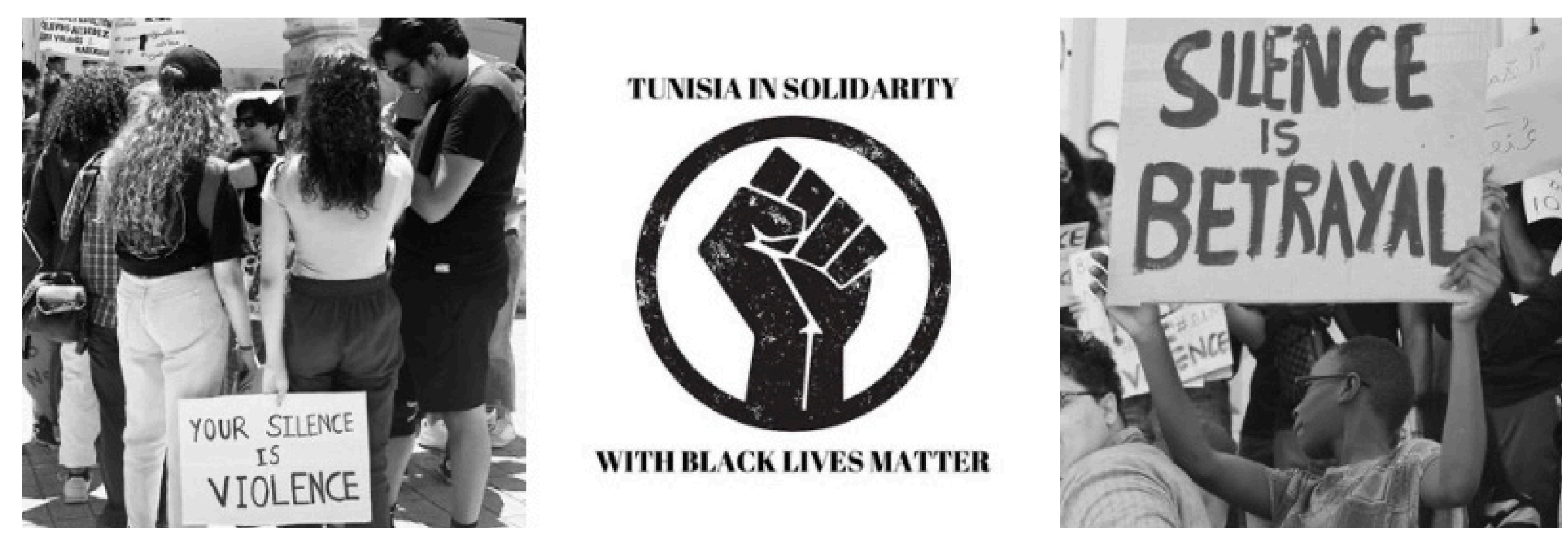

Images: Screenshot of Black Lives Matter Tunisia, via Instagram 


\section{FAKE NEWS \& MISINFORMATION}




\section{FAKE NEWS MISINFORMATION}

False and misleading information continued to spread online in the Middle East last year, just as it did around the rest of the world. From fake accounts that were agenda driven, to misinformation about COVID-19, the world of social media was bombarded with misinformation.

Responses to this challenge varied. In some cases, social media platforms traced and deactivated online accounts. Elsewhere governments continued to take steps to the source of those news, by introducing new "fake news" laws and prosecuting those accused of being purveyors of false information

\section{BLOCKS BY PLATFORMS}

Twitter suspended 16 accounts after an investigation by The Daily Beast found that 46 different publications had "published Middle East hot takes from "experts" who are actually fake personas pushing propaganda." 153

Those accounts were used by fake personas who acted as Middle East experts and wrote opinion pieces for several U.S, right-wing news outlets and some Middle-East websites like Al-Arabiya, Arab News, and The Jerusalem Post. ${ }^{154}$
"The personas in the network used a mixture of stolen or Al-generated avatars and fake biographies to make them seem more plausible," The Daily Beast explained.

"It's not just fake news we need to be wary of, but fake journalists," said Marc Owen Jones, an assistant professor at Hamad Bin Khalifa University in Qatar.

Marc Owen Jones @marcowenjones. Jul 7, 2020

For my Middle East followers, some of the outlets to have published opeds by fake journalists include @AlArabiya_Eng @arabnews and @JPostOpinion I don't expect the Arab News and Al Arabiyya ones be taken down.

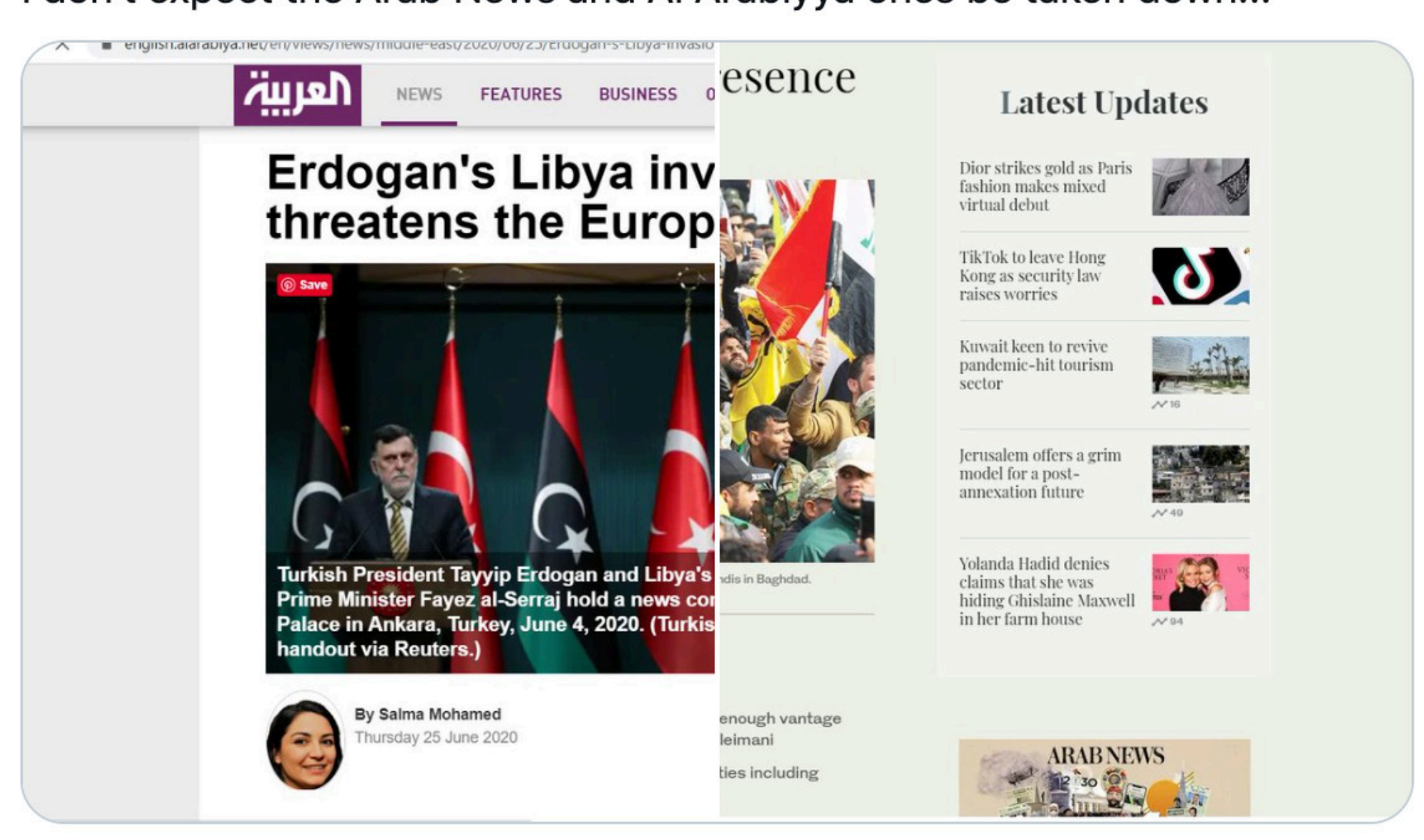

Image via Twitter 
Twitter removed 130 accounts linked to Iran claiming they were attempting to "disrupt the public conversation" during the first U.S. presidential debate. ${ }^{155}$

2

Twitter Safety @ @ TwitterSafety. Sep 30, 2020

Based on intel provided by the @FBl, last night we removed approximately 130 accounts that appeared to originate in Iran. They were attempting to disrupt the public conversation during the first 2020 US Presidential
$\checkmark 1 \mathrm{~K}$
〔】 $5 \mathrm{~K}$
○ $13.5 \mathrm{~K}$
个

\section{(1) Titter Safety
@TwitterSafety}

Replying to @TwitterSafety

We identified these accounts quickly, removed them from Twitter, and shared full details with our peers, as standard. They had very low engagement and did not make an impact on the public conversation. Our capacity and speed continue to grow, and we'll remain vigilant.

Samples $r$

\section{Emily will vote for Trump
@emilysherifft}

ıd boys stand down!

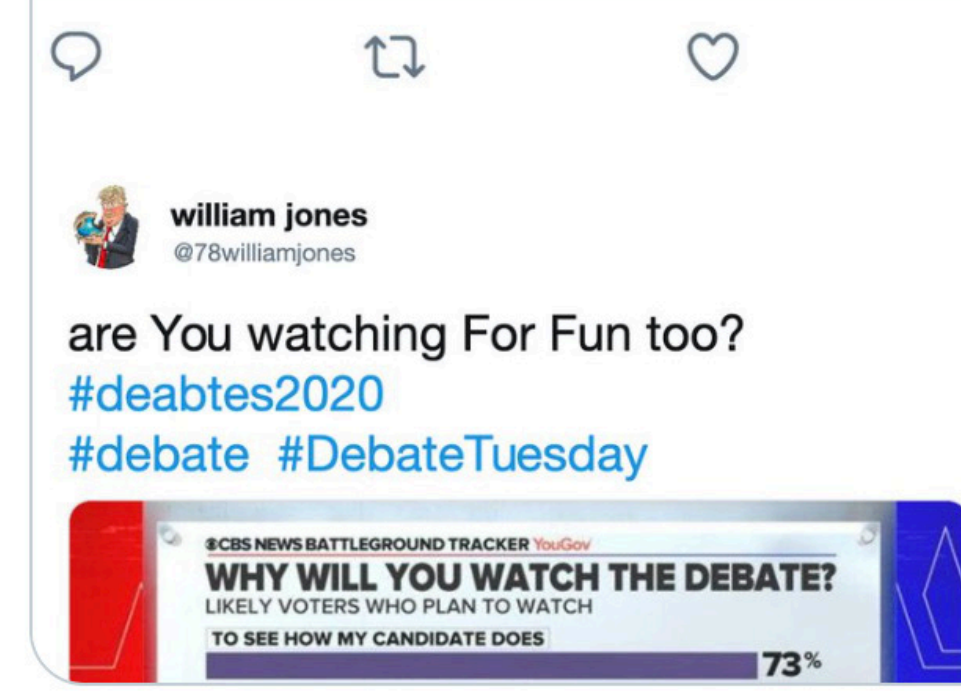

\section{Olivia Brown}

is Chris Wallace non partisan?

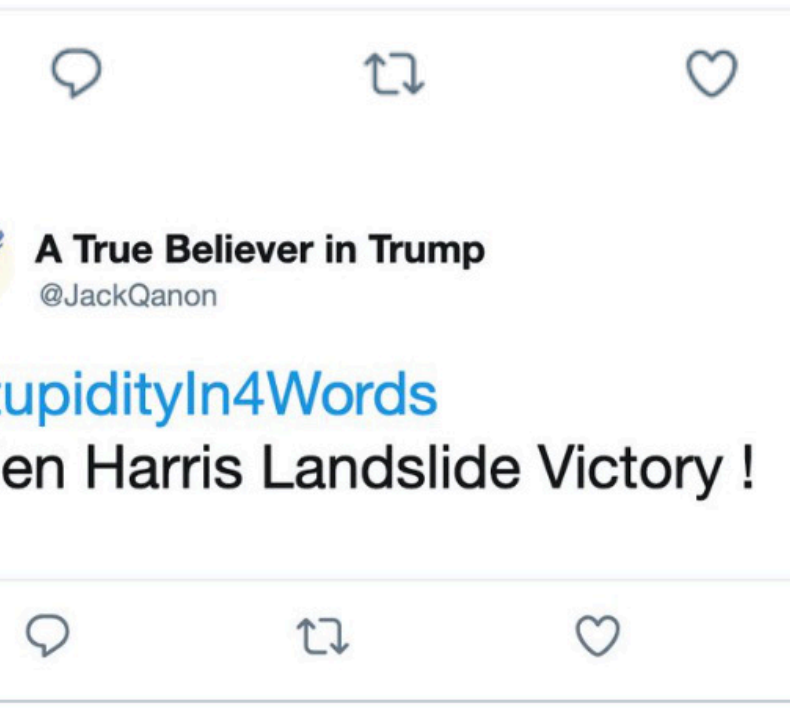

Facebook removed two networks of fake accounts with over 6 million followers linked to two digital marketing companies in Egypt and India. As Reuters explained in March, these networks "were pushing dueling narratives about countries in the Gulf on the Facebook and Instagram platforms. "the Middle East. ${ }^{156}$

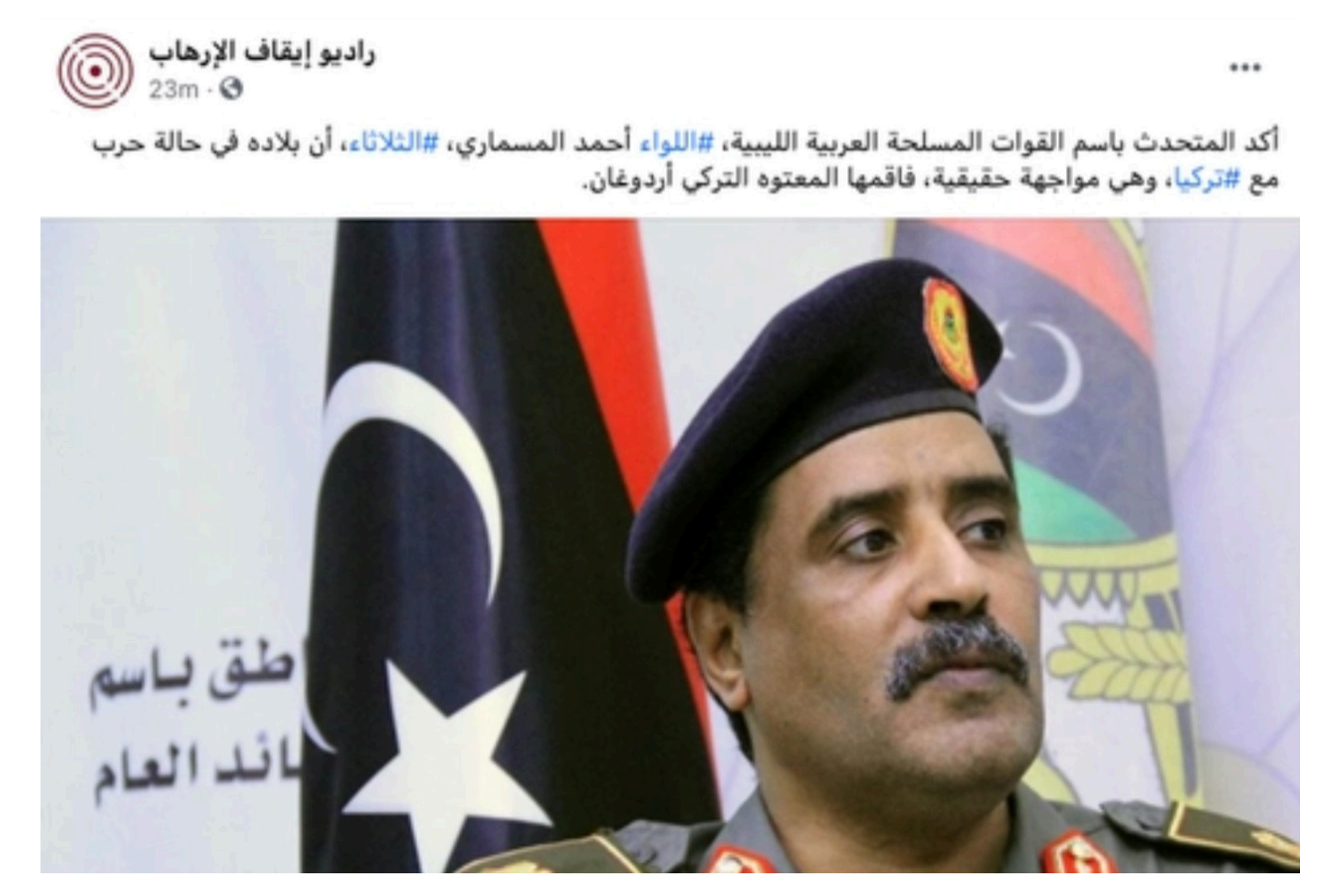

Example of a post removed by Facebook, saying that "the spokesman for the Libyan Arab Armed Forces, Major General Ahmed Al-Mismari, confirmed Tuesday that his country is at war with Turkey, and that it is a real showdown exacerbated by the

Turkish fool, Erdogan.

Later in the year, Facebook removed accounts operated from Egypt, Morocco and Turkey linked to the Muslim Brotherhood, and which the social network said included some 'terrorism-related content.' ${ }^{157}$

And in December, the company removed a series of accounts which were part of a widespread Russian disinformation campaign, targeting a number of regions including the Middle East. 158

Focused primarily on Libya, Sudan and Syria, "these accounts posed as locals based in the countries they targeted, "the company said. ${ }^{159}$ In response, the network removed 211 Facebook accounts, 126 Page, 16 Groups and 17 Instagram accounts for coordinated inauthentic behavior. 


\section{GOVERNMENT-LED DEVELOPMENTS}

The Algerian government passed a law criminalizing the broadcast of fake news deemed to harm state security and undermine national unity. ${ }^{160}$ In April, they also passed a second bill that penalizes discrimination and hate speech. Critics argued the bill could be used as a tool for censorship and to intimidate journalists and social media users, ${ }^{161}$ limiting freedom of speech. ${ }^{162}$

"More and more journalists have found themselves the targets of exceptionally violent social media hate campaigns because of comments that caused annoyance, Reporters Without Borders commented. ${ }^{163}$ AFP reported the further tightening of online laws in December. 164

During the summer, the Iraqi Defense Ministry ordered the suspension of all social media accounts that belong to security forces in order to control direct news through official channels and block the spread of false information. Fadel Abu Raghef, an Iraqi analyst and security expert, told The Media Line that the social media pages of some officers had been hacked and used to spread fake news. 165

Turkey passed a law that regulates social media content by extending control over platforms like Facebook and Twitter in the country. 166 Through this new law, socia media platforms with over one million daily users have to open offices in Turkey or face stiff penalties.

These local offices must obey the orders of the Turkish government and are required to remove any content the government deems offensive within 48 hours. Numerous activists and rights groups considered this a threat to freedom of expression in the country. ${ }^{167}$
14.

RSF_Afrique-du-Nord @RSF_NordAfrique.Apr 23, 2020 épidémie de \#covid_19, une poignée de députés ont voté un projet de réforme du code pénal "criminalisant" la diffusion de « fake news » qui portent "atteinte à l'ordre public et à la sûreté de l'Etat" $1 / 2$
Q 1
饣】 11
○ 11
个

RSF_Afrique-du-Nord @RSF_NordAfrique · Apr 23, 2020

HAlgérie : 3 ans de prison, voire 5 en « période de confinement sanitaire », c'est la peine prévue pour quiconque diffusera ou propagera ces "fausses informations". @Rsf_inter dénonce un projet de loi flou et liberticide, futur outil de censure et d'intimidation de la presse 2/2
Q 3
七】 7
○ 6
个

Image: Tweets from Reporters Without Borders (RSF) for North Africa denouncing the law as a future tool for the "censorship and intimidation of the press. "via Twitter

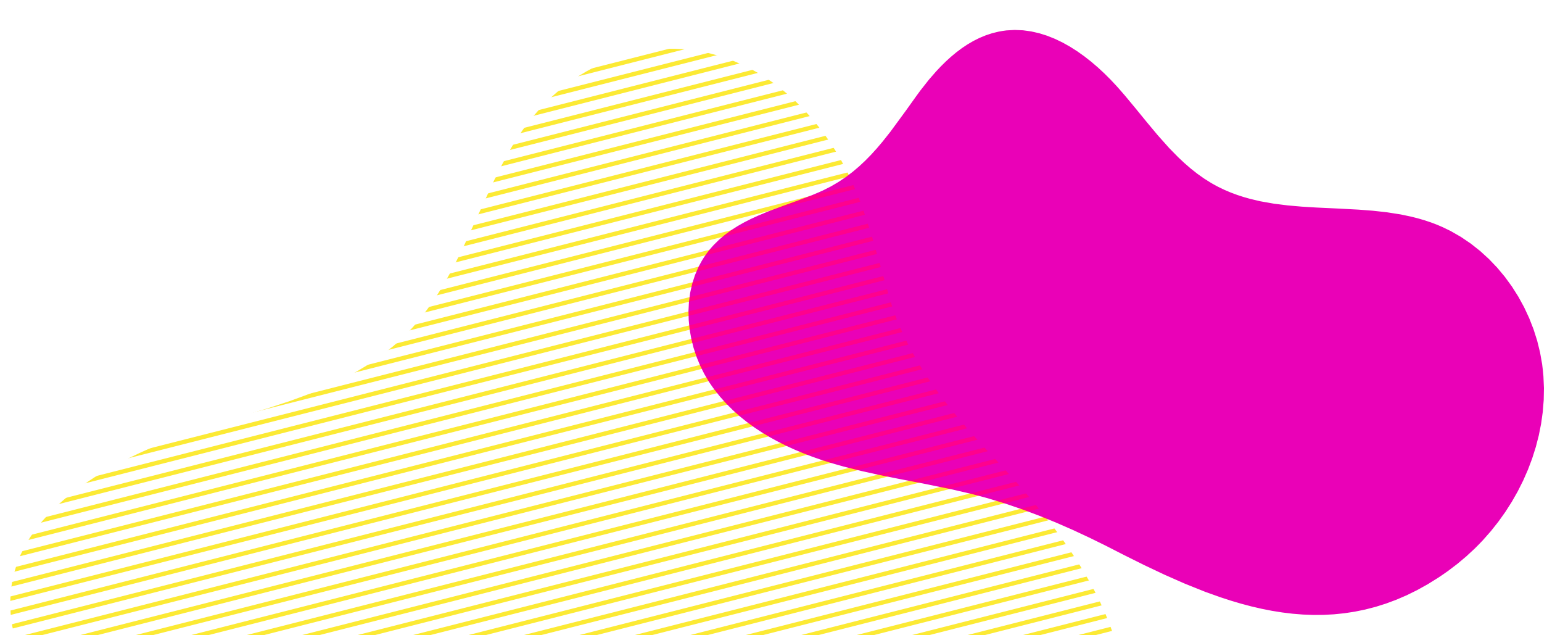

HOW THE MIDDLE EAST USED SOCIAL MEDIA IN 2020 
In Iraq, the Kata'ib Hezbollah group, which is listed as a terrorist organization by Japan and the U.S., is paying large sums of money to Facebook to boost fake accounts and pages, the UK newspaper The Telegraph reported. ${ }^{168}$ According to those reports, there are around 400 individuals working on the group's propaganda team. ${ }^{16}$

Hezbollah has trained thousands of Iran-backed social media activists, helping create so-called "electronic armies" across the region, a further article in The Telegraph said. ${ }^{170}$

Journalismfund.eu summarized the article, noting that "Hezbollah has been flying individuals into Lebanon for courses teaching participants how to digitally manipulate photographs, manage large numbers of fake social media accounts, make videos, avoid Facebook's censorship, and effectively spread disinformation online." ${ }^{171}$

United States prosecutors seized 92 domains that they claimed were used by Iran's Revolutionary Guards Corps (IRGC) to spread political disinformation around the world. ${ }^{772}$ "Prosecutors said the most recent takedown was the result of a joint investigation by the FBI and social media companies Google, Facebook and Twitter," Reuters reported.

\section{THIS WEBSITE HAS BEEN SEIZED}

This domain has been seized by the Federal Bureau of Investigation pursuant to a seizure warrant issued by the United States District Court for the Northern District of California under the authority of 18 U.S.C. $\$ 981(b)$ as part of coordinated law enforcement action by:
(astrict Court for the Northern Distict of Calfornia under the

The United States Attorney's Office for the Northern District of California

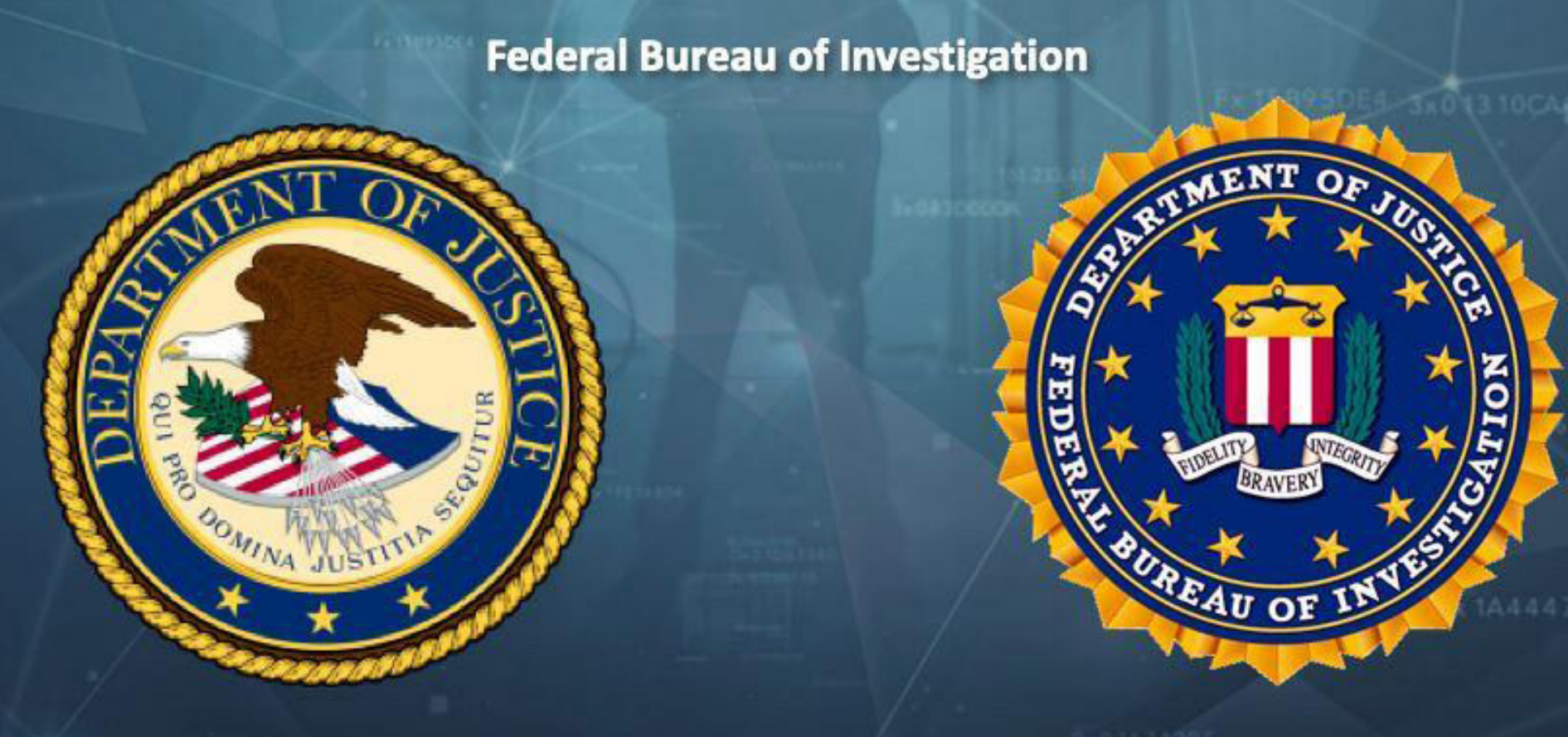

For additional information, see https://www.justice.gov 
During the pandemic, many Arab speakers fell prey to false or inaccurate information related to COVID-19. One potential reason for this is predominance of virus related news and information in English, resulting in a lack of credible Arabic-language outlets that provided information on COVID-19, its symptoms, and many other related topics.

As part of their COVID-19 response, Facebook teamed up with the Jordanian-based firm Fatabayyano, to provide Arabic language support for their third-party factchecking network. ${ }^{173}$ The network covers more than 40 languages, and features over 50 partners, around the world.

In November they launched the \#ThinkBeforeYouShare campaign, a move which includes an interactive website, designed to educate people on how to detect false news. ${ }^{174}$

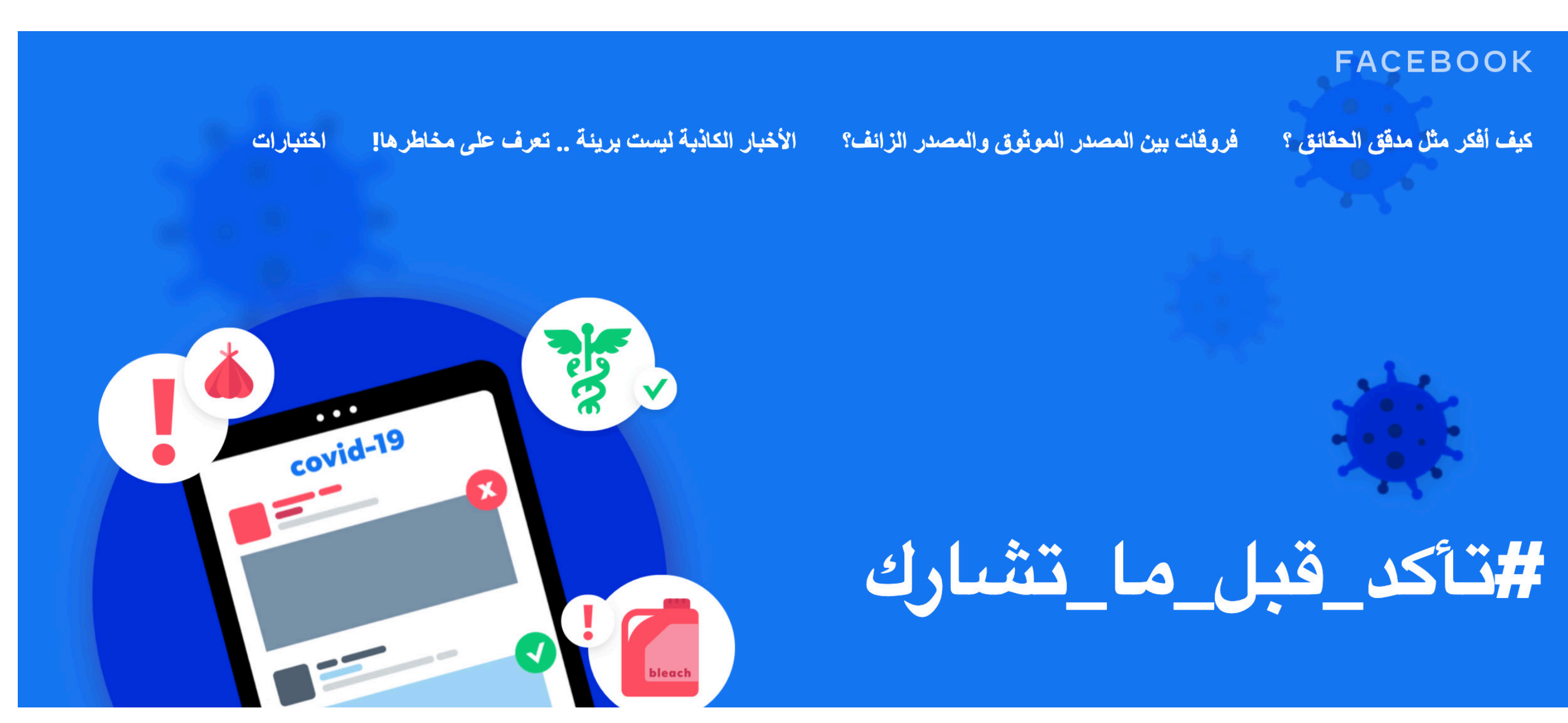

Image: Screenshot of the \#ThinkBefore YouShare website

DXwand, an Egyptian startup that provides conversational artificial intelligence (AI) solutions for over 200 businesses in the region, has also deployed this technology to help combat the spread of inaccurate information regarding COVID-19. 175

Ask Nameesa allows users to ask a question through Facebook Messenger or WhatsApp. After a few minutes, they receive a response - based on information from both local health authorities and the WHO - stored in their database, in Egyptian slang, Arabic or English.

(0): DXwand

\#COVID19, We have gathered a host of official credible information \& launched "Nameesa", a free Al service trained with the available \#coronavirus knowledge and answers your questions.

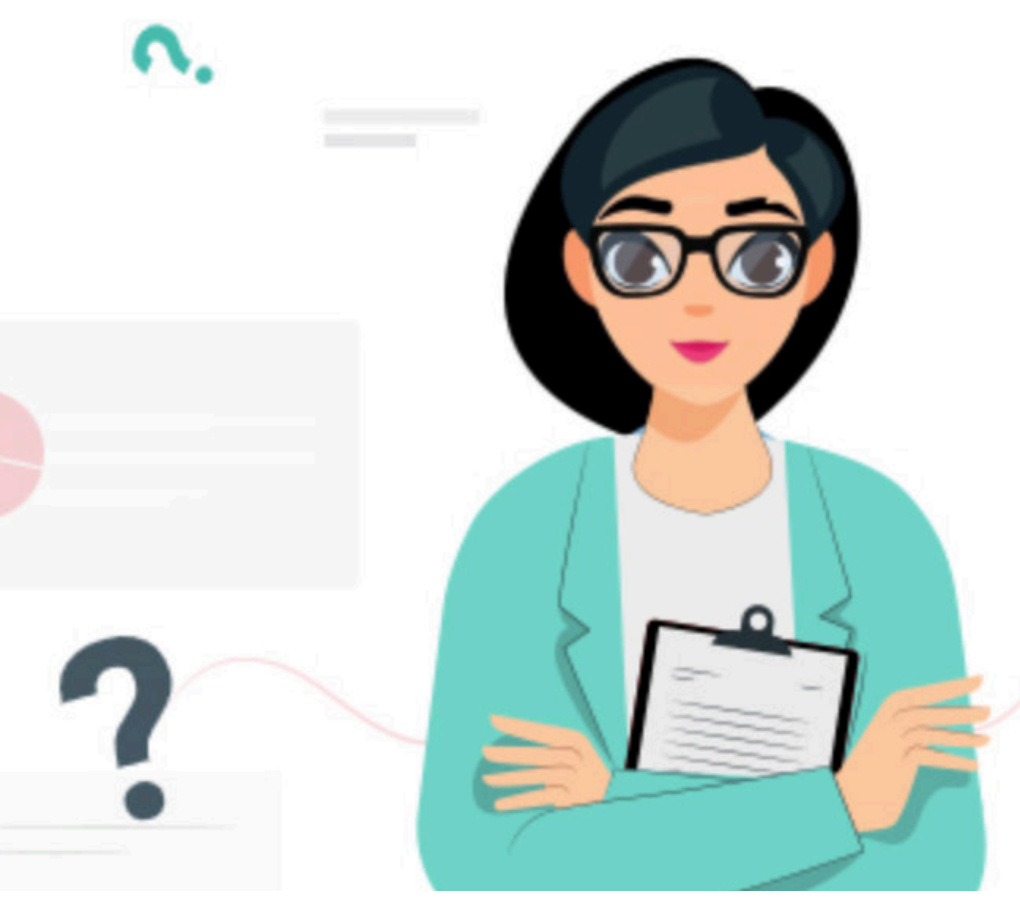

\section{Ask Nameesa اسأل نميسة$$
\text { Powered by }
$$$$
\text { Dkwand }
$$

Image: Tweet promoting the service, via Twitter 
COVID - 19

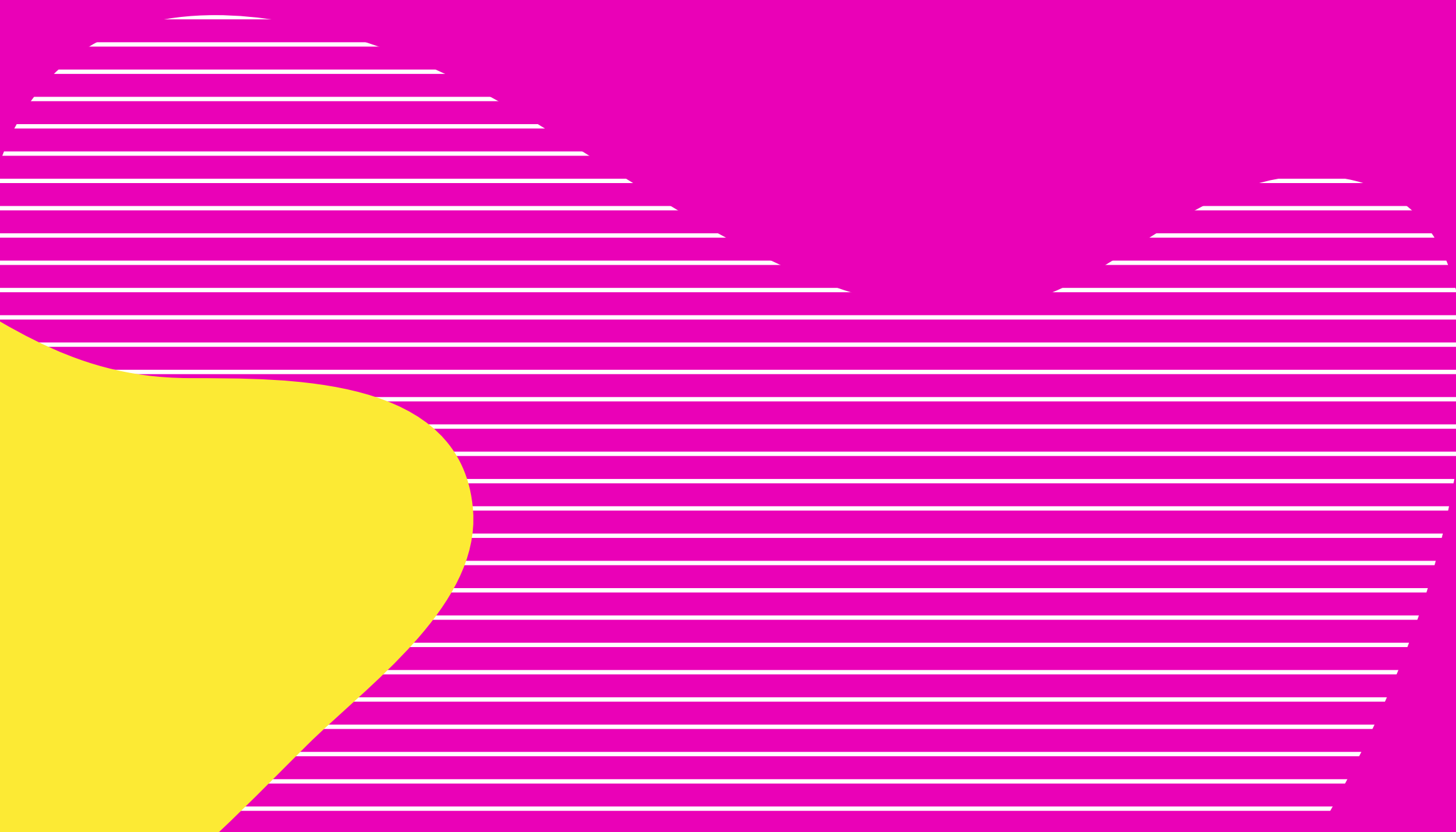




\section{COVID - 19}

The spread of the novel coronavirus dominated the news the past year. But it also unleashed an "infodemic" as incorrect, misleading or unverified information also circulated widely.

Social media played a big role in the spread of misinformation about coronavirus. In MENA, as elsewhere, social networks proved to be fertile ground for misinformation and disinformation about the virus.
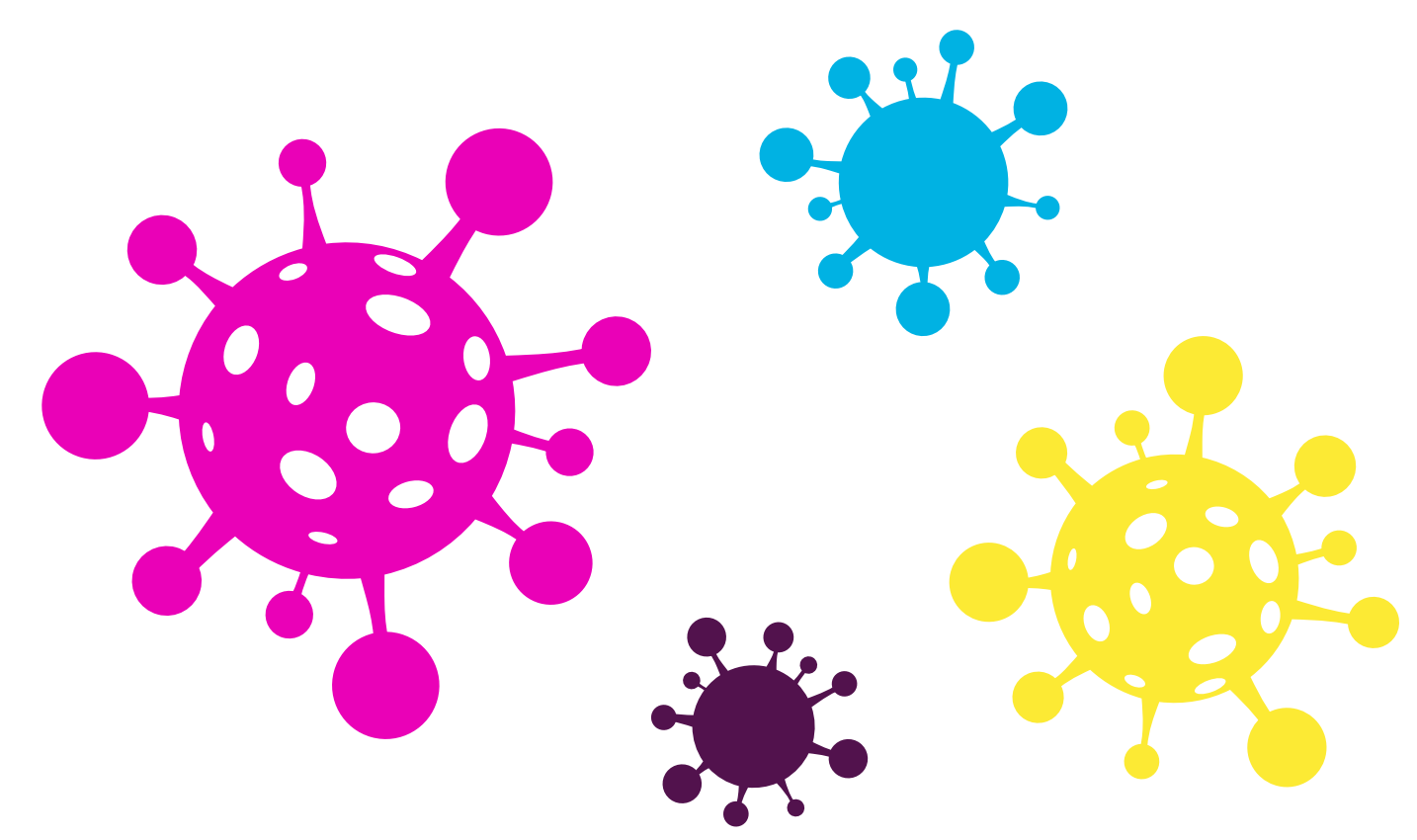

WhatsApp imposed a limit on shared messages to halt the spread of coronavirus misinformation. ${ }^{176}$ As a result, the app has seen 70\% drop in the number of vira forwarded messages. The app is also working with trustworthy sources like the WHO to create credible information sources for its users.

Due to the popularity of the app, multiple governments and other agencies embraced WhatsApp as a key platform for distributing public health messages.
In Sudan, the UNDP, UNICEF and WHO set up COVID-19 WhatsApp alerts in Arabic and English. These alerts offered "advice on staying safe, frequently asked questions, tips for protecting yourself and others, the latest news and case numbers - and easy messages to "forward" and share." 177

In Jordan, engagement by UNICEF during the early stages of the pandemic regularly reached 8,000 primary users and a secondary audience of 3.5 million people. The platform also reached over 2,000 people at the Al Hol and Areesha camps in Syria. ${ }^{178}$

\section{لديك أسئلة حول كوفيد-19؟ نحن لدينا الإجابات}

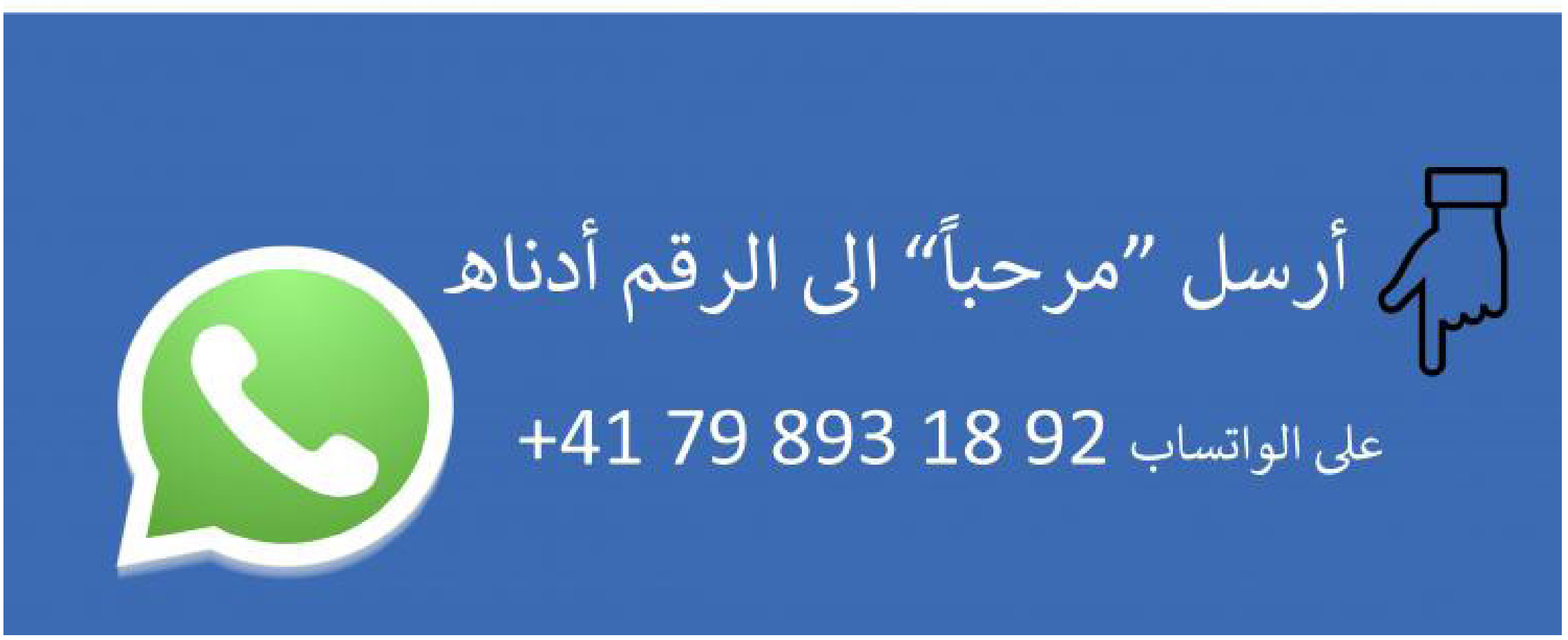

Image: via UNICEF 
The Saudi Ministry of Health launched a coronavirus awareness campaign in collaboration with Snapchat and Trend, a leading digital content creator. ${ }^{179}$ The campaign lasted around two months, and received over 15 million views on Snapchat from 12 million users. On Twitter, the campaign's videos enjoyed 4 million views and around 2,000 interactions.
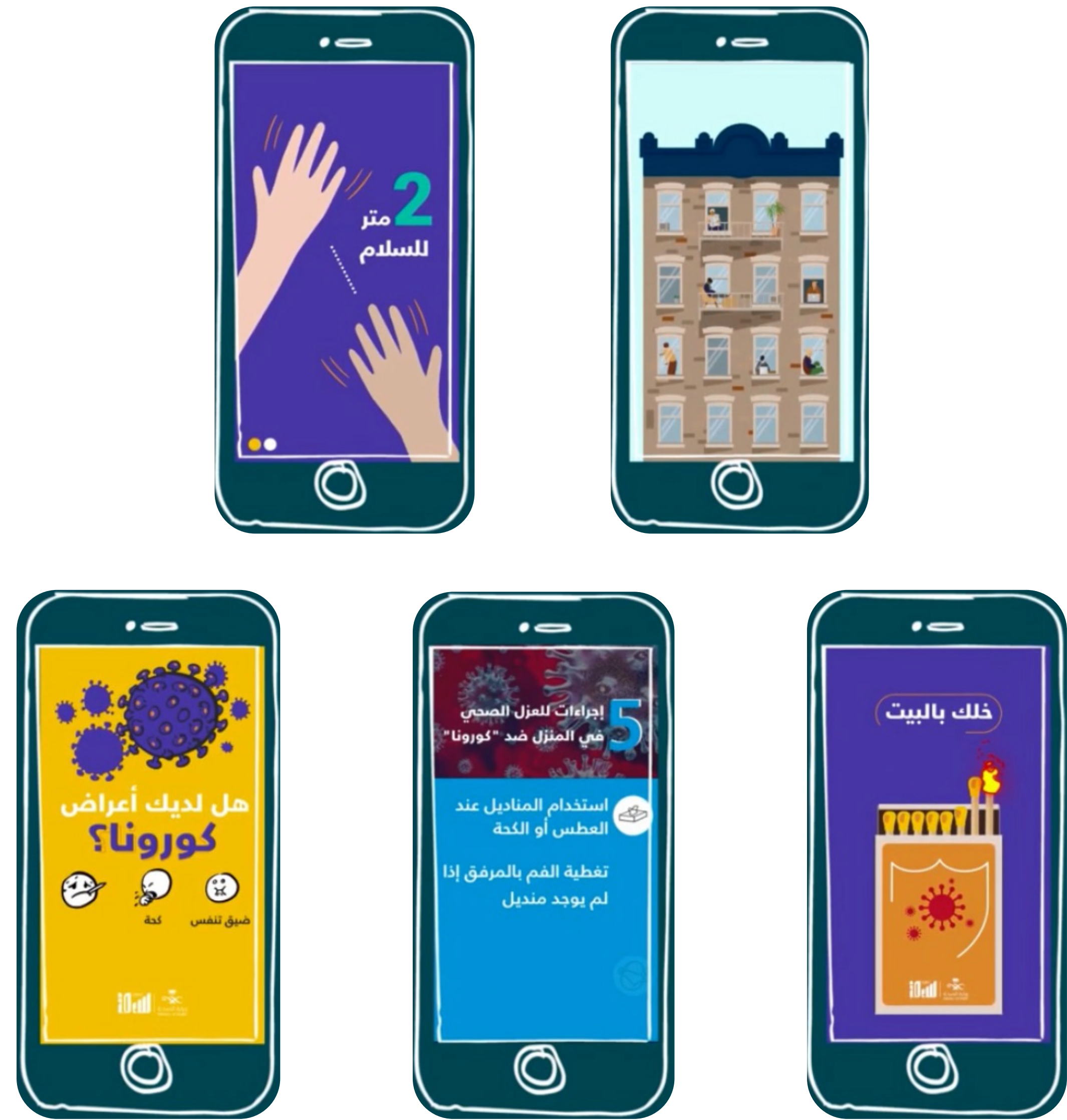

Images of messages delivered through the campaign: via Campaign Middle East
In Jordan, the Ministry of Culture enlisted a number of Jordanian actors and influencers for an awareness campaign video, titled Our Life is More Important, in which they showcased tips to combat the coronavirus, and how children quarantined at home could use their spare time. 180

The Ministry, like others around the region, also took advantage of the opportunity to share materials produced by organizations like the WHO and UNICEF, a move which the platforms encouraged through partnerships and the creation of sharable materials.

هolaAlfares · Dec 16, 2020

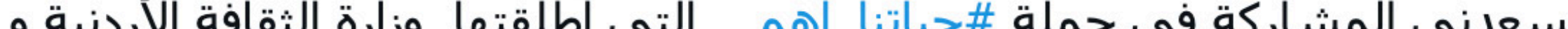

اليونيسف للتوعية بمخاطِ في فايروس كورونا ل... @UNICEFJordan @UNICEFinArabic @UNICEF @jo_culture

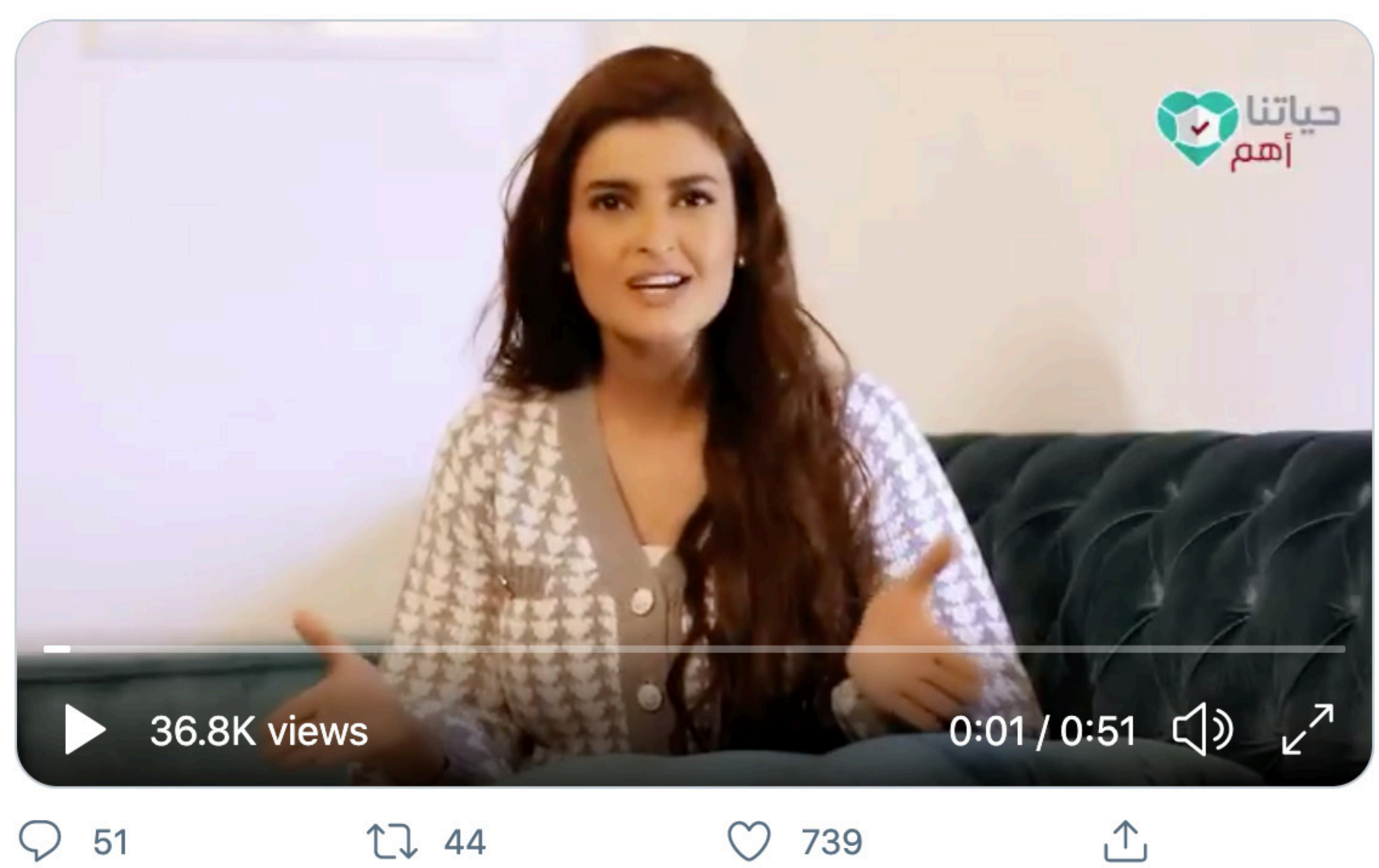

The Jordanian TV presenter and influencer Ola Al-Fares' tweeting about her participation in the campaign. Screenshot via Twitter

HOW THE MIDDLE EAST USED SOCIAL MEDIA IN 2020 


\section{3}

Citizen journalists in Syria collaborated with Truepic, a photo and video verification platform, in an effort to fight misinformation, disinformation, and fake news coming out of Syria, as well as exposing Western audiences to conditions of civilians living in conflict zones during the pandemic. ${ }^{181}$

This initiative through The Soufan Center, a non-partisan strategy center dedicated to increasing awareness of global security, gives citizen journalists the opportunity to report on the ground and capture images and videos using Truepic's software.

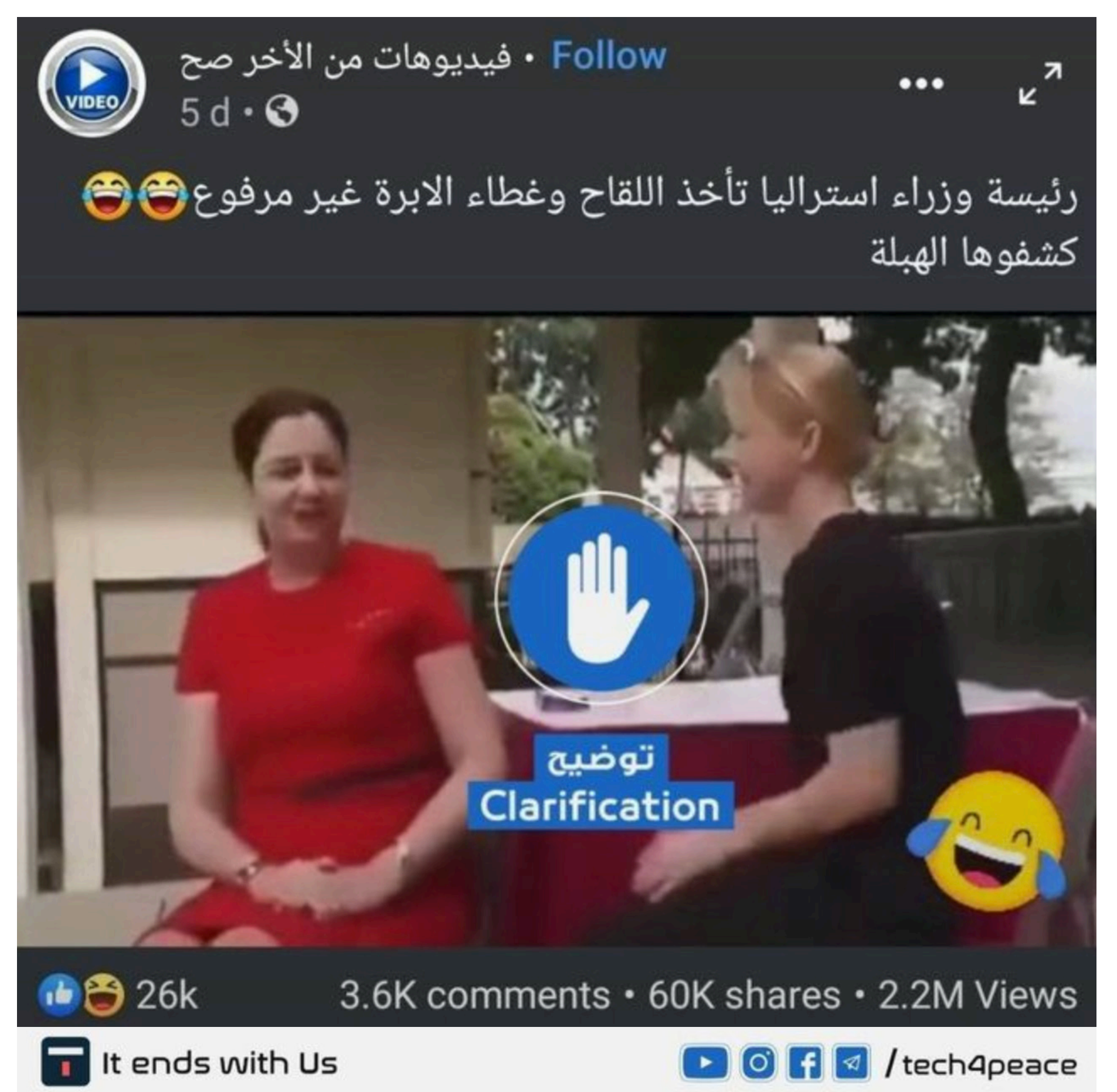

Image: Screenshot of debunking of a video claiming "The Australian prime minister is taking the vaccine and the needle cap is not removed" by Tech 4 Peace
Other civil society organizations have also been involved in COVID-19 related work. In Palestine, the Mada Center launched an online awareness campaign, guiding the public to credible information sources, while in Lebanon the Maharat Foundation's fact-o-meter tackled COVID rumours as did Tech 4 Peace in Iraq
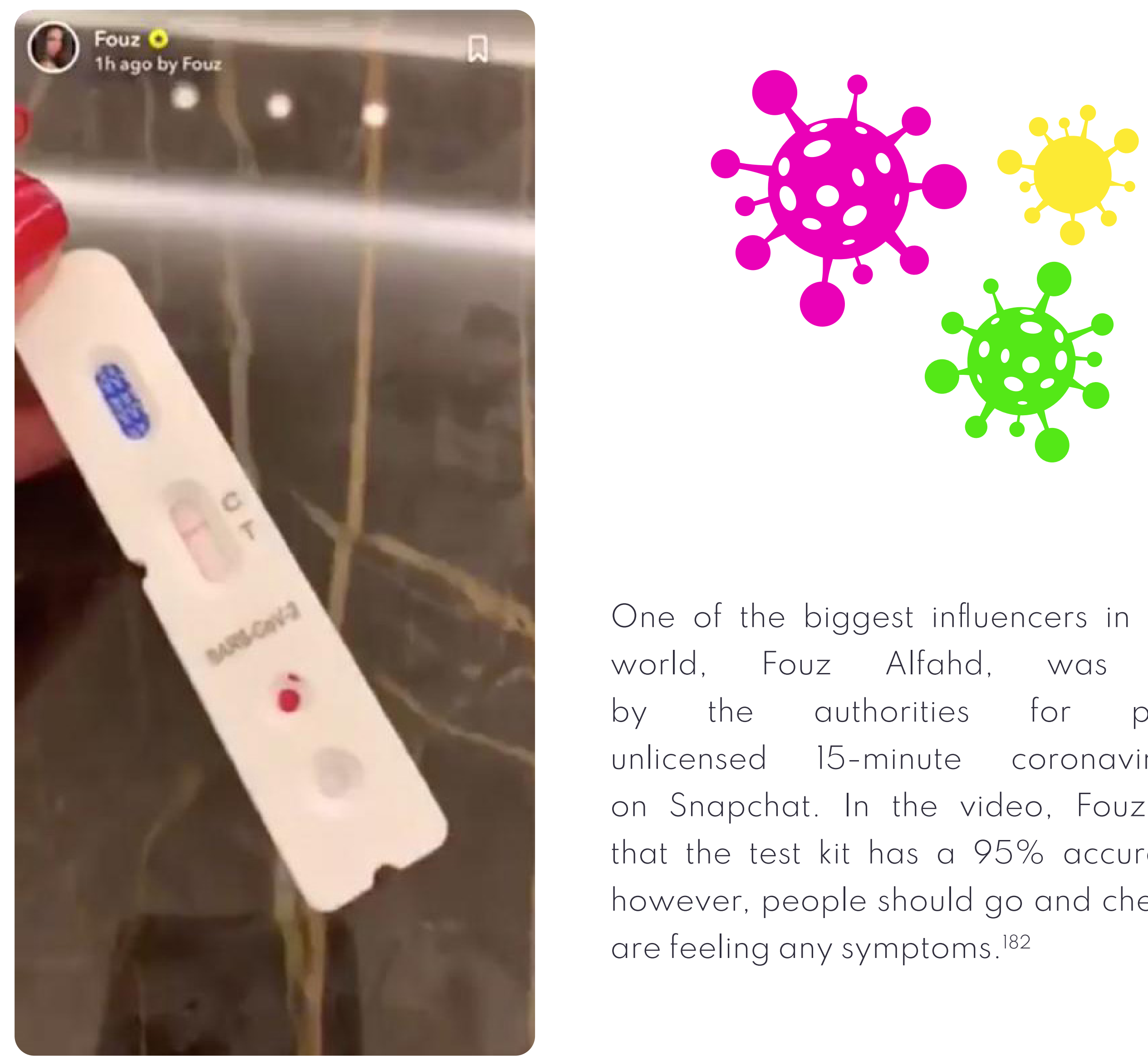

One of the biggest influencers in the Arab world, Fouz Alfahd, was arrested by the authorities for promoting unlicensed 15-minute coronavirus test on Snapchat. In the video, Fouz claimed that the test kit has a 95\% accuracy rate, however, people should go and check if they are feeling any symptoms. ${ }^{182}$

Image: Screenshot of the testing kit promoted by Alfahd on Snapchat 
Thank you to everyone who has been so concerned about my stay on the given me a new perspective and I apologize if $\mid$ sent the wrong messa wrong message before.

Things are different from what they were before. My 1st month here was a "honeymoon period", and the island fe very much sealed from COVID-19 due to restricted traffic.

But, times change. Currently, many Yemen, ben with somed in mainland the island, not all of it properly

quarantined (as it seems), locals have concerns. People (not tourists) have continued to arrive on Socotra.

$\bigcirc \bigcirc \nabla$

21,191 likes

MAY 19, 2020

(-) Add a comment...

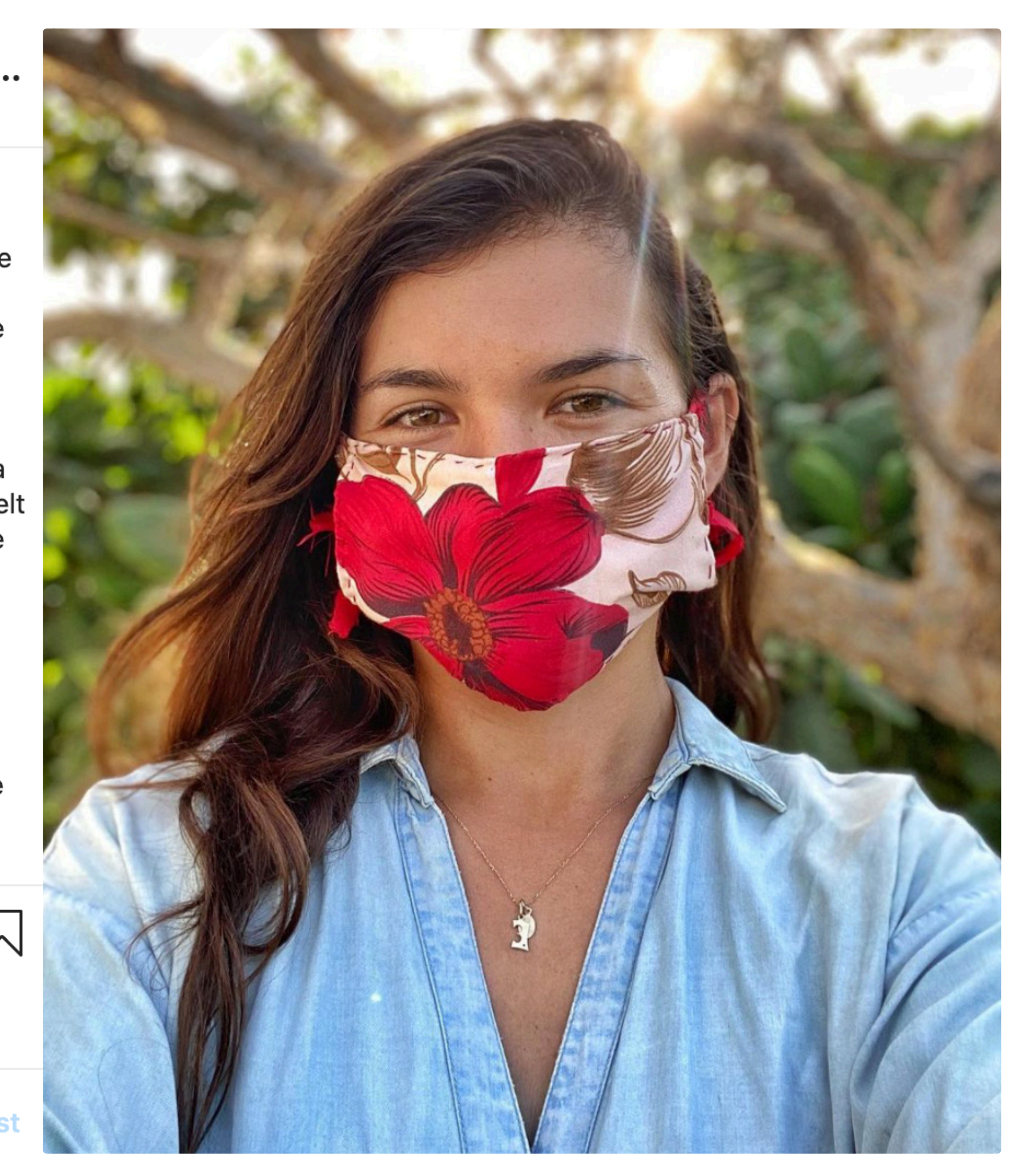

Screenshot: via Instagram
Arabian Business asked "Has Covid-19 killed off influencers?" noting how you could be "one selfie away from disaster." 185 Lockdowns and reduced marketing budgets have all impacted the influencer industry, with brands wary of being associated with proponents of misinformation. There's also a wider existential question: "Are social media users remotely interested in what influencers have to offer in such times?" wondered StepFeed. 186

To encourage people in MENA to wear masks, UNICEF also launched a campaign featuring children and influencers to encourage correct usage and disposal 187 The NGO worked with multiple platforms, including TikTok, on the \#MaskUp Campaign. 188

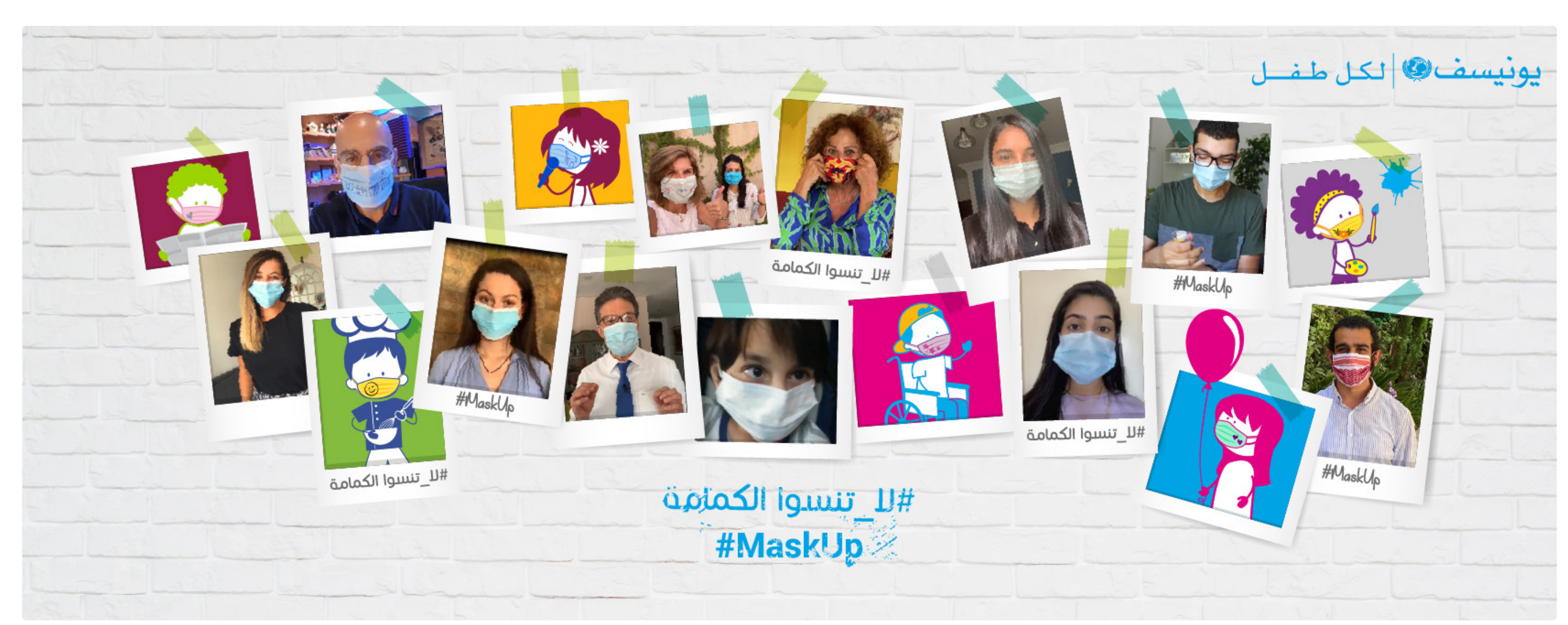

Image: UNICEF's \#MaskUp campaign via UNICEF

Polish YouTuber, Eva Zu Beck, who has over 800k followers on the video network, was criticized on social media for self-isolating in the Yemeni island, Socotra.

Critics used the hashtag \#Respect Socotra to argue that her presence on the island - and the tone of her social media posts - sounded like she was inviting people to visit the island, potentially endangering its residents. ${ }^{183}$ In an Instagram post, to her half a million followers, Zu Beck said that her intention was never to encourage active travelling, but to share its beauty. ${ }^{184}$ 

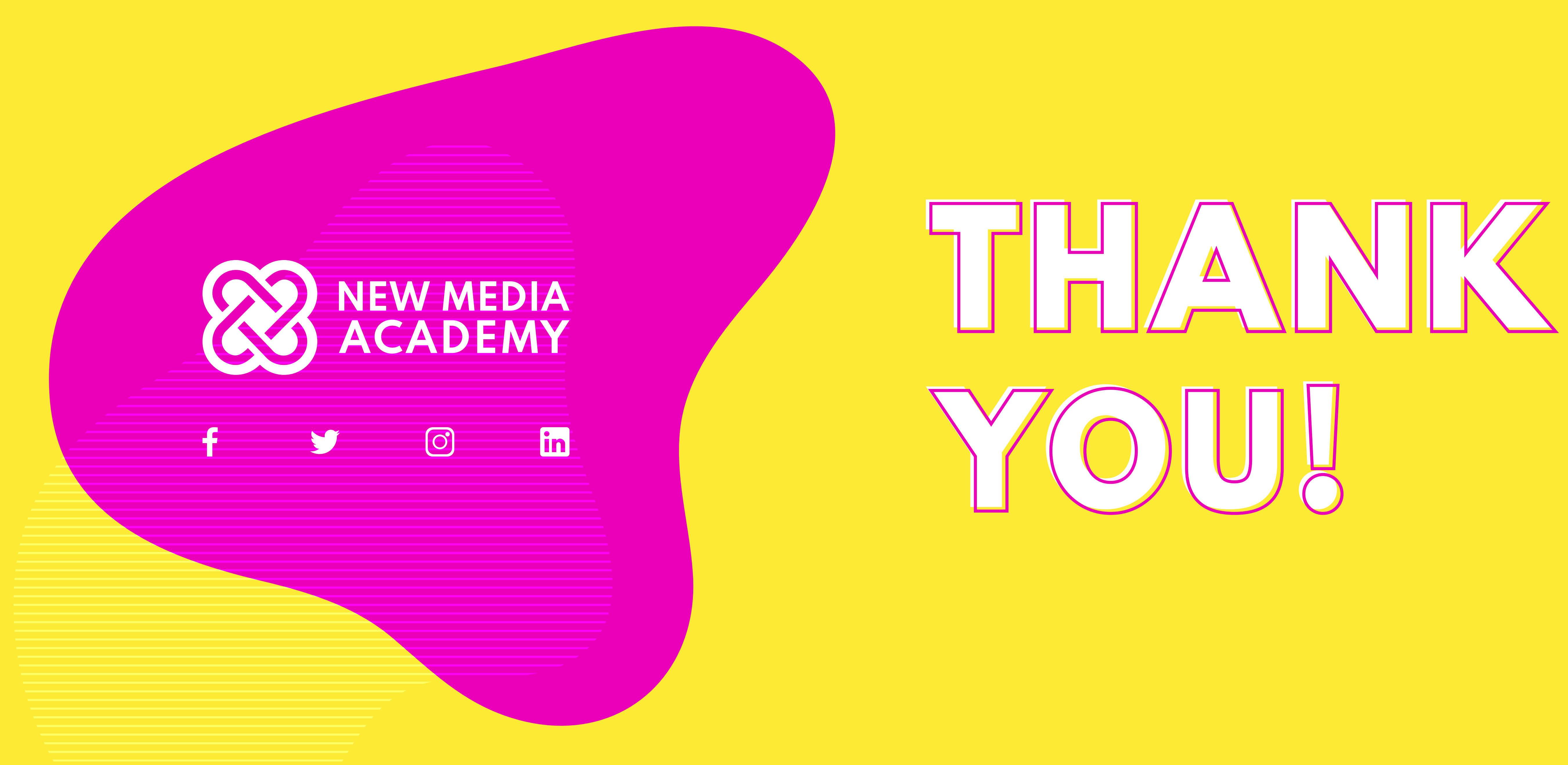
Y०U: 
2019) Social Media in the Middle East: 2019 in review by Damian Radcliffe and Hadil Abuhmaid

Download, or view online, via the University of Oregon Scholars' Bank Scribd, SlideShare, Academia.edu and Research Gate.

2(018) State of Social Media, Middle East: 2018 by Damian Radcliffe and Payton Bruni

Download from the University of Oregon Scholars' Bank, or view it online via Scribd, SlideShare, ResearchGate and Academia.edu.

2017 Social Media in the Middle East: The Story of 2017 by Damian Radcliffe and Amanda Lam

Download from the University of Oregon Scholars' Bank, or embed on Scribd, SlideShare, and Academia.edu.

2016) Social Media in the Middle East: The Story of 2016 by Damian Radcliffe

Available on University of Oregon Scholars Bank, SlideShare, Scribd. Academia.edu, UNESCO / United Nations Alliance of Civilizations Media Literacy Portal, SSRN, or download it here.
2015 Social Media in the Middle East: The Story of 2015 by Damian Radcliffe

Also available on Scribd, SlideShare, University of Oregon Scholars Bank. Academia.edu, SSRN and the UNESCO Media Literacy Portal.

2014 Social Media in the Middle East: The Story of 2014 by Damian Radcliffe

Also available on Scribd, SlideShare, SSRN and Academia.edu

Round-ups produced by Damian Radcliffe when he worked for Qatar's Ministry of Information and Communications Technology (ictQATAR)

2(0)13 Social Media in the Middle East: The Story of 2013 by Damian Radcliffe (English, Arabic)

2(0)12 Social Media in the MENA - 2012 Review by Damian Radcliffe (English, Arabic) 


\section{ENDNOTES}

All of the sources used for the creation of this report are hyperlinked throughout. You can find, and access, a full list of references featured in this document, in this PDF.

\section{DISCLOSURE}

Damian Radcliffe is owner/director of Kenja Consulting, LLC (UK) and Kenja Media Consulting (US). The work Professor Radcliffe does for the University of Oregon and for Kenja Consulting are related or overlap in that Professor Radcliffe undertakes research journalism, training, public speaking and consulting in areas which are, or may appear, related to Professor Radcliffe's University of Oregon (UO) duties. Thus, this study could affect Damian Radcliffe's personal financial status

This does not imply or suggest University of Oregon involvement, responsibility, endorsement, approval, or promotion of any commercial product, service, or outside activity. Any opinions or viewpoints expressed are not official positions of the University of Oregon or endorsed or approved by the University of Oregon

Professor Radcliffe's outside work activity was reviewed and approved by the University of Oregon in accordance with its conflict of interest and commitment. 